Cochrane Database of Systematic Reviews

\title{
Aquablation of the prostate for the treatment of lower urinary tract symptoms in men with benign prostatic hyperplasia (Review)
}

Hwang EC, Jung JH, Borofsky M, Kim MH, Dahm P

Hwang EC, Jung JH, Borofsky M, Kim MH, Dahm P.

Aquablation of the prostate for the treatment of lower urinary tract symptoms in men with benign prostatic hyperplasia.

Cochrane Database of Systematic Reviews 2019, Issue 2. Art. No.: CD013143.

DOI: 10.1002/14651858.CD013143.pub2.

www.cochranelibrary.com

Aquablation of the prostate for the treatment of lower urinary tract symptoms in men with benign prostatic 
TABLE OF CONTENTS

PLAIN LANGUAGE SUMMARY

BACKGROUND

Figure 1.

OBJECTIVES

METHODS

RESULTS

Figure 2.

Figure 3.

Figure 4.

DISCUSSION

AUTHORS' CONCLUSIONS

ACKNOWLEDGEMENTS

REFERENCES

CHARACTERISTICS OF STUDIES

DATA AND ANALYSES

Analysis 1.1. Comparison 1 Aquablation versus TURP (up to 12 months), Outcome 1 Urologic symptom scores (IPSS).

Analysis 1.2. Comparison 1 Aquablation versus TURP (up to 12 months), Outcome 2 Quality of life (IPSS-QoL).

Analysis 1.3. Comparison 1 Aquablation versus TURP (up to 12 months), Outcome 3 Major adverse events.

Analysis 1.4. Comparison 1 Aquablation versus TURP (up to 12 months), Outcome 4 Retreatment.

Analysis 1.5. Comparison 1 Aquablation versus TURP (up to 12 months), Outcome 5 Erectile function (IIEF; sexually active men only).

Analysis 1.6. Comparison 1 Aquablation versus TURP (up to 12 months), Outcome 6 Ejaculatory function (MSHQ-EjD; sexually active men only).

Analysis 1.7. Comparison 1 Aquablation versus TURP (up to 12 months), Outcome 7 Minor adverse events.

Analysis 1.8. Comparison 1 Aquablation versus TURP (up to 12 months), Outcome 8 Acute urinary retention.

Analysis 1.9. Comparison 1 Aquablation versus TURP (up to 12 months), Outcome 9 Indwelling urinary catheter (hou

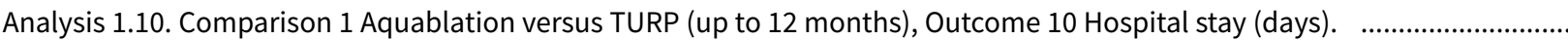

Analysis 2.1. Comparison 2 Aquablation versus TURP (up to 6 months), Outcome 1 Urologic symptom scores (IPSS). ..............

Analysis 2.2. Comparison 2 Aquablation versus TURP (up to 6 months), Outcome 2 Quality of life (IPSS-QoL). ........................

Analysis 2.3. Comparison 2 Aquablation versus TURP (up to 6 months), Outcome 3 Major adverse events.

Analysis 2.4. Comparison 2 Aquablation versus TURP (up to 6 months), Outcome 4 Retreatment.

Analysis 2.5. Comparison 2 Aquablation versus TURP (up to 6 months), Outcome 5 Erectile function (IIEF).

Analysis 2.6. Comparison 2 Aquablation versus TURP (up to 6 months), Outcome 6 Ejaculatory function (MSHQ-EjD). ............

Analysis 2.7. Comparison 2 Aquablation versus TURP (up to 6 months), Outcome 7 Minor adverse events.

Analysis 2.8. Comparison 2 Aquablation versus TURP (up to 6 months), Outcome 8 Acute urinary retention.

Analysis 2.9. Comparison 2 Aquablation versus TURP (up to 6 months), Outcome 9 Indwelling urinary catheter (hours). ..........

Analysis 2.10. Comparison 2 Aquablation versus TURP (up to 6 months), Outcome 10 Hospital stay (days).

Analysis 3.1. Comparison 3 Aquablation versus TURP (subgroup analyses up to 6 months), Outcome 1 Urologic symptom scores (IPSS) based on age.

Analysis 3.2. Comparison 3 Aquablation versus TURP (subgroup analyses up to 6 months), Outcome 2 Quality of life (IPSS-QoL) based on age.

Analysis 3.3. Comparison 3 Aquablation versus TURP (subgroup analyses up to 6 months), Outcome 3 Major adverse events based on age.

Analysis 3.4. Comparison 3 Aquablation versus TURP (subgroup analyses up to 6 months), Outcome 4 Urologic symptom scores (IPSS) based on prostate volume.

Analysis 3.5. Comparison 3 Aquablation versus TURP (subgroup analyses up to 6 months), Outcome 5 Quality of life (IPSS-QoL) based on prostate volume.

Analysis 3.6. Comparison 3 Aquablation versus TURP (subgroup analyses up to 6 months), Outcome 6 Major adverse events based on prostate volume. 
Analysis 3.7. Comparison 3 Aquablation versus TURP (subgroup analyses up to 6 months), Outcome 7 Urologic symptom scores (IPSS) based on severity of LUTS.

Analysis 3.8. Comparison 3 Aquablation versus TURP (subgroup analyses up to 6 months), Outcome 8 Quality of life (IPSS-QoL) based on severity of LUTS.

Analysis 3.9. Comparison 3 Aquablation versus TURP (subgroup analyses up to 6 months), Outcome 9 Major adverse events based on severity of LUTS.

ADDITIONAL TABLES

APPENDICES

CONTRIBUTIONS OF AUTHORS

DECLARATIONS OF INTEREST

SOURCES OF SUPPORT

DIFFERENCES BETWEEN PROTOCOL AND REVIEW 
[Intervention Review]

\title{
Aquablation of the prostate for the treatment of lower urinary tract symptoms in men with benign prostatic hyperplasia
}

\author{
Eu Chang Hwang1,2,3, Jae Hung Jung ${ }^{4}$, Michael Borofsky33, Myung Ha Kim5, Philipp Dahm²,3
}

1Department of Urology, Chonnam National University Medical School, Chonnam National University Hwasun Hospital, Hwasun, Korea, South. ${ }^{2}$ Urology Section, Minneapolis VA Health Care System, Minneapolis, Minnesota, USA. ${ }^{3}$ Department of Urology, University of Minnesota, Minneapolis, Minnesota, USA. ${ }^{2}$ Department of Urology, Yonsei University Wonju College of Medicine, Wonju, Korea, South. 5 Yonsei Wonju Medical Library, Yonsei University Wonju College of Medicine, Wonju, Korea, South

Contact: Eu Chang Hwang, Department of Urology, Chonnam National University Medical School, Chonnam National University Hwasun Hospital, Hwasun, Korea, South. urohwang@gmail.com, urohwang@naver.com.

Editorial group: Cochrane Urology Group.

Publication status and date: New, published in Issue 2, 2019.

Citation: Hwang EC, Jung JH, Borofsky M, Kim MH, Dahm P. Aquablation of the prostate for the treatment of lower urinary tract symptoms in men with benign prostatic hyperplasia. Cochrane Database of Systematic Reviews 2019, Issue 2. Art. No.: CD013143. DOI: 10.1002/14651858.CD013143.pub2.

Copyright @ 2019 The Cochrane Collaboration. Published by John Wiley \& Sons, Ltd.

\section{A B S T R A C T}

\section{Background}

New, minimally invasive surgeries have emerged as alternatives to transurethral resection of the prostate (TURP) for the management of lower urinary tract symptoms (LUTS) in men with benign prostatic hyperplasia (BPH). Aquablation is a novel, minimally invasive, waterbased therapy, combining image guidance and robotics for the removal of prostatic tissue.

\section{Objectives}

To assess the effects of Aquablation for the treatment of lower urinary tract symptoms in men with benign prostatic hyperplasia.

\section{Search methods}

We performed a comprehensive search using multiple databases (the Cochrane Library, MEDLINE, Embase, Scopus, Web of Science, and LILACS), trials registries, other sources of grey literature, and conference proceedings published up to 11 February 2019, with no restrictions on the language or status of publication.

\section{Selection criteria}

We included parallel-group randomised controlled trials (RCTs) and cluster-RCTs, as well as non-randomised observational prospective studies with concurrent comparison groups in which participants with BPH who underwent Aquablation.

\section{Data collection and analysis}

Two review authors independently assessed studies for inclusion at each stage, and undertook data extraction and 'Risk of bias' and GRADE assessments of the certainty of the evidence. We considered review outcomes measured up to and including 12 months after randomisation as short-term and beyond 12 months as long-term.

\section{Main results}

We included one RCT with 184 participants comparing Aquablation to TURP. The mean age and International Prostate Symptom Score were 65.9 years and 22.6, respectively. The mean prostate volume was $53.2 \mathrm{~mL}$. We only found short-term data for all outcomes based on a single randomised trial. 


\section{Primary outcomes}

Up to 12 months, Aquablation likely results in a similar improvement in urologic symptom scores to TURP (mean difference (MD) -0.06, $95 \%$ confidence interval $(\mathrm{CI})-2.51$ to 2.39 ; participants $=174$; moderate-certainty evidence). We downgraded the evidence certainty by one level due to study limitations. Aquablation may also result in similar quality of life when compared to TURP (MD $0.27,95 \% \mathrm{Cl}-0.24$ to 0.78 ; participants $=174$, low-certainty evidence). We downgraded the evidence certainty by two levels due to study limitations and imprecision. Aquablation may result in little to no difference in major adverse events (risk ratio (RR) $0.84,95 \% \mathrm{Cl} 0.31$ to 2.26 ; participants = 181 , very lowcertainty evidence) but we are very uncertain of this finding. This would correspond to 15 fewer major adverse events per 1000 participants (95\% Cl 64 fewer to 116 more). We downgraded the evidence certainty by one level for study limitations and two levels for imprecision.

\section{Secondary outcomes}

Up to 12 months, Aquablation may result in little to no difference in retreatments ( $\mathrm{RR} 1.68,95 \% \mathrm{Cl} 0.18$ to 15.83 ; participants $=181$, very low-certainty evidence) but we are very uncertain of this finding. This would correspond to 10 more retreatments per 1000 participants ( $95 \% \mathrm{Cl} 13$ fewer to 228 more). We downgraded the evidence certainty by one level due to study limitations and two levels for imprecision.

Aquablation may result in little to no difference in erectile function as measured by International Index of Erectile Function questionnaire Erectile Function domain compared to TURP (MD 2.31, 95\% Cl-0.63 to 5.25; participants =64, very low-certainty evidence), and may cause slightly less ejaculatory dysfunction than TURP, as measured by Male Sexual Health Questionnaire for Ejaculatory Dysfunction (MD 2.57, $95 \% \mathrm{Cl} 0.60$ to 4.53; participants $=121$, very low-certainty evidence). However, we are very uncertain of both findings. We downgraded the evidence certainty by two levels due to study limitations and one level for imprecision for both outcomes.

We did not find other prospective, comparative studies comparing Aquablation to TURP or other procedures such as laser ablation, enucleation, or other minimally invasive therapies.

\section{Authors' conclusions}

Based on short-term (up to 12 months) follow-up, the effect of Aquablation on urological symptoms is probably similar to that of TURP (moderate-certainty evidence). The effect on quality of life may also be similar (low-certainty evidence). We are very uncertain whether patients undergoing Aquablation are at higher or lower risk for major adverse events (very low-certainty evidence). We are very uncertain whether Aquablation may result in little to no difference in erectile function but offer a small improvement in preservation of ejaculatory function (both very low-certainty evidence). These conclusions are based on a single study of men with a prostate volume up to $80 \mathrm{~mL}$ in size. Longer-term data and comparisons with other modalities appear critical to a more thorough assessment of the role of Aquablation for the treatment of LUTS in men with BPH.

\section{PLAIN LANGUAGE SUMMARY}

\section{Aquablation for the treatment of lower urinary tract symptoms in men with benign prostatic hyperplasia}

\section{Review question}

How does Aquablation compare to other procedures in patients with bothersome urinary symptoms caused by an enlarged prostate?

\section{Background}

An enlarged prostate may cause bothersome urinary tract symptoms, such as having to urinate often during the day or night, having a weak stream, and the feeling of not completely emptying the bladder. When lifestyle changes (like drinking less liquids) or medications do not help, men may choose to have surgery, such as a transurethral resection of the prostate. However, this procedure may cause unwanted effects, such as erection and ejaculation problems, or require retreatment. This review looks at the results of Aquablation, which is a newer treatment that uses high-pressure water to remove prostate tissue and help with urinary tract symptoms.

\section{Study characteristics}

We looked for all studies that compared Aquablation to transurethral resection of the prostate. We included both studies in chance decided how men were treated and studies in which men and their urologist decided. We searched for studies up to 11 February 2019.

\section{Key results}

We found only one study in which chance decided how men were treated. The study compared Aquablation to transurethral resection of the prostate. On average, men were about 66 years old. We did not find any other studies.

We found that Aquablation likely improves urinary symptoms similarly to transurethral resection of the prostate and may also lead to similar quality of life. Rates of unwanted serious effects may also be similar but we are very uncertain about this.

Men who have Aquablation may have a similar risk of needing a repeat procedure as those having transurethral resection of the prostate but we are very uncertain of this finding. 
Aquablation may make little to no difference to erectile function but may have fewer issues with ejaculation, but we are very uncertain of both findings.

These findings are based on a single study funded by the company that makes the device used for Aquablation. All data were limited to 12 months' follow-up or less and prostate size was less than or equal to $80 \mathrm{~mL}$.

\section{Certainty of the evidence}

Our certainty about the evidence we found ranged from moderate to very low due to shortcomings in how the study was done and small study size. This means that we have either moderate, limited or very little confidence in the results, depending on the outcome. 


\section{SUMMARY OF FINDINGS}

\section{Summary of findings for the main comparison. Aquablation compared to transurethral resection of the prostate for benign prostatic hyperplasia}

Patient or population: men with benign prostatic hyperplasia (BPH)

Setting: multicenter (17 centres)/ multicountry (Australia 1, New Zealand 1, UK 3, USA 12)

Intervention: Aquablation

Comparison: transurethral resection of the prostate (TURP)

\begin{tabular}{|c|c|c|c|c|c|}
\hline \multicolumn{6}{|c|}{ Summary of findings for the main comparison. Aquablation co } \\
\hline \multicolumn{6}{|c|}{$\begin{array}{l}\text { Patient or population: men with benign prostatic hyperplasia (BPH) } \\
\text { Setting: multicenter (17 centres)/ multicountry (Australia 1, New Zealand 1, UK 3, USA 12) } \\
\text { Intervention: Aquablation } \\
\text { Comparison: transurethral resection of the prostate (TURP) }\end{array}$} \\
\hline \multirow[t]{2}{*}{ Outcomes } & \multirow{2}{*}{$\begin{array}{l}\text { № of participants } \\
\text { (studies) }\end{array}$} & \multirow{2}{*}{$\begin{array}{l}\text { Certainty of the } \\
\text { evidence } \\
\text { (GRADE) }\end{array}$} & \multirow{2}{*}{$\begin{array}{l}\text { Relative effect } \\
(95 \% \mathrm{Cl})\end{array}$} & \multicolumn{2}{|c|}{ Anticipated absolute effects ${ }^{\star}(95 \% \mathrm{Cl})$} \\
\hline & & & & Risk with TURP & $\begin{array}{l}\text { Risk difference with } \\
\text { Aquablation }\end{array}$ \\
\hline $\begin{array}{l}\text { Urologic symptom scores } \\
\text { Assessed with: IPSS } \\
\text { Scale from } 0 \text { (best: not at all) to } 35 \text { (worst: almost } \\
\text { always) } \\
\text { Follow-up: } 12 \text { months }\end{array}$ & $\begin{array}{l}174 \\
(1 \mathrm{RCT})\end{array}$ & $\begin{array}{l}\oplus \oplus \oplus \ominus \\
\text { Moderate }^{a}\end{array}$ & - & $\begin{array}{l}\text { The mean urologic } \\
\text { symptom score was } \\
-15.12\end{array}$ & $\begin{array}{l}\text { MD } 0.06 \text { lower } \\
(2.51 \text { lower to } 2.39 \text { high- } \\
\text { er) }\end{array}$ \\
\hline $\begin{array}{l}\text { Quality of life } \\
\text { Assessed with: IPSS-QoL } \\
\text { Scale from } 0 \text { (best: delighted) to } 6 \text { (worst: terri- } \\
\text { ble) } \\
\text { Follow-up: } 12 \text { months }\end{array}$ & $\begin{array}{l}174 \\
(1 \mathrm{RCT})\end{array}$ & $\begin{array}{l}\oplus \oplus \ominus \ominus \\
\text { Low }^{a, b}\end{array}$ & - & $\begin{array}{l}\text { The mean quality of } \\
\text { Life was }-3.45\end{array}$ & $\begin{array}{l}\text { MD } 0.27 \text { higher } \\
(0.24 \text { lower to } 0.78 \text { high- } \\
\text { er) }\end{array}$ \\
\hline \multirow{2}{*}{$\begin{array}{l}\text { Major adverse events } \\
\text { Assessed with: Clavien-Dindo classification sys- } \\
\text { tem (Grade III, IV and V complications) } \\
\text { Follow-up: } 12 \text { months }\end{array}$} & \multirow{2}{*}{$\begin{array}{l}181 \\
(1 \mathrm{RCT})\end{array}$} & \multirow{2}{*}{$\begin{array}{l}\oplus \ominus \ominus \ominus \\
\text { Very lowa,c }\end{array}$} & \multirow{2}{*}{$\begin{array}{l}\text { RR } 0.84 \\
\text { (0.31 to } 2.26)\end{array}$} & \multicolumn{2}{|l|}{ Study population } \\
\hline & & & & 92 per $1000^{d}$ & $\begin{array}{l}15 \text { fewer per } 1000 \\
\text { (64 fewer to } 116 \text { more) }\end{array}$ \\
\hline \multirow{2}{*}{$\begin{array}{l}\text { Retreatment } \\
\text { Follow-up: } 12 \text { months }\end{array}$} & \multirow{2}{*}{$\begin{array}{l}181 \\
(1 \mathrm{RCT})\end{array}$} & \multirow{2}{*}{$\begin{array}{l}\oplus \ominus \ominus \ominus \\
\text { Very low }{ }^{a, c}\end{array}$} & \multirow{2}{*}{$\begin{array}{l}\text { RR } 1.68 \\
\text { (0.18 to } 15.83)\end{array}$} & \multicolumn{2}{|l|}{ Study population } \\
\hline & & & & 15 per $1000^{d}$ & $\begin{array}{l}10 \text { more per } 1000 \\
\text { (13 fewer to } 228 \text { more) }\end{array}$ \\
\hline $\begin{array}{l}\text { Erectile function (sexually active men only) } \\
\text { Assessed with: IIEF-EF domain } \\
\text { Scale from } 1 \text { (worst; severe erectile dysfunction) } \\
\text { to } 30 \text { (best; no erectile dysfunction) } \\
\text { Follow-up: } 12 \text { months }\end{array}$ & $\begin{array}{l}64 \\
(1 \mathrm{RCT})\end{array}$ & $\begin{array}{l}\oplus \odot \odot \ominus \\
\text { Very lowb,e }\end{array}$ & - & $\begin{array}{l}\text { The mean erectile } \\
\text { function (sexually ac- } \\
\text { tive men only) was } \\
-2.73\end{array}$ & $\begin{array}{l}\text { MD } 2.31 \text { higher } \\
(0.63 \text { lower to } 5.25 \text { high- } \\
\text { er) }\end{array}$ \\
\hline $\begin{array}{l}\text { Ejaculatory function (sexually active men only) } \\
\text { Assessed with: MSHQ-EjD }\end{array}$ & $\begin{array}{l}121 \\
(1 \mathrm{RCT})\end{array}$ & $\begin{array}{l}\oplus \odot \ominus \ominus \\
\text { Very lowb,e }\end{array}$ & - & $\begin{array}{l}\text { The mean ejaculato- } \\
\text { ry function (sexually }\end{array}$ & MD 2.57 higher \\
\hline
\end{tabular}


${ }^{\star}$ The risk in the intervention group (and its $95 \%$ confidence interval) is based on the assumed risk in the comparison group and the relative effect of the intervention (and its $95 \% \mathrm{Cl})$.

BPH: benign prostate hyperplasia; CI: confidence interval; EF: erectile function; IIEF: International index of erectile function; IPSS: International prostate symptom score; MD: mean difference; MSHQ-EjD: Male Sexual Health Questionnaire for Ejaculatory Dysfunction; RCT: randomised controlled trial; RR: risk ratio; TURP: transurethral resection of prostate; QoL: quality of life

\section{GRADE Working Group grades of evidence}

High certainty: we are very confident that the true effect lies close to that of the estimate of the effect.

Moderate certainty: we are moderately confident in the effect estimate: the true effect is likely to be close to the estimate of the effect, but there is a possibility that it is substantially different.

Low certainty: our confidence in the effect estimate is limited: the true effect may be substantially different from the estimate of the effect.

Very low certainty: we have very little confidence in the effect estimate: the true effect is likely to be substantially different from the estimate of effect.

aDowngraded by one level for study limitations: high risk of performance and unclear risk of reporting bias.

bDowngraded by one level for imprecision: confidence interval crosses assumed threshold of minimal clinically important difference.

cDowngraded by two levels for imprecision: wide confidence interval crosses assumed threshold of minimal clinically important difference.

dControl group risk estimates come from single estimates of included study control group. Relative effect based on available case analysis.

eDowngraded by two levels for study limitations: high risk of performance and attrition bias. 


\section{B A C K G R O U N D}

\section{Description of the condition}

The prostate gland is an organ approximately the size of a walnut that is located below the urinary bladder encircling the urethra (Leissner 1979). Benign prostatic hyperplasia (BPH) is a histological diagnosis defined as an increased number of epithelial and stromal cells in the prostate; this may cause prostatic enlargement and subsequently compression of the urethra and obstruction (Roehrborn 2008a). BPH may therefore develop with or without lower urinary tract symptoms (LUTS) in men over the age of 40 (Dunphy 2015). Several suggestive risk factors are aging, familial history, changes in hormonal levels, elevated markers of inflammation and metabolic syndrome (Russo 2015). BPH receives clinical significance when associated with bothersome LUTS (Roehrborn 2008a). Symptom bother typically correlates with the number and severity of symptoms increased, which relates to both impairment of quality of life and seeking treatment (Agarwal 2014).

Self-administered questionnaires, namely the International Prostate Symptom Score (IPSS), include the quality-of-life domain to evaluate the relative degree of bother across all LUTS (Barry 1995). One study reported that increasing LUTS severity was associated with worsening overall distress in men, using patient perception of bladder condition which is a single-item global question, ranging from one, causes no problems at all, to six, causes severe problems (Chapple 2017). In this Cochrane Review, we define the term $\mathrm{BPH}$ as prostatic enlargement with LUTS.

Benign prostatic hyperplasia can progress over time and cause serious consequences, such as acute urinary retention, urinary tract infection, and upper urinary tract deterioration. BPH also results in a negative impact on public health, increased annual healthcare cost and a reduction in a person's quality of life (Kaplan 2015; Kozminski 2015; Martin 2014). In Europe, 30\% of men over 50 years of age, equivalent to 26 million men, are affected by bothersome LUTS, including storage symptoms (such as urinary frequency, urgency, and nocturia) or voiding symptoms (such as urinary hesitancy, weak urinary stream, straining to void and prolonged voiding), or both. A yearly reported associated number of medical prescriptions is estimated to be around 11.6 million for 74 million men at risk from 2004 to 2008 (Cornu 2010). The prevalence of LUTS, according to an international study involving 7588 men, was $18 \%, 29 \%, 40 \%$, and $56 \%$ in men aged in their forties, fifties, sixties and seventies, respectively (Homma 1997). In the USA, 8 million men older than 50 years of age also suffer from BPH (Roehrborn 2008b).

\section{Diagnosis}

The diagnosis of BPH is based on followed clinical features: a prostate enlargement, bothersome LUTS and no other identified causes for the urinary problems. The initial evaluation of $\mathrm{BPH}$ includes medical history, symptom score questionnaires (e.g. the IPSS), physical examination including a digital rectal examination, urinalysis, prostate-specific antigen (PSA) blood test, and frequency volume chart (EAU 2017; Foster 2018; McVary 2011). A digital rectal examination is an important examination and may help to determine the coexistence of prostate cancer (EAU 2017). Urinalysis is useful for differential diagnosis to urinary tract infection. Together with a digital rectal examination, a PSA test increases the detection rate of prostate cancer, but would be performed if life expectancy is greater than 10 years and if a diagnosis of prostate cancer would modify the management approach (EAU 2017; McVary 2011). The IPSS is used to assess urinary symptom severity and quality of life. It is also used to document subjective responses to treatment (Barry 1992; EAU 2017; Foster 2018). Measurement of urinary flow rates and residual urine are helpful in diagnostic evaluation and treatment response (EAU 2017; Foster 2018). A low maximum flow rate (Qmax) and a large post-voided residuals (PVR) predict an increased risk of symptom progression (Crawford 2006). Other tests, including radiologic imaging, pressure flow study and urethrocystoscopy, are recommended for the assessment of prostate volume or morphology and bladder function before surgical treatment (Egan 2016; Foster 2018; McVary 2011).

\section{Treatment}

Treatment decisions are based on the burden of symptoms and the degree of bother noted by the patient. Initial treatment options for BPH include conservative management (watchful waiting and lifestyle modification) and medication, such as alpha-blockers and 5-alpha reductase inhibitors (EAU 2017; McVary 2011). If patients have been refractory to conservative and medical treatment, or BPH causes subsequent complications, such as acute urinary retention, recurrent urinary tract infection, bladder stones or diverticula, hematuria, or renal insufficiency, surgical options are considered (EAU 2017; Foster 2018; McVary 2011). Until the 1970s, the only option available to treat this condition and relieve LUTS was an open or endoscopic surgery with the aim of removing or resecting prostatic tissue to open up the blocked urethra (Pariser 2015). Clinical guidelines recommend monopolar or bipolar transurethral resection of the prostate (TURP) as a standard treatment for subjective symptom relief and objective improvements in urinary flow (EAU 2017; Foster 2018; McVary 2011). However, TURP can cause complications, such as dilutional hyponatraemia (known as TUR syndrome), sexual dysfunction including erectile dysfunction and anejaculation (more than $5 \%$ ), bladder neck contracture, urinary tract infection and hematuria (Reich 2008). Furthermore, BPH is a disease common in older men who have an increased risk of complications for general anaesthesia and the surgery itself (Dunphy 2015; Yoo 2012). Even though a systematic review reported that bipolar TURP alleviates these complications (Omar 2014), these issues have contributed to the emergence of minimally invasive procedures using laser (laser ablation or enucleation), thermal delivery devices (microwave thermotherapy, radiofrequency, high-intensity focused ultrasound, water vapour therapy), mechanical devices (prostatic stent, prostatic urethral lift), fractionation of prostatic tissue (histotripsy, Aquablation), prostate artery embolization, and intraprostatic drugs. Some of these methods can be carried out in an outpatient setting with local anaesthesia and acceptable adverse events (Aoun 2015; EAU 2017).

\section{Description of the intervention}

Aquablation is performed using the AquaBeam System (PROCEPT BioRobotics). It is a novel, minimally invasive water ablation therapy for LUTS due to BPH, which combines image guidance and robotics for the removal of prostatic tissue. The Aquablation device consists of three main components: the conformal planning unit (CPU), the console and the robotic hand piece (Figure 1). The procedure is largely automated and is performed under general 
anaesthesia (Gilling 2016; Gilling 2017). It involves introducing a custom 22 French (or Charrière; equivalent to $0.33 \mathrm{~mm}$ in diameter) rigid cystoscope into the bladder under direct vision with the aid of a visual obturator. The obturator is then removed from the cystoscope sheath, leaving the distal end of the sheath flush with the bladder neck. The Aquablation handpiece is advanced through the sheath until the distal end of the device is positioned in the bladder. The $15 \mathrm{~mL}$ balloon is then inflated with saline and retracted until it seals against the bladder neck, obstructing antegrade flow. The articulating arm is locked into place to securely anchor the handpiece within the prostate. Transrectal ultrasound is then performed and displayed on the CPU, enabling the operator to map the contour of the prostate and define the area of resection. Utilising the planning parameters entered into the CPU, the console generates and adjusts the saline pressure to allow for controlled resection of the prostate tissue (Gilling 2016; Gilling 2017). The system includes a peristaltic pump for active fluid aspiration to maintain intravesical volume equilibrium, and aspiration through the handpiece to enable sample collection for histological analysis (Gilling 2016; Gilling 2017). At completion of the procedure, the articulating arm is unlocked, and the device removed from the urethra. For the sake of haemostasis, a three-way Foley catheter is placed into the bladder and inflated with $5 \mathrm{cc}$ to $7 \mathrm{cc}$ of saline. The balloon is pulled distally into the prostatic fossa, inflated to a total volume equalling the approximate volume removed during the Aquablation and kept at this inflation volume for two to five hours (Aljuri 2017). However, during early experience with the Aquablation procedure, TUR-coagulation was also used for haemostasis (Gilling 2017).

Figure 1. The current AquaBeam console, $\mathrm{CPU}$, and robotic handpiece with an articulating arm Reproduced with permission from Springer Customer Service Centre GmbH: Springer Nature, Current Urology Reports, Aquablation of the Prostate for Symptomatic Benign Prostatic Hyperplasia: Early Results, Omid Yassaie, Joshua A. Silverman, Peter J. Gilling, COPYRIGHT 2017

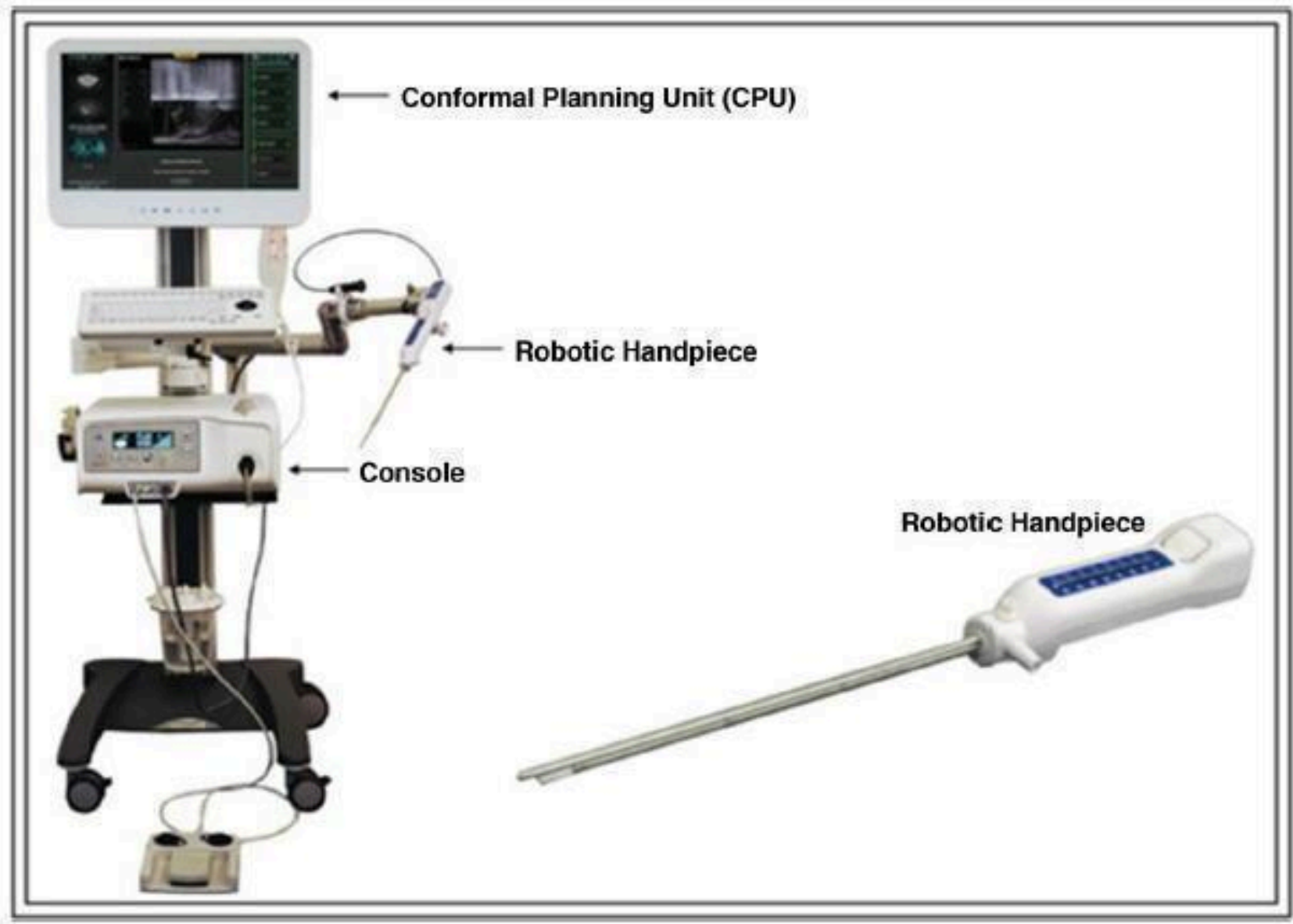

\section{Adverse events of the intervention}

To date, experience with Aquablation is limited. Reported adverse events include postoperative pain, hematuria, urinary tract infections, urethral stricture disease, acute urinary retention and one instance of blood transfusion (Gilling 2018). The reported rates of reoperations is $2.5 \%$ (Gilling 2018).

\section{How the intervention might work}

High-pressure water jet technology has been adapted to dissect parenchymal tissues, which has been suggested to be safe and effective in the transurethral setting in the resection of bladder tumours (Nagele 2011). The development of the Aquablation technology for BPH is based on the hypothesis that the highpressure water jet will preferentially ablate the adenomatous 
tissue, preserving collagenous structures such as the surgical capsule, bladder neck, and blood vessels. The Aquablation system delivers a conformal, quantifiable and standardised heat-free ablation and thereby opens widely the patent prostatic urethra between the bladder neck and peripheral sphincter. There are two phases in the Aquablation system (Faber 2015). In the first phase (the cutting mode) the surgeon has the ability to adjust the angle, length, contour and depth of penetration. Upon initiating the procedure, the console activates the pump that drives physiologic saline $(0.9 \%)$ through the probe's nozzle at pressures ranging from 500 to 8000 pounds per square inch (PSI), to cut and dissect soft tissue at the predetermined system parameters. In the second phase (the coagulation mode), the console drives the pump at low pressure ( 5 to $15 \mathrm{PSI}$ ) and activates the 2 watt (W) green light laser (532 nanometres) to allow for cauterisation after resection (Faber 2015).

\section{Why it is important to do this review}

Minimally invasive surgery for BPH is a dynamic field, with novel treatment modalities emerging in experimental and clinical use with various safety and efficacy profiles. Aquablation is a new technology in terms of treatment of $\mathrm{BPH}$, and reported experimental and clinical initial results suggest it is efficacious and well-tolerated. However, it is unclear whether Aquablation actually translates into more clinical benefits and fewer adverse events in clinical practice compared to conventional surgical treatment. In addition, no systematic review so far has used the same rigorous methodology as a Cochrane Review, which includes the application of the GRADE approach and its focus on patient-important outcomes (Guyatt 2008). In today's era, with the availability of numerous minimally invasive procedures to treat $\mathrm{BPH}$, the findings of this Cochrane Review will be highly relevant to policymakers, healthcare providers and patients alike. We expect this review to complement a suite of related Cochrane Reviews focused on the endourological management (Jung 2017a) and vascular management (Jung 2017b) of LUTS related to BPH.

\section{OB JECTIVES}

To assess the effects of Aquablation for the treatment of lower urinary tract symptoms in men with benign prostatic hyperplasia.

\section{METHODS}

\section{Criteria for considering studies for this review}

\section{Types of studies}

This review is based on a published protocol (Hwang 2018). For details on the differences between that protocol and this review, please refer to the Differences between protocol and review section. We included parallel-group RCTs and cluster-RCTs. We excluded cross-over trials, as these study designs are not relevant in this setting. If we only found RCTs that provided low-certainty evidence for a given outcome or comparison (e.g. limited information about adverse events and long-term effects), we planned to include non-RCTs as a source of complementary, sequential, or replacement evidence for RCTs. However, we limited this to prospective cohort studies with concurrent comparison groups, which are similar to relevant RCTs (Schünemann 2013; Sterne 2016a; Sterne 2016b). We did not include single-armed studies. We included studies regardless of their publication status or language.

\section{Types of participants}

We defined the eligible patient population as men over the age of 40 years with a prostate volume of $20 \mathrm{~mL}$ or greater (as assessed by ultrasound or cross-sectional imaging), with LUTS as determined by International Prostate Symptom Scores (IPSS) of eight or over, and a maximum flow rate $\left(\mathrm{Q}_{\max }\right)$ of less than $15 \mathrm{~mL} / \mathrm{second}$, as measured by non-invasive uroflowmetry, invasive pressure flow studies, or both (Dunphy 2015; EAU 2017; McNicholas 2016; McVary 2011). We based the age limitation on the fact that the prevalence of BPH increases in middle-aged and older men and is infrequent in younger men (Barry 1997; EAU 2017; Egan 2016). We included studies in which only a subset of participants was relevant to this review (i.e. studies with more than $75 \%$ of participants only as relevant to the review), if data were available separately for the relevant subset.

We excluded studies that included men with active urinary tract infection, bacterial prostatitis, chronic renal failure, untreated bladder calculi or large diverticula, prostate cancer, and urethral stricture disease, as well as those who had undergone prior prostate, bladder neck, or urethral surgery. We also excluded studies of people with other conditions that affect urinary symptoms, such as neurogenic bladder due to spinal cord injury, multiple sclerosis, or central nervous system disease.

\section{Types of interventions}

\section{Experimental intervention}

- Aquablation

\section{Comparator interventions}

- Sham control (or no intervention)

- Transurethral resection of the prostate (TURP) (monopolar or bipolar)

- Laser ablations of the prostate (e.g. photoselective vaporisation of the prostate)

- Laser enucleations of the prostate (e.g. Holmium laser enucleation of the prostate (HoLEP))

- Prostatic urethral lift (PUL)

- Convective radiofrequency water vapour thermal therapy (e.g. Rezum)

- Other minimally invasive therapies (e.g. transurethral incision of the prostate, transurethral thermal ablation of the prostate (needle ablation, microwave therapy, and radiofrequency ablative techniques), prostate stent, and prostatic arterial embolization)

- Simple prostatectomy (e.g. open, laparoscopic, and roboticassisted prostatectomy)

We planned to investigate the following comparisons of experimental interventions versus comparator interventions. Concomitant interventions had to be the same in the experimental and comparator groups in order to establish fair comparisons.

\section{Comparisons}

- Aquablation versus sham control (or no intervention)

- Aquablation versus TURP

- Aquablation versus laser ablations of the prostate

- Aquablation versus laser enucleations of the prostate

Aquablation of the prostate for the treatment of lower urinary tract symptoms in men with benign prostatic hyperplasia (Review) 
- Aquablation versus PUL

- Aquablation versus convective radiofrequency water vapour thermal therapy

- Aquablation versus other minimally invasive therapies

- Aquablation versus simple prostatectomy

\section{Types of outcome measures}

We did not use the measurement of the outcomes assessed in this review as an eligibility criterion.

\section{Primary outcomes}

- Urologic symptom scores (continuous outcome)

- Quality of life (continuous outcome)

- Major adverse events (dichotomous outcome)

\section{Secondary outcomes}

- Retreatment (dichotomous outcome)

- Erectile function (continuous outcome)

- Ejaculatory function (continuous outcome)

- Minor adverse events (dichotomous outcome)

- Acute urinary retention (dichotomous outcome)

- Indwelling urinary catheter (continuous outcome)

- Hospital stay (continuous outcome)

\section{Method and timing of outcome measurement}

We considered the clinically important differences for the review outcome measures to rate the overall certainty of evidence in Summary of findings for the main comparison (Jaeschke 1989; Johnston 2013).

\section{Urologic symptom scores}

- Mean change from baseline or final mean value, measured using a validated scale (such as IPSS)

- We considered the improvement of an IPSS score of three points as the minimal clinically important difference (MCID) to assess efficacy and comparative effectiveness (Barry 1995). If possible, we used different thresholds of MCID based on the severity of IPSS, with a threshold of three points for men with mild LUTS, five for moderate LUTS, and eight for severe LUTS (Barry 1995).

\section{Quality of life}

- Mean change from baseline or final mean value measured as a validated scale (such as IPSS-quality of life or BPH Impact index)

- We used a MCID of 0.5 to assess efficacy and comparative effectiveness (Rees 2015). A BPH Impact Index score of one as an MCID was used to indicate improvement (Barry 2013).

\section{Major adverse events}

- Example: postoperative haemorrhage requiring admission or intervention

- We used the Clavien-Dindo classification system to assess surgical complications (Dindo 2004), and categorised grade III, IV and V complications as major adverse events (Gilling 2018). If the study authors of eligible studies did not use the ClavienDindo system, we judged the adverse events by severity using the available information described in the studies.

\section{Retreatment}

- Events requiring other surgical treatment modalities (e.g. TURP) after intervention

\section{Erectile function}

- Mean change from baseline or final mean value measured as total score on the International Index of Erectile Function (IIEF)-5 questionnaire, also known as Sexual Health Inventory for Men (Rosen 1997)

- We considered the MCID an erectile function domain score of four on the IIEF (Rosen 2011). If possible, we used different thresholds of MCID based on the severity of erectile dysfunction, with a threshold of two for men with mild erectile dysfunction, five for moderate erectile dysfunction, and seven for men with severe erectile dysfunction (Rosen 2011). We considered a difference in IIEF-5 score of over five points as the MCID (Spaliviero 2010).

\section{Ejaculatory function}

- Mean change from baseline or final mean value measured using the Male Sexual Health Questionnaire for Ejaculatory Dysfunction (MSHQ-EjD) or the four-item version of the MSHQEjD (Rosen 2004; Rosen 2007)

- We considered the MCID as an ejaculatory function domain score of two on the MSHQ or four-item version of the MSHQ-EjD (Gilling 2018; Rosen 2004; Rosen 2007)

\section{Minor adverse events}

- Example: postoperative fever or pain requiring medication

- We used the Clavien-Dindo classification system to assess surgical complications (Dindo 2004), and categorised grade I and II complications as minor adverse events (Gilling 2018). If the authors of eligible studies did not use the Clavien-Dindo system, we judged the severity of adverse events using the available information described in these studies.

\section{Acute urinary retention}

- Events requiring catheterization after the intervention

\section{Indwelling urinary catheter}

- Measured in hours from intervention to urinary catheter removal

\section{Hospital stay}

\section{- Measured in days from admission to discharge}

There were no reported thresholds in adverse events, retreatment, acute urinary retention, indwelling urinary catheter, and hospital stay. We considered the clinically important differences for adverse events, retreatment, acute urinary retention, and indwelling catheter as relative risk reductions of at least 25\% (Guyatt 2011a). We used a MCID of one day ( 24 hours) to assess efficacy and comparative effectiveness for indwelling urinary catheter and hospital stay.

We considered outcomes measured up to and including 12 months after randomisation as short-term, and later than 12 months as long-term, for urologic symptom scores, quality of life, major adverse events, retreatment, erectile function, ejaculatory function, minor adverse events, and acute urinary retention. We 
assessed retreatment, indwelling urinary catheter and hospital stay as short-term only.

\section{Main outcomes for 'Summary of findings' table}

We have presented a 'Summary of findings' table that reports on the following outcomes (listed according to priority).

- Urologic symptom scores

- Quality of life

- Major adverse events

- Retreatment

- Erectile function

- Ejaculatory function

\section{Search methods for identification of studies}

We performed a comprehensive search with no restrictions on the language or status of publication. We plan to rerun searches within three months prior to the anticipated publication of this review.

\section{Electronic searches}

We searched the following sources, from the inception of each database (Appendix 1). The date of last search of all databases was 11 February 2019.

- Cochrane Library via Wiley

- Cochrane Database of Systematic Reviews (CDSR, 2019, Issue 1)

- Cochrane Central Register of Controlled Trials (CENTRAL; 2019, Issue 1)

- Database of Abstracts of Reviews of Effects (DARE)

- Health Technology Assessment Database (HTA)

- MEDLINE via Ovid (from 1946 to February 2019)

- Embase via Elsevier (from 1974 to February 2019)

- Scopus (from 1966 to February 2019)

- Web of Science (from 1900 to February 2019)

- LILACS (Latin American and the Caribbean Health Sciences Literature, www.bireme.br/, from 1982 to February 2019)

We also searched the following.

- ClinicalTrials.gov (www.clinicaltrials.gov/)

- World Health Organization (WHO) International Clinical Trials Registry Platform search portal (apps.who.int/trialsearch/)

- Grey literature repository from the current Grey Literature Report (www.greylit.org/)

If we detected additional relevant key words during any of the electric or other searches, we modified the electronic search strategies to incorporate these terms and documented the changes.

\section{Searching other resources}

We tried to identify other potentially eligible studies or ancillary publications by searching the reference lists of included studies, reviews, meta-analyses and health technology assessment reports. We also contacted the authors of included studies to identify any further studies that we may have missed. We contacted drug/device manufacturers for ongoing or unpublished studies. We searched only the published abstract proceedings of relevant meetings of the
American Urological Association, European Association of Urology, and International Continence Society for the last three years (2016 to 2018) for unpublished studies.

\section{Data collection and analysis}

\section{Selection of studies}

We used Endnote 2016 reference management software to identify and remove potential duplicate records. Two review authors independently scanned abstracts and titles to determine which studies should be assessed further using Covidence 2017 software. Two review authors categorised all potentially relevant records as full text or mapped records to studies, and classified studies as included studies, excluded studies, studies awaiting classification, or ongoing studies, in accordance with the criteria in the Cochrane Handbook for Systematic Reviews of Interventions (Higgins 2011). We resolved any disagreements between the two authors through consensus or recourse to a third review author (PD). If a resolution was not possible, we designated the corresponding study as 'awaiting classification', and we documented reasons for the exclusion of studies in the Characteristics of excluded studies table. We presented an adapted PRISMA flow diagram showing the process of study selection (Liberati 2009).

\section{Data extraction and management}

We developed a dedicated data extraction form that we pilot tested ahead of time.

For studies that fulfilled our inclusion criteria, two review authors independently abstracted the following information, which we provide in the Characteristics of included studies table.

- Study design

- Study dates ( if dates were not available then this was reported as such)

- Study settings and country

- Participant inclusion and exclusion criteria (e.g. age, baseline IPSS, medical pretreatment)

- Participant details, baseline demographics (e.g. age, prostate size, IPSS)

- The number of participants by study and by study arm

- Details of relevant experimental intervention, such as delivery devices (e.g. size of cystoscope) for Aquablation and comparator intervention (e.g. monopolar versus bipolar energy, type of laser)

- Definitions of relevant outcomes, and method (e.g. type of instrument, such as IPSS) and timing of outcome measurement (e.g. in months) as well as any relevant subgroups (e.g. based on age, prostate volume, severity of LUTS)

- Study funding sources

- Declarations of interest by primary investigators

We extracted outcome data relevant to this Cochrane Review as needed for the calculation of summary statistics and measures of variance. For dichotomous outcomes, we attempted to obtain numbers of events and totals for the study population in a $2 \times 2$ table, as well as summary statistics with corresponding measures of variance. For continuous outcomes, we attempted to obtain means and standard deviations or other data necessary to calculate this information. 
We resolved any disagreements by discussion, or, if required, by consultation with a third review author (PD).

We have provided information, including study identifiers, about potentially relevant ongoing studies in the Characteristics of ongoing studies table.

We contacted the authors of included studies to obtain key missing data as needed.

\section{Dealing with duplicate and companion publications}

In the event of duplicate publications, companion documents or multiple reports relating to a primary study, we maximised the yield of information by mapping all publications to unique studies and collating all available data. We used the most complete data set aggregated across all known publications. In case of doubt, we gave priority to publications reporting the longest follow-ups associated with our primary or secondary outcomes.

\section{Assessment of risk of bias in included studies}

Two review authors (ECH and $\mathrm{JHJ}$ ) independently assessed the risk of bias of each included study. We resolved disagreements by consensus, or by consultation with a third review author (PD). We have presented a 'Risk of bias' summary figure to illustrate these findings. We further summarised the risk of bias across the studies and domains for each outcome in each included study in accordance with the approach for the summary assessments of the risk of bias presented in the Cochrane Handbook for Systematic Reviews of Interventions (Higgins 2017a).

\section{Assessment of risk of bias in RCTs}

We assessed risk of bias using Cochrane's 'Risk of bias' assessment tool (Higgins 2017a). We assessed the following domains.

- Random sequence generation (selection bias)

- Allocation concealment (selection bias)

- Blinding of participants and personnel (performance bias)

- Blinding of outcome assessment (detection bias)

- Incomplete outcome data (attrition bias)

- Selective reporting (reporting bias)

- Other sources of bias

We judged 'Risk of bias' domains as 'low risk', 'high risk' or 'unclear risk' and evaluated individual bias items as described in the Cochrane Handbook for Systematic Reviews of Interventions (Higgins 2017a).

For selection bias (random sequence generation and allocation concealment), we evaluated risk of bias at study level.

For performance bias (blinding of participants and personnel), we considered all outcomes similarly susceptible to performance bias.

For detection bias (blinding of outcome assessment), we grouped outcomes as susceptible to detection bias (subjective) or not susceptible to detection bias (objective).

We defined the following outcomes as subjective outcomes.

- Urologic symptom scores

- Quality of life
- Erectile function

- Ejaculatory function

- Minor adverse events

We defined the following outcomes as objective outcomes.

- Major adverse events

- Retreatment

- Acute urinary retention

- Indwelling urinary catheter

- Hospital stay

We also assessed attrition bias (incomplete outcome data) on an outcome-specific basis and presented the judgment for each outcome separately when reporting our findings in the 'Risk of bias' tables.

For reporting bias (selective reporting), we evaluated risk of bias at study level.

\section{Assessment of risk of bias in non-RCTs}

We could not find any non-RCTs with concurrent comparison groups. However, if we had included non-RCTs, we would have used ROBINS-I for assessing risk of bias in non-RCTs (Sterne 2016a; Sterne 2016b). We would have assessed the following domains.

- Bias due to confounding

- Bias in selection of participants into the study

- Bias in classification of interventions

- Bias due to deviations from intended interventions

- Bias due to missing data

- Bias in measurement of outcomes

- Bias in selection of the reported result

We would have judged 'Risk of bias' domains as 'low risk', 'moderate risk', 'serious risk', 'critical risk', or 'no information' and would have evaluated individual bias items as described in Sterne 2016a and Sterne 2016b.

\section{Confounding factors}

We would have considered the following factors as sources of baseline confounding. We would have not considered time-varying confounding as this is not relevant in this setting (Sterne 2016b)

- Age

- Major comorbidities such as pre-existing cardiovascular disease

- Prostate size

- Baseline questionnaire score (such as IPSS, IPSS-quality of life, IIEF-5, MSHQ-EjD)

\section{Measures of treatment effect}

We expressed dichotomous data as risk ratios (RRs) with 95\% confidence intervals (Cls). We expressed continuous data as mean differences (MDs) with 95\% Cls, unless different studies used different measures to assess the same outcome, in which case we re-expressed the data as standardised mean differences (SMDs) with $95 \% \mathrm{Cls}$. 


\section{Unit of analysis issues}

The unit of analysis was each individual participant. We planned to take into account the level at which randomisation occurred, such as cluster-randomised trials, and the multiple observations of the same outcome. If more than one comparison from the same study was eligible for inclusion in the same meta-analysis, we either combined study groups to create a single pairwise comparison or appropriately reduced the sample size so that the same participants did not contribute multiple times (if possible, splitting the 'shared' group into two or more groups). While the latter approach offers some solution to adjusting the precision of the comparison, it does not account for correlations arising from the same set of participants being in multiple comparisons (Deeks 2017).

\section{Dealing with missing data}

We obtained missing data from corresponding study authors, if feasible, and performed intention-to-treat analyses if data were available. Otherwise, we performed available case analyses. We investigated attrition rates (e.g. dropouts, losses to follow-ups and withdrawals), and the critically appraised issues of missing data. We did not impute missing data.

\section{Assessment of heterogeneity}

We planned to assess heterogeneity. However, we included only one RCT and, therefore, we could not assess heterogeneity. If we had included at least two studies, we would have identified heterogeneity (inconsistency) through visual inspection of the forest plots to assess the amount of overlap of $\mathrm{Cls}$, and by using the 12 statistic, which quantifies inconsistency across studies to assess the impact of heterogeneity on the meta-analysis (Higgins 2002; Higgins 2003). We would have interpreted the $I^{2}$ statistic as follows (Deeks 2017).

- $0 \%$ to $40 \%$ : may not be important

- $30 \%$ to $60 \%$ : may indicate moderate heterogeneity

- $50 \%$ to $90 \%$ : may indicate substantial heterogeneity

- $75 \%$ to $100 \%$ : considerable heterogeneity

If we had identified heterogeneity, we would have attempted to determine possible reasons for it by examining individual study and subgroup characteristics.

\section{Assessment of reporting biases}

We tried to obtain study protocols to assess selective outcome reporting.

As we included only one study, we could not use funnel plots to assess small study effects. If we had included 10 or more studies in a meta-analysis, we would have used funnel plots to assess small study effects (Sterne 2017). Several explanations can be offered for the asymmetry of a funnel plot, including true heterogeneity of effect with respect to study size, poor methodological design (and hence bias of small studies) and publication bias. Therefore, we would have interpreted results carefully.

\section{Data synthesis}

As we included only one RCT, we only re-analysed and reported single study data using Review Manager 5 software (Review Manager 2014) in accordance with the guidelines contained in the
Cochrane Handbook for Systematic Reviews of Interventions (Deeks 2017).

\section{Subgroup analysis and investigation of heterogeneity}

We expected the following characteristics to introduce clinical heterogeneity and carried out subgroup analyses with the investigation of interactions.

- Patient age (less than 65 years versus 65 years or more)

- Prostate volume (less than $50 \mathrm{~mL}$ versus $50 \mathrm{~mL}$ or more)

- Severity of LUTS based on IPSS (score less than or equal to 19 (moderately symptomatic) versus greater than 19 (severely symptomatic))

These subgroup analyses are based on the following observations.

- Age is a well-known risk factor of BPH surgery. Older patients have a higher rate of postoperative complications compared with younger patients (Bhojani 2014; Pariser 2015). The age cutoff is based on the World Health Organization (WHO) definition of old age (WHO 2012).

- The outcomes and complications of minimally invasive procedures, such as TURP, correlate with prostate volume (Reich 2008). We adjusted the prostate volume of $40 \mathrm{~mL}$, which we selected as a threshold on our protocol (Hwang 2018), to $50 \mathrm{~mL}$ based on the available evidence (Gilling 2018).

- The relationship between changes in IPSS scores and patient global ratings of improvement is influenced by the baseline scores (Barry 1995).

We planned to limit subgroup analyses to the primary outcomes only.

\section{Sensitivity analysis}

We only identified one RCT and were, therefore, not able to perform sensitivity analyses. If we had performed sensitivity analysis, we would have limited this to the primary outcomes, in order to explore the influence of the following (when applicable) on effect sizes.

- Restricting the analysis in RCTs by taking into account risk of bias, by excluding studies at 'high risk' or 'unclear risk

\section{'Summary of findings' table}

We presented the overall certainty of evidence for each outcome, according to the GRADE approach (Guyatt 2008). For each comparison, two review authors (ECH and $\mathrm{JHJ}$ ) independently rated the certainty of evidence for each outcome as 'high', 'moderate', 'low', or 'very low' using the GRADEpro Guideline Development Tool (GRADEpro GDT 2015). We resolved any discrepancies by consensus, or, if needed, by arbitration by a third review author (PD). For each comparison, we presented a summary of the evidence for the main outcomes in the 'Summary of findings' table, which provides key information about the best estimate of the magnitude of effect in relative terms and absolute differences for each relevant comparison of alternative management strategies; numbers of participants and studies addressing each important outcome; and the rating of the overall confidence of effect estimates for each outcome (Guyatt 2011b; Schünemann 2017a). 
For RCTs, we considered five criteria, not only related to internal validity (risk of bias, inconsistency, imprecision, and publication bias), but also to external validity (directness of results), for downgrading the certainty of evidence for a specific outcome (Schünemann 2017b). For non-RCTs, we planned to consider five criteria for downgrading the certainty of evidence, followed by three criteria for upgrading the certainty of evidence (large magnitude of effects, all plausible confounding that would reduce a demonstrated effect or suggest a spurious effect when results show no effect, and dose-response gradient; Guyatt 2011c).

However, we could not find any non-RCTs. Please refer to the Types of outcome measures for the outcomes included in Summary of findings for the main comparison.

\section{RES U LTS}

\section{Description of studies}

\section{Results of the search}

We identified 152 records through searching electronic databases and 20 records in trials registers. We found no applicable records in the grey literature repository. After the removal of duplicates, we screened the titles and abstracts of the remaining 134 records, of which we excluded 111 . Only one study, reported in 17 records, ultimately met the inclusion criteria for the assessment of the review question (for details, refer to Figure 2). There were no ongoing studies that met the inclusion criteria, or were relevant to the review question. 
Figure 2. Study flow diagram

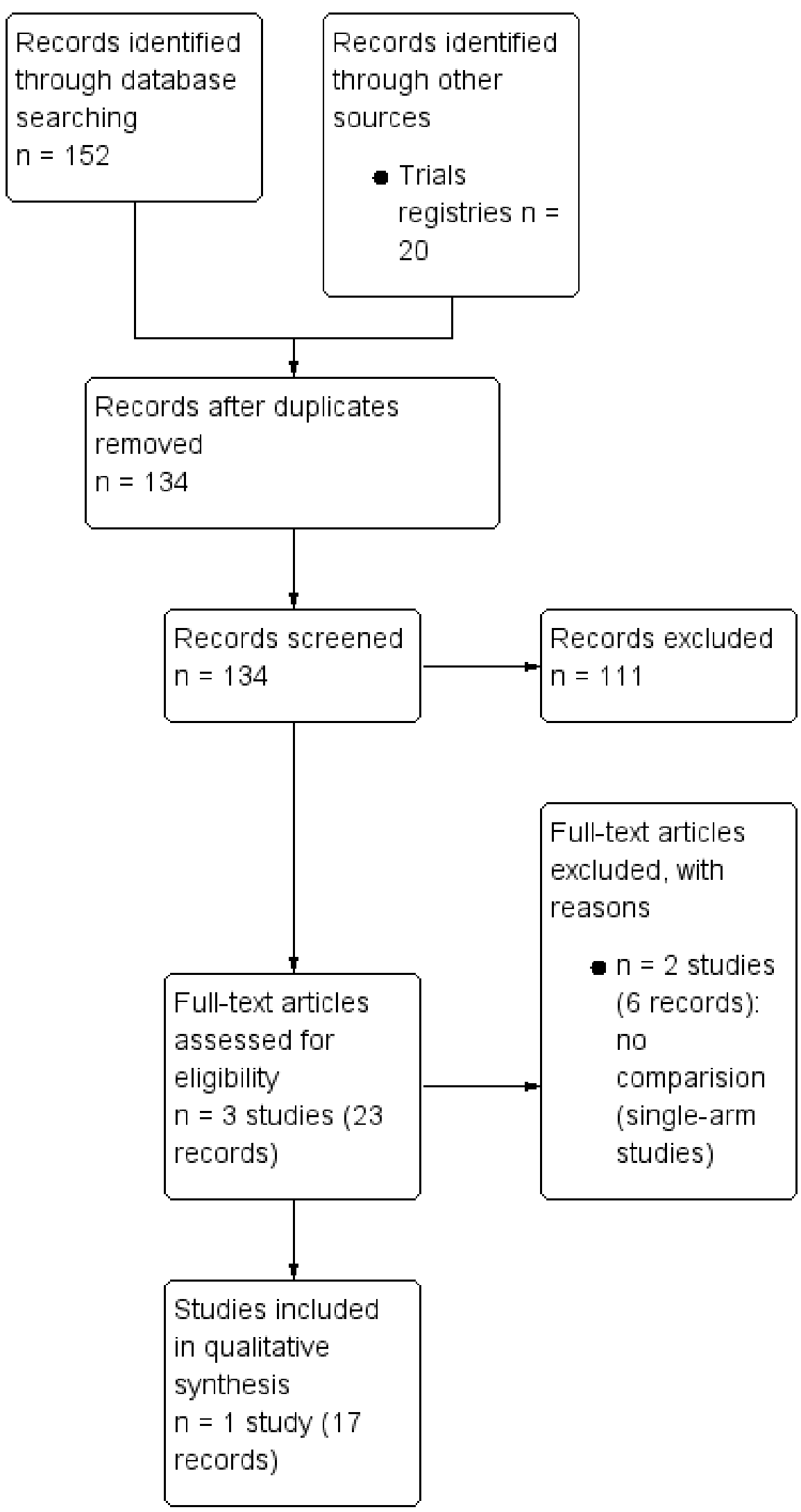




\section{Included studies}

We identified one RCT (Gilling 2018). For details, please refer to the Characteristics of included studies table, Table 1 and Table 2. The included study compared Aquablation with transurethral resection of the prostate (TURP) for the treatment of benign prostatic hyperplasia (BPH). Altogether, 275 participants were screened for enrolment in 17 sites in four countries (Australia, New Zealand, the UK and the USA). Between October 2015 and December 2016, Gilling 2018 randomly assigned 184 participants. Nineteen surgeons were involved in this study.

\section{Source of data}

We identified two published full-text records, the first record being an overall analysis and the second record being a preplanned subgroup analysis of the same study. We contacted the corresponding author of the included study to get additional information and received a reply (Appendix 2).

\section{Participants}

We included 184 randomised participants (Aquablation $\mathrm{n}=117$; TURP $n=67$ ), of whom 174 were included in the efficacy analysis (Aquablation $n=114$; TURP $n=60$ ) and 181 were included in the safety analysis (Aquablation $n=116$; TURP $n=65$ ). We have reported the baseline characteristics in Characteristics of included studies.

\section{Intervention and comparator}

The study used Aquablation, which was performed using the AquaBeam System (PROCEPT BioRobotics), as an intervention and used TURP as a comparator. The follow-up duration was 12 months.

\section{Comparisons}

No study compared Aquablation to laser ablation of the prostate, laser enucleation of the prostate, other minimally invasive therapies, or simple prostatectomy. We did not find any non-RCTs with concurrent comparison groups that met our review's inclusion criteria.

\section{Outcomes}

We identified reporting of all primary outcomes in the included study for this comparison (Gilling 2018). In addition, Gilling 2018 reported all our secondary outcomes, except for the duration of indwelling urinary catheter usage.

\section{Funding sources and conflicts of interest}

This study was supported by the company that produced the Aquablation device. This study's authors also have financial relationships with the same company.

\section{Excluded studies}

We excluded two studies (6 records) out of three studies ( 23 records) after evaluation of the full-text publications. These studies had no comparator, that is, they were single-armed studies (Bach 2018; Desai 2019). Please refer to Characteristics of excluded studies table.

\section{Studies awaiting classification and ongoing studies}

There were no studies awaiting classification or ongoing studies.

\section{Risk of bias in included studies}

For details, please refer to Characteristics of included studies section, the 'Risk of bias' table, Summary of findings for the main comparison for the main comparison, Figure 3 and Figure 4.

\section{Figure 3. Risk of bias graph: review authors' judgements about each risk of bias item presented as percentages} across all included studies

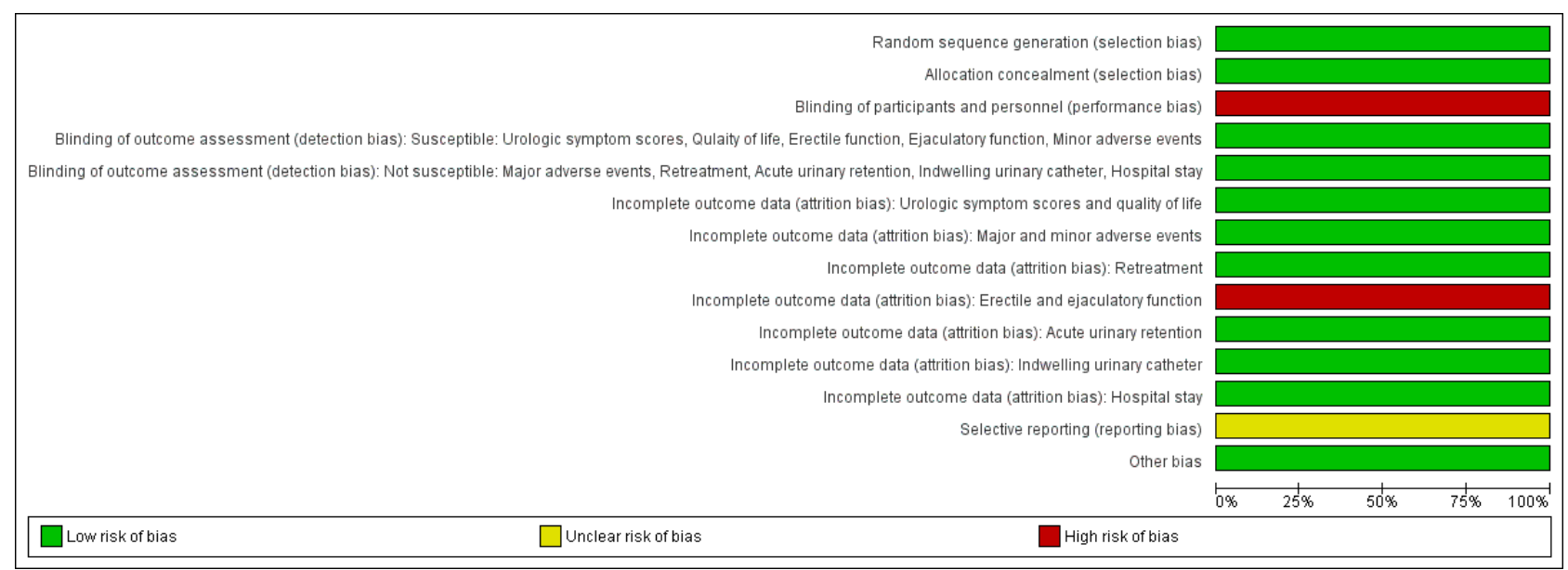


Figure 4. Risk of bias summary: review authors' judgements about each risk of bias item for each included study

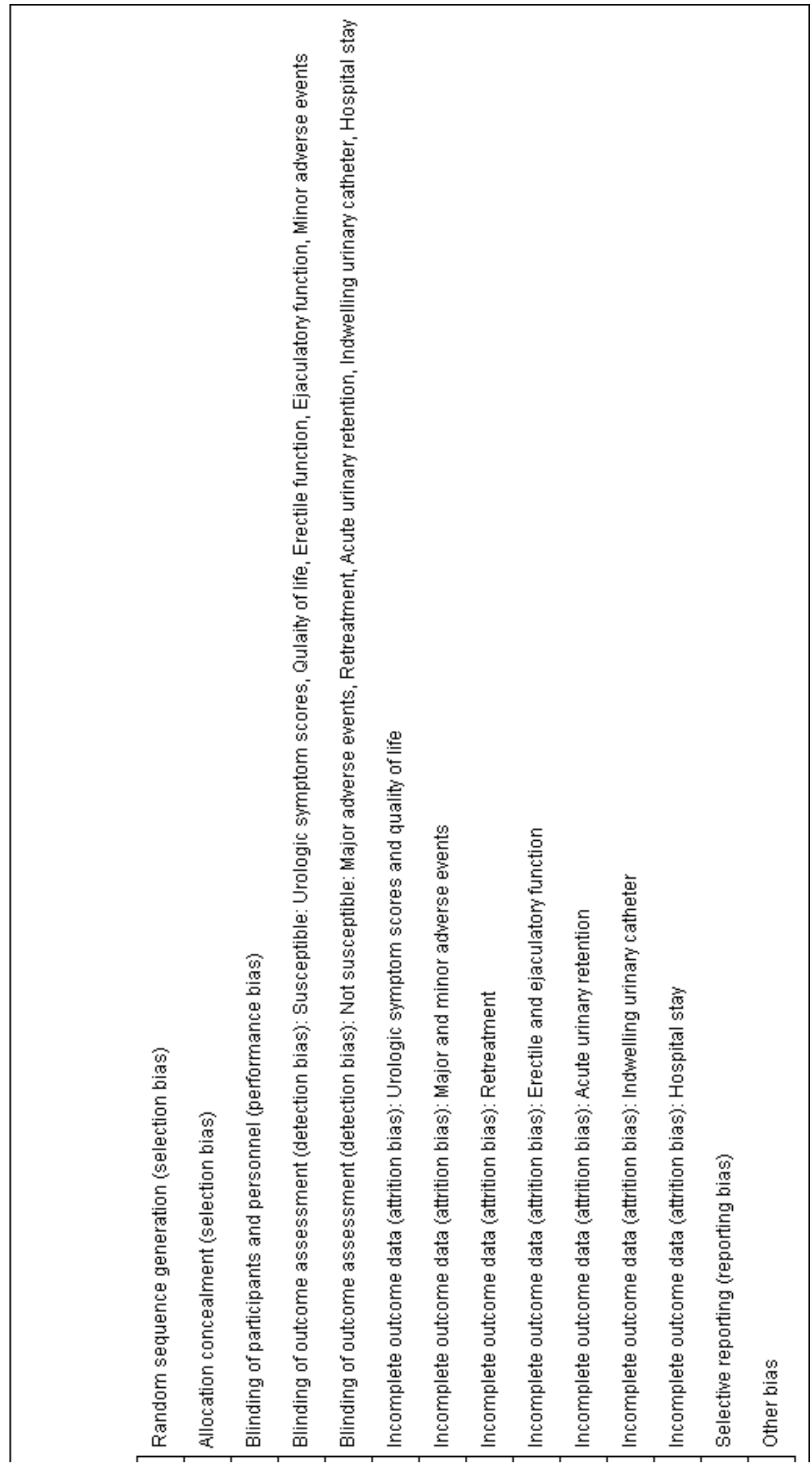

Aquablation of the prostate for the treatment of lower urinary tract symptoms in men with benign prostatic hyperplasia (Review) 
Figure 4. (Continued)

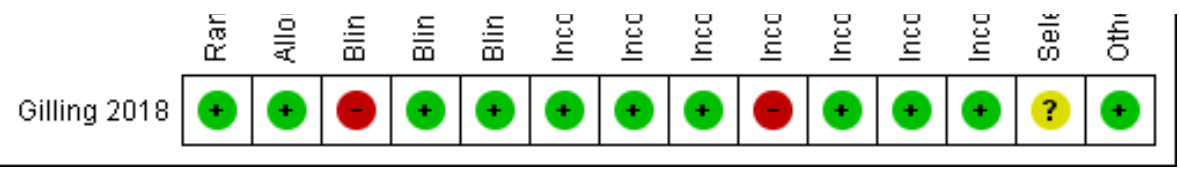

\section{Allocation}

Random sequence generation and allocation concealment were performed adequately, and we judged this study to be at low risk of selection bias.

\section{Blinding}

\section{Performance bias}

Participants were blinded, but personnel (surgeons) were not blinded. We, therefore, rated the risk of bias as high.

\section{Detection bias}

\section{Susceptible (subjective) outcomes}

These were urologic symptom scores, quality of life, erectile function, ejaculatory function, and minor adverse events.

Gilling 2018 reported that the assessors of these outcomes were blinded. We rated the risk of bias for these outcomes as low.

\section{Not susceptible (objective) outcomes}

These were major adverse events, retreatment, acute urinary retention, indwelling urinary catheter usage, and hospital stay.

Blinding of outcome assessors is not relevant to these outcomes. We rated the risk of bias for these outcomes as low.

\section{Incomplete outcome data}

Gilling 2018 measured erectile and ejaculatory function in a limited subset of participants who were sexually active at baseline and sexually active during the follow-up period. We judged the risk of attrition bias as high for these outcomes.

Attrition was less than $10 \%$ in both the Aquablation and TURP groups for other outcomes. We judged the risk of attrition bias as low for these outcomes.

\section{Selective reporting}

A protocol was available and the reported outcomes and their analyses in the included study corresponded to how these had been planned. However, secondary outcomes were not pre-specified in the ClinicalTrials.gov registry (NCT02505919) and several qualityof-life measurement were not reported (e.g. EuroQOL-5D). We therefore, assigned a judgment of unclear risk of reporting bias to these secondary outcomes.

\section{Other potential sources of bias}

We identified no other potential sources of bias.

\section{Effects of interventions}

See: Summary of findings for the main comparison Aquablation compared to transurethral resection of the prostate for benign prostatic hyperplasia
Please refer to Analysis 1.1 to Analysis 1.10 , and Summary of findings for the main comparison. We also analysed the six-month results for each outcome in Analysis 2.1 to Analysis 2.10 but did not describe these below.

\section{Aquablation versus transurethral resection of the prostate (TURP)}

\section{Primary outcomes}

\section{Urologic symptom scores (assessed with: IPSS)}

Aquablation likely results in little to no difference in urologic symptom scores compared to TURP (MD $-0.06,95 \% \mathrm{Cl}-2.51$ to 2.39; participants $=174$; studies $=1$; follow-up time: 12 months; Analysis 1.1). We judged the certainty of the evidence to be moderate. We downgraded the certainty of the evidence by one level due to study limitations, namely that of performance bias.

\section{Quality of life (assessed with: IPSS-QOL)}

Aquablation may result in little to no difference in quality of life (MD $0.27,95 \% \mathrm{Cl}-0.24$ to 0.78 ; participants $=174$; studies $=1$; followup time: 12 months; Analysis 1.2). We judged the certainty of the evidence to be low. We downgraded the certainty of the evidence by two levels due to study limitations, namely performance bias and imprecision, given that the $\mathrm{Cl}$ crossed the assumed minimally important difference of 0.5 .

\section{Major adverse events (assessed with: Clavien-Dindo classification system; Grade III, IV and V complications)}

Aquablation may result in little to no difference in major adverse events (RR 0.84, 95\% Cl 0.31 to 2.26; participants = 181; studies $=1$; follow-up time: 12 months; Analysis 1.3), but we are very uncertain of this finding. This corresponds to 15 fewer major adverse events per 1000 participants ( $95 \% \mathrm{Cl} 64$ fewer to 116 more). We judged the certainty of the evidence to be very low. We downgraded the certainty of the evidence by one level due to study limitations, namely performance bias, and by two levels for imprecision, given that the $\mathrm{Cl}$ was consistent both with a small reduction in major adverse events as well as an appreciable increase in major adverse events.

\section{Secondary outcomes}

\section{Retreatment}

Aquablation may result in little to no difference in retreatments (RR $1.68,95 \% \mathrm{Cl} 0.18$ to 15.83 ; participants $=181$; studies $=1$; followup time: 12 months; Analysis 1.4), but we are very uncertain of this finding. This corresponds to 10 more retreatments per 1000 participants ( $95 \% \mathrm{Cl} 13$ fewer to 228 more). We judged the certainty of the evidence to be very low. We downgraded the certainty of the evidence by one level due to study limitations, namely performance bias, and by two levels for imprecision, given that the $\mathrm{Cl}$ was consistent with both a small or no reduction as well as an appreciable increase in the number of retreatments. 


\section{Erectile function (assessed with: IIEF-EF domain)}

Aquablation may result in little to no difference in erectile function (MD 2.31, 95\% Cl -0.63 to 5.25; participants $=64$ (sexually active men only); studies = 1; follow-up time: 12 months; Analysis 1.5), but we are very uncertain of this finding. We judged the certainty of the evidence to be very low. We downgraded the certainty of the evidence by two levels for study limitations due to risk of performance and attrition bias, and by one level for imprecision, given that the $\mathrm{Cl}$ crossed the assumed minimally important difference of 4 .

\section{Ejaculatory function (assessed with: MSHQ-EjD)}

Aquablation may reduce ejaculatory dysfunction slightly (MD 2.57, $95 \% \mathrm{Cl} 0.60$ to 4.53; participants $=121$ (sexually active men only); studies = 1; follow-up time: 12 months; Analysis 1.6), but we are very uncertain of this finding. We judged the certainty of the evidence to be very low. We downgraded the certainty of the evidence by two levels due to study limitations, namely performance and attrition bias, and by one level for imprecision, given that the $\mathrm{Cl}$ crossed the assumed minimally important difference of 2 .

\section{Minor adverse events (assessed with: Clavien-Dindo classification system; Grade I and II complications)}

Aquablation may result in little to no difference in minor adverse events (RR 0.96, 95\% Cl 0.76 to 1.21 ; participants $=181$; studies $=1$; follow-up time: 12 months; Analysis 1.7), but we are very uncertain of this finding. This corresponds to 26 fewer minor adverse events per 1000 participants ( $95 \% \mathrm{Cl} 155$ fewer to 136 more). We judged the certainty of the evidence to be very low. We downgraded the certainty of the evidence by one level due to study limitations, namely performance bias, and by two levels for imprecision, based on the assumption that the boundaries of the $\mathrm{Cl}$ are consistent with both a (large) beneficial effect and undesirable effect.

\section{Acute urinary retention}

Aquablation may result in little to no difference in acute urinary retention (RR $1.01,95 \% \mathrm{Cl} 0.35$ to 2.88 ; participants $=181$; studies = 1; follow-up time: 12 months; Analysis 1.8), but we are very uncertain of this finding. This corresponds to one more acute urinary retention per 1000 participants $(95 \% \mathrm{Cl} 50$ fewer to 145 more). We judged the certainty of the evidence to be very low. We downgraded the certainty of the evidence by one level due to study limitations, namely performance bias, and by two levels for imprecision, given that the $\mathrm{Cl}$ is consistent with both a small desirable effect as well as a large undesirable effect.

\section{Indwelling urinary catheter}

Aquablation likely results in little to no difference in duration of indwelling urinary catheter usage (MD 6.00 hours, $95 \% \mathrm{Cl}-9.45$ to 21.45; participants $=173$; studies $=1$; follow-up time: 3 months; Analysis 1.9). We judged the certainty of the evidence to be moderate. We downgraded the certainty of the evidence by one level due to study limitations, namely performance bias.

\section{Hospital stay}

Aquablation likely results in little to no difference in hospital stay (MD 0.00 days, $95 \% \mathrm{Cl}-0.21$ to 0.21 ; participants $=181$; studies $=1$; follow-up time: 3 months; Analysis 1.10). We judged the certainty of the evidence to be moderate. We downgraded the certainty of the evidence by one level due to study limitations, namely performance bias.

\section{Subgroup analyses}

We performed pre-planned subgroup analyses (stratified by age, the severity of lower urinary tract symptoms (LUTS) based on International Prostate Symptom Score (IPSS) and prostate volume) with regard to primary outcomes. However, these outcomes come from up to six months' follow-up.

\section{Patient age (under 65 years versus 65 years and older)}

For details, please refer to Analysis 3.1 to Analysis 3.3. In terms of urologic symptom and quality-of-life scores, of the 176 participants, 75 were aged under 65 years (Aquablation $n=49$; TURP $n=26$ ), and 101 were aged 65 years old or older (Aquablation $n=65$; TURP $n=$ $36)$.

\section{Urologic symptom scores}

For participants aged under 65 years, the MD was $-2.40(95 \% \mathrm{Cl}$ -6.34 to 1.54 ), and for those aged 65 years or older, the MD was -1.30 $(95 \% \mathrm{Cl}-4.12$ to 1.52$)$. The test for interaction was not significant ( $\mathrm{P}$ $\left.=0.66, \mathrm{I}^{2}=0 \%\right)$.

\section{Quality of life}

The MD for quality of life with Aquablation was $0.20(95 \% \mathrm{Cl}-0.52$ to $0.92)$, for participants aged under 65 years and $-0.50(95 \% \mathrm{Cl}-1.23$ to 0.23 ), for those aged 65 years or older. The test for interaction was not significant $\left(P=0.18,1^{2}=44 \%\right)$

\section{Major adverse events}

Of the 181 participants, 77 were under 65 years old (Aquablation $n$ $=50$; TURP $n=27$ ), and 104 were 65 years or older (Aquablation $n$ $=66 ;$ TURP $n=38$.

The RR of major adverse events with Aquablation was 6.04 (95\% $\mathrm{Cl} 0.35$ to 105.26), for participants aged under 65 years, and 0.23 $(95 \% \mathrm{Cl} 0.05$ to 1.13$)$, for those aged 65 years or older. The test for interaction was not significant $(P=0.05,12=73.9 \%)$.

\section{Prostate volume (less than $50 \mathrm{~mL}$ versus $50 \mathrm{~mL}$ or more)}

For details, please refer to Analysis 3.4 to Analysis 3.6. In terms of urologic symptom and quality-of-life scores, of the 176 participants, 80 had a prostate volume of less than $50 \mathrm{~mL}$ (Aquablation $\mathrm{n}=51$; TURP group $n=29$ ), and 96 had a prostate volume of $50 \mathrm{~mL}$ or more (Aquablation $n=63$; TURP $n=33$ ).

\section{Urologic symptom scores}

For prostate volume of less than $50 \mathrm{~mL}$, the MD was $0.90(95 \% \mathrm{Cl}$ -2.12 to 3.92 ), and for prostate volume of $50 \mathrm{~mL}$ or more, the MD was $-4.10(95 \% \mathrm{Cl}-7.45$ to -0.75$)$. The test for interaction was significant $\left(\mathrm{P}=0.03, \mathrm{I}^{2}=78.8 \%\right)$.

\section{Quality of life}

The MD for quality of life with Aquablation was $0.10(95 \% \mathrm{Cl}-0.61$ to 0.81$)$ for prostate volume of less than $50 \mathrm{~mL}$, and $-0.50(95 \% \mathrm{Cl}$ -1.24 to 0.24$)$ for prostate volume of $50 \mathrm{~mL}$ or more. The test for interaction was not significant $(P=0.25,12=23.6 \%)$. 


\section{Major adverse events}

Of the 181 participants, 82 had a prostate volume of less than $50 \mathrm{~mL}$ (Aquablation $n=52$; TURP $n=30$ ), and 99 had a prostate volume of $50 \mathrm{~mL}$ or more (Aquablation $\mathrm{n}=64$; TURP $\mathrm{n}=35$ ).

The RR of major adverse events with Aquablation was $2.31(95 \% \mathrm{Cl}$ 0.27 to 19.71 ), for prostate volume of less than $50 \mathrm{~mL}$, and 0.41 ( $95 \%$ $\mathrm{Cl} 0.10$ to 1.73), for prostate volume of $50 \mathrm{~mL}$ or more. The test for interaction was not significant $\left(P=0.19,1^{2}=41.8 \%\right)$.

\section{Severity of LUTS based on IPSS (19 or less versus more than 19)}

For details, please refer to Analysis 3.7 to Analysis 3.9. In terms of urologic symptoms and quality-of-life scores, of the 176 participants, 59 had an IPSS of 19 or less (Aquablation $n=36$; TURP $n=23$ ), and 117 had an IPSS of more than 19 (Aquablation $n=78$; TURP $n=39$ ).

\section{Urologic symptom scores}

For IPSS of 19 or less, the MD was $-2.70(95 \% \mathrm{Cl}-5.42$ to 0.02$)$, and for IPSS of more than 19 , the MD was $-0.40(95 \% \mathrm{Cl}-2.77$ to 1.97$)$. The test for interaction was not significant $\left(P=0.21, \mathrm{I}^{2}=35.9 \%\right)$.

\section{Quality of life}

The MD for quality of life with Aquablation was $-0.30(95 \% \mathrm{Cl}-1.14$ to 0.54$)$, for IPSS of 19 or less, and $-0.10(95 \% \mathrm{Cl}-0.77$ to 0.57$)$ for IPSS of more than 19. The test for interaction was not significant ( $P$ $\left.=0.71, \mathrm{I}^{2}=0 \%\right)$.

\section{Major adverse events}

Of the 181 participants, 59 had an IPSS of 19 or less (Aquablation $n=$ 36; TURP $n=23$ ), and 122 had an IPSS of more than 19 (Aquablation $n=80 ;$ TURP $n=42$ ).

The RR of major adverse events with Aquablation was $0.64(95 \% \mathrm{Cl}$ 0.10 to 4.22 ), for IPSS of 19 or less, and 0.88 ( $95 \% \mathrm{Cl} 0.22$ to 3.48 ) for IPSS of more than 19. The test for interaction was not significant ( $P$ $\left.=0.79,1^{2}=0 \%\right)$.

\section{DISCUSSION}

\section{Summary of main results}

Findings of this review are based on a single study with 184 participants, sponsored by the device manufacturer, comparing Aquablation to TURP, that only provided results after short-term follow-up of 12 months or less, depending on the outcome. We found no other studies or prospective non-randomised studies to compare Aquablation to other treatment modalities.

Based on this study, Aquablation likely has similar results to TURP for urological symptoms scores and similarly, may improve quality of life. The risk of major adverse events appears to be similar too, but we are very uncertain about this finding.

With regard to secondary outcomes, Aquablation may offer similar outcomes in terms of rates of retreatment (up to 12 months), erectile function, minor adverse events, acute urinary retention, indwelling urinary catheter duration and hospital stay. Aquablation may offer a small benefit for sexually active men in terms of ejaculatory function. However, the evidence is very uncertain about the effect of Aquablation on retreatment, erectile and ejaculatory function, minor adverse events and acute urinary retention.
Aquablation may improve urologic symptom scores more in participants with a prostate volume of $50 \mathrm{~mL}$ or above than in participants with a prostate volume of less than $50 \mathrm{~mL}$. This result should be interpreted with caution because the included study was not designed to assess subgroup effects. We judged the certainty of the evidence for this outcome as low due to study limitations and imprecision.

\section{Overall completeness and applicability of evidence}

The following issues deserve consideration when interpreting the results of this review.

- The body of evidence stems from a multicenter study sponsored by the device maker. The developmental stages of Aquablation did not follow the IDEAL (Idea, Development, Exploration, Assessment, and Long-term Study) framework (Hirst 2018). Surgeons performing the procedure likely had specific expertise and experience in this technique. The learning curve for this procedure is not well defined and it is unclear how the results will translate to the larger community.

- Findings of this review are limited to a time-frame of 12 months and prostate volume of $80 \mathrm{~mL}$ or less, which may be inadequate to assess the comparative effectiveness of this newer technology. This is reflected in the relevant 2018 American Urological Association guideline (Foster 2018), which focused on outcomes at follow-up of 12 months or longer. We hope to see long-term follow-up data, including large prostate volume, reported by this study to update this review.

- Cost-effectiveness was outside the scope of this review yet it deserves mention that Aquablation requires specialized equipment and considerable capital investment unlike the relatively ubiquitous technology used in TURP.

- It is of major clinical interest how the effects of Aquablation compare for different prostate sizes. To address this question, we performed and report a predefined subgroup analysis. We could not confirm (based on the published trial protocol) that this analysis was prespecified by the investigators (clinicaltrials.gov/ct2/show/NCT02505919). Due to the risk of spurious findings based on prognostic baseline imbalances, we would downgrade the certainty of evidence for subgroup findings further.

- Whereas TURP continues to be widely recognised as reference standard when it comes to the surgical management of LUTS in men with $\mathrm{BPH}$, there is increasing interest in alternative procedures that are perceived to be less invasive, for example because they can be performed in an outpatient setting (e.g. PUL; Magistro 2017), or can be performed in higher-risk patients on systemic anticoagulation (e.g. HoLEP, photoselective vaporisation of the prostate; Foster 2018). Direct comparisons, for example of Aquablation and the water vapour thermal therapy would be helpful to compare their comparative effectiveness. Cochrane Reviews for other relevant procedures are ongoing (Kang 2019; Jung 2017a; Jung 2017b; Mamoulakis 2014).

\section{Quality of the evidence}

We consistently downgraded the certainty of the evidence to moderate, low or very low. The reasons for downgrading the certainty of the evidence were mainly concerns over study limitations (issues surrounding performance bias and reporting 
bias), and imprecision (Cls that crossed the assumed thresholds of clinically important differences or few events, or both). For details on the certainty of the evidence, please refer to Summary of findings for the main comparison.

\section{Potential biases in the review process}

- Although we performed this review with a broad search strategy for multiple biomedical databases and the evaluation of the literature, it is possible that additional studies may have been conducted, but not yet published, or that we may not have identified additional studies.

- The included study (Gilling 2018), included two different modes of TURP as comparator (i.e. monopolar (55.4\%) and bipolar (44.6\%)). Whereas the two TURP modalities appear to have similar efficacy and safety (EAU 2017), this could have introduced bias.

- In the subgroup analysis, we had predefined the prostate volume cut-off for small and large prostates as $40 \mathrm{~mL}$ for this review, but we analysed it using a $50 \mathrm{~mL}$ cut-off because this was a predefined analysis stated by the authors of the included study (Gilling 2018). This may be the source a bias.

- We could not assess the effect of bias by carrying out a sensitivity analysis since we only included one study.

\section{Agreements and disagreements with other studies or reviews}

Most subject-related published reviews have been narrative reviews that evaluated the initial results of Aquablation for the treatment LUTS in men with BPH (Lee 2018; Taktak 2018). These reviews concluded that Aquablation provides reduced resection and overall procedure times, had minimal adverse events (no major complications; i.e. Clavien-Dindo grades of III or higher), and improved urinary symptom scores and urinary streams while preserving sexual function. This comes from several single-arm study results. One systematic review (Lebdai 2018), and minireview (Rieken 2018), assessed the loss of ejaculation and erectile dysfunction after surgical treatment for BPH. Both concluded that Aquablation seems to be a reasonable option for those concerned with sexual dysfunction but also labelled the need for longer-term data. A systematic review for the National Institute for Health and Care Excellence (NICE) Interventional Procedures Program found that "the evidence on efficacy is limited in quantity" but was limited to 6 months' follow-up data available at the time (NICE guidance).

Aside from using the most rigorous methodology based on a published protocol, this review stands out by virtue of its assessment of the certainty of the evidence on a per-outcome basis. This may be particularly important for those outcomes, such as major adverse events, for which we found only very low-certainty evidence, signalling major uncertainty about the true effect size.
Assuming that decision-makers would consider major adverse events as a critical outcome, any recommendation for or against the use of Aquablation would be based on only very low-certainty evidence. In addition, this review distinguishes itself from existing reviews by using thresholds for minimally important differences in the interpretation of effect sizes, thereby emphasising clinically important over statistically significant differences.

\section{AUTHORS' CONCLUSIONS}

\section{Implications for practice}

Based on moderate- to very low-certainty evidence, the short-term effect of Aquablation appears similar to transurethral resection of the prostate (TURP) with regard to urologic symptom scores and quality of life. We are very uncertain about the true rate of major adverse events. Patients and decision-makers should be aware that the available evidence for this newer technology stems from a single, relatively small randomised controlled trial (RCT), sponsored by the device maker. Follow-up was limited to 12 months' duration, which may be insufficient to fully appreciate its comparative effectiveness, and prostate volume was $80 \mathrm{~mL}$ or less.

\section{Implications for research}

Our knowledge could be improved by focusing on the following issues.

- This review identified only one RCT to contribute to its findings, and conclusions are limited by concerns over imprecision and selective reporting bias. More rigorously conducted and transparently reported, larger studies are important.

- Future studies should compare Aquablation to other treatment forms in men with lower urinary tract symptoms (LUTS) due to benign prostatic hyperplasia (BPH), such as laser enucleation techniques, prostatic urethral lift, and robotic-assisted simple prostatectomy, for example, in which there is increasing interest.

- Longer-term data are expected from the included study (Gilling 2018). In addition, further, separate studies and well-designed prospective observational studies with at least 12 months' follow-up are needed.

\section{ACKNOWLEDGEMENTS}

We acknowledge the support received from the authors of the included study, Daniel Cher, Barry Templin, Mark Plante and Peter Gilling, who provided additional, unpublished data.

We are very grateful to Dong Gil Shin, Jong Jin Oh, Sean McAdams and Sevann Helo for having served as peer reviewers. We thank Cochrane Urology, our contact editor Juan Franco, and Managing Editor Robert Lane for the support we received. 


\section{R E F E R E N C E S}

\section{References to studies included in this review}

Gilling 2018 \{published data only\}

A prospective multicenter randomized blinded study comparing Aquablation of the prostate with the AQUABEAM system and TURP for the treatment of LUTS. apps.who.int/trialsearch/ Trial2.aspx?TrialID=DRKS00010848.

Waterjet ablation therapy for endoscopic resection of prostate tissue (WATER). clinicaltrials.gov/ct2/show/NCT02505919.

Anderson P. The WATER study clinical results: a subgroup analysis of larger prostates from the phase 3 , blinded, randomized trial of Aquablation vs. transurethral resection of the prostate. Canadian Urological Association Journal = Journal de l'Association des Urologues du Canada 2018;12(6Suppl2):S58. [PUBMED: 29877793]

Barber N. The water study sexual function results-a phase III blinded randomized parallel group trial of Aquablation vs. transurethral resection of the prostate with blinded outcome assessment for moderate-to-severe LUTS in men with benign prostatic hyperplasia. Journal of Urology 2018;199(4 Supplement):e832.

Barber N, Thomas A, Aho T. The WATER study clinical resultsa phase III blinded randomized trial of Aquablation vs. TURP with blinded outcome assessment for moderate-tosevere LUTS in men with BPH. Journal of Clinical Urology 2018;11(1_suppl):9-94. [DOI: 10.1177/2051415818773021]

Bidair M. The water study sexual function results-a phase III blinded randomized parallel group trial of Aquablation vs. transurethral resection of the prostate with blinded outcome assessment for moderate-to-severe LUTS in men with benign prostatic hyperplasia. Journal of Sexual Medicine 2018;15(2):S61-2. [DOI: 10.1016/j.jsxm.2017.11.153]

* Gilling P, Barber N, Bidair M, Anderson P, Sutton M, Aho T, et al. Randomized controlled trial of Aquablation vs. transurethral resection of the prostate in benign prostatic hyperplasia: oneyear outcomes. Urology 2018 Dec 12 [Epub ahead of print]. [DOI: 10.1016/j.urology.2018.12.002]

Gilling P, Barber N, Bidair M, Anderson P, Sutton M, Aho T, et al. WATER: a double-blind, randomized, controlled trial of Aquablation ${ }^{\otimes}$ vs transurethral resection of the prostate in benign prostatic hyperplasia. Journal of Urology 2018;199(5):1252-61. [DOI: 10.1016/j.juro.2017.12.065]

Gilling P, Roehrborn C. The WATER study clinical resultsa phase iii blinded randomized trial of Aquablation vs. TURP with blinded outcome assessment for moderate-tosevere LUTS in men with BPH. Journal of Urology 2018;199(4 Supplement):e1219.

Gilling P, Roehrborn C. The WATER study-a phase III blinded randomized trial of Aquablation vs. transurethral resection of the prostate for the treatment of benign prostatic hyperplasia. Journal of Endourology / Endourological Society 2017;31(S2):A355. [DOI: 10.1089/end.2017.29029.abstracts]
Kasivisvanathan V, Hussain M. Aquablation versus transurethral resection of the prostate: 1 year United States - cohort outcomes. Canadian Journal of Urology 2018;25(3):9317-22. [PUBMED: 29900819]

Plante M, Gilling P, Barber N, Bidair M, Anderson P, Sutton M, et al. Symptom relief and anejaculation after Aquablation or transurethral resection of the prostate: subgroup analysis from a blinded randomized trial. BJU International 2018 Jun 4 [Epub ahead of print]. [DOI: 10.1111/bju.14426]

Roehrborn C, Anderson P, Gilling P. The WATER study clinical results-a subgroup analysis of larger prostates from the Phase III blinded randomized trial of Aquablation versus TURP. BJU International 2018;121(S1):12. [DOI: 10.1111/bju.14116]

Roehrborn C, Gilling P. Outcomes assessment of Aquablation in prostates 50 to $80 \mathrm{ml}$ in volume-a subgroup analysis from the phase III blinded randomized water study comparing Aquablation vs. transurethral resection of the prostate for moderate-to-severe LUTS in men with BPH. Journal of Urology 2018;199(4 Supplement):e833-4.

Roehrborn C, Gilling P. The WATER study clinical results-a phase III blinded randomized trial of Aquablation vs. TURP with blinded outcome assessment for moderate-to-severe LUTS in men with BPH. European Urology Supplements 2018;17(2):e1035-6. [DOI: 10.1016/S1569-9056(18)31551-3]

Roehrborn C, Gilling P. Water study clinical results-phase III double blind randomized control trial of Aquablation vs. transurethral resection of the prostate for moderate-to-severe benign prostatic hyperplasia. Journal of Urology 2017;197(4 Supplement):e603-4.

Zorn K, Bhojani N, Elterman D, Roehrborn C, Gilling P. The WATER study clinical results: a phase 3 , blinded, randomized trial of Aquablation vs. transurethral resection of the prostate with blinded outcome assessment for lower urinary tract symptoms. Canadian Urological Association Journal = Journal de l'Association des Urologues du Canada 2018;12(6Suppl2):S79. [PUBMED: 29877793]

\section{References to studies excluded from this review}

Bach 2018 \{published data only\}

Bach T, Giannakis I, Bachmann A, Fiori C, Gomez-

Sancha F, Herrmann TR, et al. Aquablation of the prostate: single-center results of a non-selected, consecutive patient cohort. World Journal of Urology 2018 Oct 4 [Epub ahead of print]. [DOI: 10.1007/s00345-018-2509-y]

\section{Desai 2019 \{published data only\}}

Waterjet ablation therapy for endoscopic resection of prostate tissue II (WATERII). clinicaltrials.gov/ct2/show/NCT03123250.

Bhojani N, Nguyen DD, Kaufman RP Jr, Elterman D, Zorn KC. Comparison of $<100 \mathrm{cc}$ prostates and $>100 \mathrm{cc}$ prostates undergoing Aquablation for benign prostatic hyperplasia. World 
Journal of Urology 2018 Oct 28 [Epub ahead of print]. [DOI: $10.1007 / \mathrm{s} 00345-018-2535-9]$

* Desai M, Bidair M, Bhojani N, Trainer A, Arther A, Kramolowsky E, et al. WATER II (80-150 mL) procedural outcomes. BJU International 2019;123(1):106-12. [DOI: 10.1111/ bju.14360]

Desai M, Bidair M, Zorn KC, Trainer A, Arther A, Kramolowsky E, et al. Aquablation for BPH in Large Prostates (80-150cc): 6Month Results From the WATER II Trial. BJU international 2019 Feb 8 [Epub ahead of print]. [DOI: 10.1111/bju.14703]

Zorn KC, Goldenberg SL, Paterson R, So A, Elterman D, Bhojani N. Aquablation among novice users in Canada: a WATER II subpopulation analysis. Canadian Urological Association Journal = Journal de l'Association des Urologues du Canada 2018 Oct 15 [Epub ahead of print]. [DOI: 10.5489/cuaj.5501]

\section{Additional references}

\section{Agarwal 2014}

Agarwal A, Eryuzlu LN, Cartwright R, Thorlund K, Tammela TL, Guyatt GH, et al. What is the most bothersome lower urinary tract symptom? Individual- and population-level perspectives for both men and women. European Urology 2014;65(6):1211-7. [PUBMED: 24486308]

\section{Aljuri 2017}

Aljuri N, Gilling P, Roehrborn C. How I do it: balloon tamponade of prostatic fossa following Aquablation. Canadian Journal of Urology 2017;24(4):8937-40. [PUBMED: 28832316]

\section{Aoun 2015}

Aoun F, Marcelis Q, Roumeguere T. Minimally invasive devices for treating lower urinary tract symptoms in benign prostate hyperplasia: technology update. Research and Reports in Urology 2015;7:125-36. [PUBMED: 26317083]

\section{Barry 1992}

Barry MJ, Fowler FJ Jr, O'Leary MP, Bruskewitz RC, Holtgrewe HL, Mebust WK, et al. The American Urological Association symptom index for benign prostatic hyperplasia. The Measurement Committee of the American Urological Association. Journal of Urology 1992;148(5):1549-57; discussion 1564. [PUBMED: 1279218]

\section{Barry 1995}

Barry MJ, Williford WO, Chang Y, Machi M, Jones KM, WalkerCorkery $\mathrm{E}$, et al. Benign prostatic hyperplasia specific health status measures in clinical research: how much change in the American Urological Association symptom index and the benign prostatic hyperplasia impact index is perceptible to patients?. Journal of Urology 1995;154(5):1770-4. [PUBMED: 7563343]

\section{Barry 1997}

Barry MJ, Fowler FJ Jr, Bin L, Pitts JC 3rd, Harris CJ, Mulley AG Jr. The natural history of patients with benign prostatic hyperplasia as diagnosed by North American urologists. Journal of Urology 1997;157(1):10-4; discussion 14-5. [PUBMED: 8976204]

\section{Barry 2013}

Barry MJ, Cantor A, Roehrborn CG, CAMUS Study Group. Relationships among participant international prostate symptom score, benign prostatic hyperplasia impact index changes and global ratings of change in a trial of phytotherapy in men with lower urinary tract symptoms. Journal of Urology 2013;189(3):987-92. [PUBMED: 23017510]

\section{Bhojani 2014}

Bhojani N, Gandaglia G, Sood A, Rai A, Pucheril D, Chang SL, et al. Morbidity and mortality after benign prostatic hyperplasia surgery: data from the American College of Surgeons national surgical quality improvement program. Journal of Endourology 2014;28(7):831-40. [PUBMED: 24517323]

\section{Chapple 2017}

Chapple C, Castro-Diaz D, Chuang YC, Lee KS, Liao L, Liu SP, et al. Prevalence of lower urinary tract symptoms in China, Taiwan, and South Korea: results from a cross-sectional, populationbased study. Advances in Therapy 2017;34(8):1953-65. [PUBMED: 28687936]

\section{Cornu 2010}

Cornu JN, Cussenot O, Haab F, Lukacs B. A widespread population study of actual medical management of lower urinary tract symptoms related to benign prostatic hyperplasia across Europe and beyond official clinical guidelines. European Urology 2010;58(3):450-6. [PUBMED: 20554374]

\section{Covidence 2017 [Computer program]}

Veritas Health Innovation. Covidence. Version accessed 16 August 2017. Melbourne, Australia: Veritas Health Innovation, 2013.

\section{Crawford 2006}

Crawford ED, Wilson SS, McConnell JD, Slawin KM, Lieber MC, Smith JA, et al. Baseline factors as predictors of clinical progression of benign prostatic hyperplasia in men treated with placebo. Journal of Urology 2006;175(4):1422-6; discussion 1426-7. [PUBMED: 16516013]

\section{Deeks 2017}

Deeks JJ, Higgins JP, Altman DG (editors) on behalf of the Cochrane Statistical Methods Group. Chapter 9: Analysing data and undertaking meta-analyses. In: Higgins JPT, Churchill R, Chandler J, Cumpston MS (editors), Cochrane Handbook for Systematic Reviews of Interventions version 5.2.0 (updated June 2017), Cochrane, 2017. Available from www.training.cochrane.org/handboo. Available from www.training.cochrane.org/handbook.

\section{Dindo 2004}

Dindo D, Demartines N, Clavien PA. Classification of surgical complications: a new proposal with evaluation in a cohort of 6336 patients and results of a survey. Annals of Surgery 2004;240(2):205-13. [PUBMED: 15273542]

\section{Dunphy 2015}

Dunphy C, Laor L, Te A, Kaplan S, Chughtai B. Relationship between depression and lower urinary tract symptoms 
secondary to benign prostatic hyperplasia. Reviews in Urology 2015;17(2):51-7. [PUBMED: 27222640]

\section{EAU 2017}

European Association of Urology. Treatment of non-neurogenic male LUTS. uroweb.org/guideline/treatment-of-nonneurogenic-male-luts/ (accessed 1 March 2018).

\section{Egan 2016}

Egan KB. The epidemiology of benign prostatic hyperplasia associated with lower urinary tract symptoms: prevalence and incident rates. Urologic Clinics of North America 2016;43(3):289-97. [PUBMED: 27476122]

\section{Endnote [Computer program]}

Clarivate Analytics. EndNote. Version 7.5. Clarivate Analytics, 2016.

\section{Faber 2015}

Faber K, de Abreu AL, Ramos P, Aljuri N, Mantri S, Gill I, et al. Image-guided robot-assisted prostate ablation using water jethydrodissection: initial study of a novel technology for benign prostatic hyperplasia. Journal of Endourology 2015;29(1):63-9. [PUBMED: 25000418]

\section{Foster 2018}

Foster HE, Barry MJ, Dahm P, Gandhi MC, Kaplan SA, Kohler TS, et al. Surgical management of lower urinary tract symptoms attributed to benign prostatic hyperplasia: AUA Guideline. Journal of Urology 2018;200(3):612-9. [PUBMED: 29775639]

\section{Gilling 2016}

Gilling P, Reuther R, Kahokehr A, Fraundorfer M. Aquablation image-guided robot-assisted waterjet ablation of the prostate: initial clinical experience. BJU International 2016;117(6):923-9. [PUBMED: 26477826]

\section{Gilling 2017}

Gilling P, Anderson P, Tan A. Aquablation of the prostate for symptomatic benign prostatic hyperplasia: 1-year results. Journal of Urology 2017;197(6):1565-72. [PUBMED: 28111300]

\section{GRADEpro GDT 2015 [Computer program]}

McMaster University (developed by Evidence Prime). GRADEpro GDT. Version accessed 13 December 2018. Hamilton (ON): McMaster University (developed by Evidence Prime), 2015.

\section{Guyatt 2008}

Guyatt GH, Oxman AD, Kunz R, Vist GE, Falck-Ytter Y, Schunemann HJ. What is "quality of evidence" and why is it important to clinicians?. BMJ (Clinical Research Ed.) 2008;336(7651):995-8. [PUBMED: 18456631]

\section{Guyatt 2011a}

Guyatt GH, Oxman AD, Kunz R, Brozek J, Alonso-Coello P, Rind $D$, et al. GRADE guidelines 6 . Rating the quality of evidence--imprecision. Journal of Clinical Epidemiology 2011;64(12):1283-93. [PUBMED: 21839614]

\section{Guyatt 2011b}

Guyatt G, Oxman AD, Akl EA, Kunz R, Vist G, Brozek J, et al. GRADE guidelines: 1 . Introduction-GRADE evidence profiles and summary of findings tables. Journal of Clinical Epidemiology 2011;64(4):383-94. [PUBMED: 21195583]

\section{Guyatt 2011c}

Guyatt GH, Oxman AD, Sultan S, Glasziou P, Akl EA, AlonsoCoello P, et al. GRADE guidelines: 9. Rating up the quality of evidence. Journal of Clinical Epidemiology 2011;64(12):1311-6. [PUBMED: 21802902]

\section{Higgins 2002}

Higgins JP, Thompson SG. Quantifying heterogeneity in a metaanalysis. Statistics in Medicine 2002;21(11):1539-58. [PUBMED: 12111919]

\section{Higgins 2003}

Higgins JP, Thompson SG, Deeks JJ, Altman DG. Measuring inconsistency in meta-analyses. BMJ 2003;327(7414):557-60. [PUBMED: 12958120]

\section{Higgins 2011}

Higgins JP, Deeks JJ (editors). Chapter 7: Selecting studies and collecting data. In: Higgins JPT, Green S (editors), Cochrane Handbook for Systematic Reviews of Interventions. Version 5.1.0 (updated March 2011). The Cochrane Collaboration, 2011. Available from www.cochrane-handbook.org.

\section{Higgins 2017a}

Higgins JPT, Altman DG, Sterne JA (editors). Chapter 8: Assessing risk of bias in included studies. In: Higgins JPT, Churchill R, Chandler J, Cumpston MS (editors), Cochrane Handbook for Systematic Reviews of Interventions Version 5.2.0 (updated June 2017). Cochrane, 2017. Available from www.training.cochrane.org/handbook.

\section{Hirst 2018}

Hirst A, Philippou Y, Blazeby J, Campbell B, Campbell M, Feinberg J, et al. No surgical innovation without evaluation: evolution and further development of the IDEAL framework and recommendations. Annals of Surgery 2018 Apr 24 [Epub ahead of print]. [DOI: 10.1097/SLA.0000000000002794.]

\section{Homma 1997}

Homma Y, Kawabe K, Tsukamoto T, Yamanaka H, Okada K, Okajima E, et al. Epidemiologic survey of lower urinary tract symptoms in Asia and Australia using the international prostate symptom score. International Journal of Urology: Official Journal of the Japanese Urological Association 1997;4(1):40-6. [PUBMED: 9179665]

\section{Jaeschke 1989}

Jaeschke R, Singer J, Guyatt GH. Measurement of health status. Ascertaining the minimal clinically important difference. Controlled Clinical Trials 1989;10(4):407-15. [PUBMED: 2691207]

\section{Johnston 2013}

Johnston BC, Patrick DL, Busse JW, Schunemann HJ, Agarwal A, Guyatt GH. Patient-reported outcomes in meta-analyses--Part 
1: assessing risk of bias and combining outcomes. Health and Quality of Life Outcomes 2013;11:109. [PUBMED: 23815754]

\section{Jung 2017a}

Jung JH, McCutcheon KA, Reddy B, Borofsky M, Narayan V, Kim MH, et al. Prostatic urethral lift for the treatment of lower urinary tract symptoms in men with benign prostatic hyperplasia. Cochrane Database of Systematic Reviews 2017, Issue 10. [DOI: 10.1002/14651858.CD012832]

\section{Jung 2017b}

Jung JH, Shin TY, McCutcheon KA, Borofsky M, Narayan V, Young $S$, et al. Prostatic arterial embolization for the treatment of lower urinary tract symptoms in men with benign prostatic hyperplasia. Cochrane Database of Systematic Reviews 2017, Issue 11. [DOI: 10.1002/14651858.CD012867]

\section{Kang 2019}

Kang TW, Jung JH, Hwang EC, Borofsky M, Kim MH, Dahm P. Convective radiofrequency water vapor thermal therapy for lower urinary tract symptoms in men with benign prostatic hyperplasia. Cochrane Database of Systematic Reviews 2019, Issue 1. [DOI: 10.1002/14651858.CD013251]

\section{Kaplan 2015}

Kaplan AL, Agarwal N, Setlur NP, Tan HJ, Niedzwiecki D, McLaughlin N, et al. Measuring the cost of care in benign prostatic hyperplasia using time-driven activity-based costing (TDABC). Healthcare (Amsterdam, Netherlands) 2015;3(1):43-8. [PUBMED: 26179588]

\section{Kozminski 2015}

Kozminski MA, Wei JT, Nelson J, Kent DM. Baseline characteristics predict risk of progression and response to combined medical therapy for benign prostatic hyperplasia (BPH). BJU International 2015;115(2):308-16. [PUBMED: 24825577]

\section{Lebdai 2018}

Lebdai S, Chevrot A, Doizi S, Pradere B, Delongchamps NB, Benchikh A, et al. Do patients have to choose between ejaculation and miction? A systematic review about ejaculation preservation technics for benign prostatic obstruction surgical treatment. World Journal of Urology 2018 Jul 2 [Epub ahead of print]. [DOI: 10.1007/s00345-018-2368-6]

\section{Lee 2018}

Lee R, Roehrborn C. What's new in Aquablation?. European Urology Focus 2018 May 7 [Epub ahead of print]. [DOI: 10.1016/ j.euf.2018.04.018]

\section{Leissner 1979}

Leissner KH, Tisell LE. The weight of the human prostate. Scandinavian Journal of Urology and Nephrology 1979;13(2):137-42. [PUBMED: 90380]

\section{Liberati 2009}

Liberati A, Altman DG, Tetzlaff J, Mulrow C, Gotzsche PC, Ioannidis JP, et al. The PRISMA statement for reporting systematic reviews and meta-analyses of studies that evaluate health care interventions: explanation and elaboration. PLOS medicine 2009;6(7):e1000100. [PUBMED: 19621070]

\section{Magistro 2017}

Magistro G, Chapple CR, Elhilali M, Gilling P, McVary KT, Roehrborn CG, et al. Emerging minimally invasive treatment options for male lower urinary tract symptoms. European Urology 2017;72(6):986-97. [PUBMED: 28734706]

\section{Mamoulakis 2014}

Mamoulakis C, Sofras F, de la Rosette J, Omar MI, Lam TBL, N'Dow JM, et al. Bipolar versus monopolar transurethral resection of the prostate for lower urinary tract symptoms secondary to benign prostatic obstruction. Cochrane Database of Systematic Reviews 2014, Issue 1. [DOI: 10.1002/14651858.CD009629.pub3]

\section{Martin 2014}

Martin S, Lange K, Haren MT, Taylor AW, Wittert G. Risk factors for progression or improvement of lower urinary tract symptoms in a prospective cohort of men. Journal of Urology 2014;191(1):130-7. [PUBMED: 23770136]

\section{McNicholas 2016}

McNicholas TA. Benign prostatic hyperplasia and new treatment options - a critical appraisal of the UroLift system. Medical Devices (Auckland, N.Z.) 2016;9:115-23. [PUBMED: 27274321]

\section{McVary 2011}

McVary KT, Roehrborn CG, Avins AL, Barry MJ, Bruskewitz RC, Donnell RF, et al. Update on AUA guideline on the management of benign prostatic hyperplasia. Journal of Urology 2011;185(5):1793-803. [PUBMED: 21420124]

\section{Nagele 2011}

Nagele U, Kugler M, Nicklas A, Merseburger AS, Walcher U, Mikuz G, et al. Waterjet hydrodissection: first experiences and short-term outcomes of a novel approach to bladder tumor resection. World Journal of Urology 2011;29(4):423-7. [PUBMED: 21305303]

\section{NICE guidance}

Transurethral water jet ablation for lower urinary tract symptoms caused by benign prostatic hyperplasia. https:// www.nice.org.uk/guidance/ipg629 (accessed 11 February 2019).

\section{Omar 2014}

Omar MI, Lam TB, Alexander CE, Graham J, Mamoulakis C, Imamura M, et al. Systematic review and meta-analysis of the clinical effectiveness of bipolar compared with monopolar transurethral resection of the prostate (TURP). BJU International 2014;113(1):24-35. [PUBMED: 24053602]

\section{Pariser 2015}

Pariser JJ, Pearce SM, Patel SG, Bales GT. National trends of simple prostatectomy for benign prostatic hyperplasia with an analysis of risk factors for adverse perioperative outcomes. Urology 2015;86(4):721-5. [PUBMED: 26276574] 


\section{PROCEPT BioRobotics}

PROCEPT BioRobotics, Redwood Shores, California, USA. www.procept-biorobotics.com.

\section{Rees 2015}

Rees J. Patients not P values. BJU International 2015; Vol. 115, issue 5:678-9. [PUBMED: 25885560]

\section{Reich 2008}

Reich O, Gratzke C, Bachmann A, Seitz M, Schlenker B, Hermanek $P$, et al. Morbidity, mortality and early outcome of transurethral resection of the prostate: a prospective multicenter evaluation of 10,654 patients. Journal of Urology 2008;180(1):246-9. [PUBMED: 18499179]

\section{Review Manager 2014 [Computer program]}

Nordic Cochrane Centre, The Cochrane Collaboration. Review Manager 5 (RevMan 5). Version 5.3. Copenhagen: Nordic Cochrane Centre, The Cochrane Collaboration, 2014.

\section{Rieken 2018}

Rieken M, Antunes-Lopes T, Geavlete B, Marcelissen T. What is new with sexual side effects after transurethral male lower urinary tract symptom surgery?. European Urology Focus 2018;4(1):43-5. [PUBMED: 29803559]

\section{Roehrborn 2008a}

Roehrborn CG. Pathology of benign prostatic hyperplasia. International Journal of Impotence Research 2008;20 Suppl 3:S11-8. [PUBMED: 19002119]

\section{Roehrborn 2008b}

Roehrborn CG. Current medical therapies for men with lower urinary tract symptoms and benign prostatic hyperplasia: achievements and limitations. Reviews in Urology 2008;10(1):14-25. [PUBMED: 18470272]

\section{Rosen 1997}

Rosen RC, Riley A, Wagner G, Osterloh IH, Kirkpatrick J, Mishra A. The international index of erectile function (IIEF): a multidimensional scale for assessment of erectile dysfunction. Urology 1997;49(6):822-30. [PUBMED: 9187685]

\section{Rosen 2004}

Rosen RC, Catania J, Pollack L, Althof S, O'Leary M, Seftel AD. Male Sexual Health Questionnaire (MSHQ): scale development and psychometric validation. Urology 2004;64(4):777-82. [PUBMED: 15491719]

\section{Rosen 2007}

Rosen RC, Catania JA, Althof SE, Pollack LM, O'Leary M, Seftel AD, et al. Development and validation of four-item version of Male Sexual Health Questionnaire to assess ejaculatory dysfunction. Urology 2007;69(5):805-9. [PUBMED: 17482908]

\section{Rosen 2011}

Rosen RC, Allen KR, Ni X, Araujo AB. Minimal clinically important differences in the erectile function domain of the International Index of Erectile Function scale. European Urology 2011;60(5):1010-6. [PUBMED: 21855209]

\section{Russo 2015}

Russo GI, Castelli T, Urzi D, Privitera S, La Vignera S, Condorelli RA, et al. Emerging links between non-neurogenic lower urinary tract symptoms secondary to benign prostatic obstruction, metabolic syndrome and its components: a systematic review. International Journal of Urology: Official Journal of the Japanese Urological Association 2015;22(11):982-90. [PUBMED: 26193757]

\section{Schünemann 2013}

Schünemann HJ, Tugwell P, Reeves BC, Akl EA, Santesso N, Spencer FA, et al. Non-randomized studies as a source of complementary, sequential or replacement evidence for randomized controlled trials in systematic reviews on the effects of interventions. Research Synthesis Methods 2013;4(1):49-62. [PUBMED: 26053539]

\section{Schünemann 2017a}

Schünemann HJ, Oxman AD, Higgins JP, Vist GE, Glasziou P, Akl E, et al. on behalf of the Cochrane GRADEing Methods Group and the Cochrane Statistical Methods Group. Chapter 11: Completing 'Summary of findings' tables and grading the confidence in or quality of the evidence. In: Higgins JPT, Churchill R, Chandler J, Cumpston MS (editors), Cochrane Handbook for Systematic Reviews of Interventions version 5.2.0 (updated June 2017). Cochrane, 2017. Available from www.training.cochrane.org/handbook.

\section{Schünemann 2017b}

Schünemann HJ, Oxman AD, Vist GE, Higgins JP, Deeks JJ, Glasziou P, et al. on behalf of the Cochrane Applicability and Recommendations Methods Group. Chapter 12: Interpreting results and drawing conclusions. In: Higgins JPT, Churchill R, Chandler J, Cumpston MS (editors), Cochrane Handbook for Systematic Reviews of Interventions version 5.2.0 (updated June 2017). Cochrane, 2017. Available from www.training.cochrane.org/handbook.

\section{Spaliviero 2010}

Spaliviero M, Strom KH, Gu X, Araki M, Culkin DJ, Wong C. Does Greenlight HPS $\left({ }^{\mathrm{TM}}\right)$ laser photoselective vaporization prostatectomy affect sexual function?. Journal of Endourology 2010;24(12):2051-7. [PUBMED: 20964486]

\section{Sterne 2016a}

Sterne JA, Hernan MA, Reeves BC, Savovic J, Berkman ND, Viswanathan M, et al. ROBINS-I: a tool for assessing risk of bias in non-randomised studies of interventions. BMJ (Clinical Research Ed.) 2016;355:i4919. [PUBMED: 27733354]

\section{Sterne 2016b}

Sterne JA, Higgins JP, Elbers RG, Reeves BC and the development group for ROBINS-I. Risk of bias in nonrandomized studies of interventions (ROBINS-I): detailed guidance, updated 12 October 2016. Available from www.riskofbias.info (accessed 6 July 2018).

\section{Sterne 2017}

Sterne JA, Egger M, Moher D, Boutron I (editors). Chapter 10: Addressing reporting biases. In: Higgins JPT, Churchill R, Chandler J,Cumpston MS (editors), Cochrane Handbook 
for Systematic Reviews of Interventions version 5.2.0 (updated June 2017), Cochrane, 2017. Available from www.training.cochrane.org/handbook.

\section{Taktak 2018}

Taktak S, Jones P, Haq A, Rai BP, Somani BK. Aquablation: a novel and minimally invasive surgery for benign prostate enlargement. Therapeutic Advances in Urology 2018;10(6):183-8. [PUBMED: 29899759]

\section{WHO 2012}

World Health Organization. Proposed working definition of an older person in Africa for the MDS project. www.who.int/ healthinfo/survey/ageingdefnolder/en (accessed 1 March 2018).

\section{Yoo 2012}

Yoo TK, Cho HJ. Benign prostatic hyperplasia: from bench to clinic. Korean Journal of Urology 2012;53(3):139-48. [PUBMED: 22468207]

\section{References to other published versions of this review Hwang 2018}

Hwang EC, Jung JH, Borofsky M, Kim MH, Dahm P. Aquablation of the prostate for the treatment of lower urinary tract symptoms in men with benign prostatic hyperplasia. Cochrane Database of Systematic Reviews 2018, Issue 10. [DOI: 10.1002/14651858.CD013143]

* Indicates the major publication for the study

\section{CHARACTERISTICS OF STUDIES}

Characteristics of included studies [ordered by study ID]

Gilling 2018

Study design: double-blinded, parallel, randomised clinical study (2:1)
Statistical design: non-inferiority
Setting/Country: multicenter (17 centres)/ multicountry (Australia 1, New Zealand 1, UK 3, USA 12)
Dates when study was conducted: October 2015-December 2016

Participants

Ethnicity: Asian 5, Hispanic 5, black 4, white 168, other 1, unknown 1 (participant did not provide race during baseline data gathering)

\section{Inclusion criteria}

- LUTS due to BPH

- Men aged 45-80 years

- Prostate size $30 \mathrm{~mL}-80 \mathrm{~mL}$ (measured with TRUS)

- $\operatorname{IPSS} \geq 12$,

- $\mathrm{Q}_{\max }<15 \mathrm{~mL} / \mathrm{s}$

- Normal range of serum creatinine

- History of inadequate response, contraindication, or refusal to medical therapy

\section{Exclusion criteria}

- $\mathrm{BMI} \geq 42$

- History of prostate cancer or current/suspected bladder cancer

- Prostate cancer should be ruled out before participation to the satisfaction of the investigator if PSA is above acceptable thresholds

- History of actively treated bladder cancer within the past 2 years

- Bladder calculus or clinically significant bladder diverticulum (e.g. pouch size $>20 \%$ of full bladder size)

- Active infection, including urinary tract infection

- Prostatitis treated with antibiotics within 1 year of enrolment

- Ever been diagnosed with a urethral stricture, meatal stenosis, or bladder neck contracture

- Damage to external urinary sphincter

- Diagnosis of stress urinary incontinence that requires treatment or daily pad or device use

- $\mathrm{PVR}>300 \mathrm{~mL}$ 
- Urinary retention at time of enrolment or has been catheterised in the 14 days prior to the surgical procedure

- History of intermittent self-catheterisation

- Previous prostate surgery or history of other lower urinary tract surgery such as e.g. urinary diversion, artificial urinary sphincter or penile prosthesis

- Taking anticoagulants (if medication cannot be stopped before and after procedure) or known coagulopathy (except aspirin $<100 \mathrm{mg} /$ day)

- Any severe illness that would prevent complete study participation or confound study results

- Participants using systematic immune-suppressants including corticosteroids; unable to withhold NSAIDs, including aspirin for 3-5 days prior to treatment except for low-dose aspirin (e.g. $\leq 100 \mathrm{mg}$ )

- Participants using anticholinergics specifically for bladder problems. Use of medications with anticholinergic properties was allowable provided the participant did not have documented adverse urinary adverse events from these medications

- Contraindication to general or spinal anaesthesia

- Any other disease or condition(s) that would interfere with completion of the study and follow-up assessments, would increase risks of the procedure, or in the judgment of the investigator would potentially interfere with compliance to this study or would adversely affect outcomes

- Unwilling to accept a transfusion should one be required

\section{Total number of participants randomly assigned:}

- Screened: 275

- Eligible: 184

\section{Aquablation}

- number of all participants randomly assigned: 117

- age (years): $66.0 \pm 7.3$

- prostate volume $(\mathrm{mL}): 54.1 \pm 16.2$

- PSA (ng/mL): $3.7 \pm 3.0$

- IPSS: $22.9 \pm 6.0$

- $\mathrm{Q}_{\max }(\mathrm{mL} / \mathrm{s}): 9.4 \pm 3.0$

TURP: monopolar 36 (55.4\%), bipolar $29(44.6 \%))$

- number of all participants randomly assigned: 67

- age (years): $65.8 \pm 7.2$

- prostate volume $(\mathrm{mL}): 51.8 \pm 13.8$

- PSA $(\mathrm{ng} / \mathrm{mL}): 3.3 \pm 2.3$

- IPSS: $22.2 \pm 6.1$

- $\mathrm{Q}_{\max }(\mathrm{mL} / \mathrm{s}): 9.1 \pm 2.7$

\section{Aquablation}

Using the Aquabeam System (PROCEPT BioRobotics, Redwood Shores, California, USA). A 24 F handpiece probe similar to a rigid cystoscope is inserted into the prostatic urethra and locked into place using a bed-mounted rigid arm. Under real-time prostate visualisation using transrectal ultrasound, the surgeon uses a console to mark the target resection contour. Under the surgeon's control, the ablation of tissue is robotically executed using a high-velocity waterjet to resect adenomatous tissue while avoiding the verumontanum and the ejaculatory ducts.

TURP (monopolar 36 (55.4\%), bipolar $29(44.6 \%))$

TURP was performed according to standard practice

Follow-up: 12 months 
Gilling 2018 (Continued)

- Change in IPSS from baseline to 12 months

- How measured: questionnaire

- Time to measured: not reported

- Time to reported: baseline, 1 month, 3 months, 6 months, 12 months

\section{Secondary outcome}

- Resection time, total operative time, length of hospital stay, reoperation or reintervention rate

- Worsening of sexual function through 6 months, change in incontinence, pelvic pain, quality of life, duration of bladder catheterization, Work Productivity and Activity Impairment, relationship between prostate size reduction and change in symptoms scores

- How measured: IIEF (sexual function), MSHQ-EjD (sexual function), EuroQoL-5D (QoL), TRUS (prostate size), Incontinence Severity Index and the others were not reported

- Time to measured: not reported

- Time to reported: baseline, 1 month, 3 months, 6 months, 12 months

\section{Safety outcome}

- Adverse events

- How measured: Clavien-Dindo classification of adverse events

- Time points measured: not reported

- Time points reported: 12 months post-treatment

Subgroup: pre-planned subgroup analysis

- Baseline IPSS ( $<20$ versus $\geq 20$ )

- Prostate size ( $<50$ versus $\geq 50 \mathrm{~mL}$ )

- Age ( $<65$ versus $\geq 65$ years)

\begin{tabular}{ll}
\hline Funding Sources & PROCEPT BioRobotics \\
\hline Declarations of interest & $\begin{array}{l}\text { Dr Peter Gilling, Dr Paul Anderson, Dr Mihir Desai, Dr Alexis E. Te and Dr Mark DeGuenther report finan- } \\
\text { cial interest and/or other relationship with PROCEPT }{ }^{\circledR} \text { Biorobotics }\end{array}$ \\
\hline
\end{tabular}

Notes

Manuscript preparation supported by PROCEPT ${ }^{\circledR}$ BioRobotics

Protocol: NCT02505919

Language of publication: English

\section{Risk of bias}

\begin{tabular}{lll}
\hline Bias & Authors' judgement & Support for judgement \\
\hline $\begin{array}{l}\text { Random sequence genera- } \\
\text { tion (selection bias) }\end{array}$ & Low risk & $\begin{array}{l}\text { Quote from publication: "Randomization was obtained through a web-based } \\
\text { system and was stratified by study site" }\end{array}$ \\
& $\begin{array}{l}\text { Comment: we considered this method of random sequence generation to } \\
\text { have low risk of bias }\end{array}$ \\
\hline
\end{tabular}

Allocation concealment Low risk
(selection bias)

Quote from publication: "Randomization was obtained through a web-based (selection bias) system and was stratified by study site"

Comment: random sequence generation seems to have been carried out by the central computer randomisation system. This method may ensure allocation concealment.

\begin{tabular}{|c|c|c|}
\hline $\begin{array}{l}\text { Blinding of participants } \\
\text { and personnel (perfor- } \\
\text { mance bias) }\end{array}$ & High risk & $\begin{array}{l}\text { Quote from publication: "Baseline evaluation and study treatment were pro- } \\
\text { vided by an unblinded research team" }\end{array}$ \\
\hline
\end{tabular}


Gilling 2018 (Continued)

All outcomes
Comment: while participants were blinded (protocol), surgeon was not blinded; therefore we considered risk of performance bias to be high

$\begin{array}{lll}\text { Blinding of outcome as- } & \text { Low risk } & \begin{array}{l}\text { Quote from publication: "participants were blinded" (protocol), "A separate } \\ \text { blinded team (coordinator and physician) conducted the follow-up visits and }\end{array} \\ \text { Susceptible: Urologic } & \text { will do so out to the completion of the trial" }\end{array}$

symptom scores, Qulaity

of life, Erectile function,

Ejaculatory function, $\mathrm{Mi}$ -

nor adverse events drom (coordinator and physician) conducted the follow-up visits and

Comment: outcome assessor was blinded; therefore we considered risk of detection bias to be low

\begin{tabular}{|c|c|c|}
\hline $\begin{array}{l}\text { Blinding of outcome as- } \\
\text { sessment (detection bias) } \\
\text { Not susceptible: Major } \\
\text { adverse events, Retreat- } \\
\text { ment, Acute urinary reten- } \\
\text { tion, Indwelling urinary } \\
\text { catheter, Hospital stay }\end{array}$ & Low risk & $\begin{array}{l}\text { Quote from publication: "All adverse events were adjudicated by an indepen- } \\
\text { dent clinical events committee blinded to treatment assignment" } \\
\text { Comment: outcome assessor was blinded; therefore we considered risk of de- } \\
\text { tection bias to be low }\end{array}$ \\
\hline $\begin{array}{l}\text { Incomplete outcome data } \\
\text { (attrition bias) } \\
\text { Urologic symptom scores } \\
\text { and quality of life }\end{array}$ & Low risk & $\begin{array}{l}\text { Comment: } 3 / 117(2.5 \%) \text { in Aquablation and } 7 / 67(10.4 \%) \text { in TURP participants } \\
\text { were not included in the analysis. Owing to the small number of participants } \\
\text { lost to follow-up and this not affecting the effect size, we considered risk of at- } \\
\text { trition bias to be low }\end{array}$ \\
\hline
\end{tabular}

\begin{tabular}{lll}
\hline Incomplete outcome data & Low risk & Comment: $1 / 117(0.8 \%)$ in Aquablation and 2/67 (2.9\%) in TURP participants \\
(attrition bias) & & were not included in the analysis but missing outcome data balanced in num- \\
Major and minor adverse & bers across intervention group. Owing to the small number of participants lost \\
events & to follow-up, we considered risk of attrition bias to be low
\end{tabular}

\begin{tabular}{|c|c|c|}
\hline $\begin{array}{l}\text { Incomplete outcome data } \\
\text { (attrition bias) } \\
\text { Retreatment }\end{array}$ & Low risk & $\begin{array}{l}\text { Comment: } 1 / 117(0.8 \%) \text { in Aquablation and } 2 / 67(2.9 \%) \text { in TURP participants } \\
\text { were not included in the analysis but missing outcome data balanced in num- } \\
\text { bers across intervention group. Owing to the small number of participants lost } \\
\text { to follow-up, risk of attrition bias was considered to be low }\end{array}$ \\
\hline
\end{tabular}

\begin{tabular}{|c|c|c|}
\hline $\begin{array}{l}\text { Incomplete outcome data } \\
\text { (attrition bias) }\end{array}$ & High risk & $\begin{array}{l}\text { Quote from publication: "Since IIEF and MSHQ assume that a man is sexual- } \\
\text { ly active, those who were not sexually active at baseline or the study visit were } \\
\text { excluded from this analysis" }\end{array}$ \\
\hline
\end{tabular}

Erectile and ejaculatory

function

\begin{abstract}
Comment: analyses of these outcomes were not consistent during the follow-up period (i.e. included participants may differ at each measured time point). As a result, analyses for these outcomes up to 12 months were limited to $45 / 117$ (38.4\%) participants in the Aquablation arm and 19/67 (28.3\%) participants in the TURP arm for erectile function and to $79 / 117$ (67.5\%) participants in the Aquablation arm and 42/67 (62.6\%) participants in the TURP arm for ejaculatory function; therefore we considered risk of attrition bias to be high
\end{abstract}

\begin{tabular}{|c|c|c|}
\hline $\begin{array}{l}\text { Incomplete outcome data } \\
\text { (attrition bias) } \\
\text { Acute urinary retention }\end{array}$ & Low risk & $\begin{array}{l}\text { Comment: } 1 / 117(0.8 \%) \text { in Aquablation and } 2 / 67(2.9 \%) \text { in TURP participants } \\
\text { were not included in the analysis but missing outcome data balanced in num- } \\
\text { bers across intervention group. Owing to the small number of participants lost } \\
\text { to follow-up, we considered risk of attrition bias to be low }\end{array}$ \\
\hline
\end{tabular}

Incomplete outcome data Low risk

(attrition bias)

Indwelling urinary

catheter

\begin{abstract}
Comment: the study did not address this outcome but study investigator provided this outcome.

$7 / 117$ (5.9\%) in Aquablation and 4/67 (5.9\%) in TURP participants were not included in the analysis but missing outcome data balanced in numbers across intervention group. Owing to the small number of participants lost to follow-up, we considered risk of attrition bias to be low
\end{abstract}


Gilling 2018 (Continued)

Incomplete outcome data Low risk Comment: $1 / 117(0.8 \%)$ in Aquablation and 2/67 (2.9\%) in TURP participants (attrition bias) were not included in the analysis but missing outcome data balanced in numHospital stay bers across intervention group. Owing to the small number of participants lost to follow-up, we considered risk of attrition bias to be low

Selective reporting (re- Unclear risk porting bias)
Comment: protocol (NCT02505919) was provided but all secondary outcomes in the articles were not reported in the protocol. Secondary outcomes were not pre-specified and several quality-of-life measurements were not reported (EuroQoL-5D); therefore we considered risk of reporting bias to be unclear

Other bias Low risk Comment: no other sources of bias could be found; therefore we considered risk of other bias to be low

BMI: body mass index; BPH: benign prostate hyperplasia; IIEF: International index of erectile function; IPSS: International prostate symptom score; LUTS: lower urinary tract symptom; MSHQ-EjD: Male Sexual Health Questionnaire for Ejaculatory Dysfunction; NSAID: nonsteroidal anti-inflammatory drugs; PSA: prostate specific antigen; PVR: post voided residuals; $\mathbf{Q}_{\max }$ : maximum urine flow; QoL: quality of life; TRUS: transrectal ultrasound; TURP: transurethral resection of the prostate

Characteristics of excluded studies [ordered by study ID]

\begin{tabular}{ll}
\hline Study & Reason for exclusion \\
\hline Bach 2018 & No comparator (single-arm study) \\
\hline Desai 2019 & No comparator (single-arm study) \\
\hline
\end{tabular}

\section{DATA AND ANALYSES}

Comparison 1. Aquablation versus TURP (up to 12 months)

\begin{tabular}{|c|c|c|c|c|}
\hline Outcome or subgroup title & No. of studies & $\begin{array}{l}\text { No. of partici- } \\
\text { pants }\end{array}$ & Statistical method & Effect size \\
\hline $\begin{array}{l}1 \text { Urologic symptom scores } \\
\text { (IPSS) }\end{array}$ & 1 & & $\begin{array}{l}\text { Mean Difference (IV, Random, } \\
95 \% \mathrm{CI} \text { ) }\end{array}$ & Totals not selected \\
\hline 2 Quality of life (IPSS-QoL) & 1 & & $\begin{array}{l}\text { Mean Difference (IV, Random, } \\
95 \% \mathrm{CI} \text { ) }\end{array}$ & Totals not selected \\
\hline 3 Major adverse events & 1 & & Risk Ratio (M-H, Random, 95\% Cl) & Totals not selected \\
\hline 4 Retreatment & 1 & & Risk Ratio (M-H, Random, 95\% Cl) & Totals not selected \\
\hline $\begin{array}{l}5 \text { Erectile function (IIEF; sexu- } \\
\text { ally active men only) }\end{array}$ & 1 & & $\begin{array}{l}\text { Mean Difference (IV, Random, } \\
95 \% \mathrm{CI} \text { ) }\end{array}$ & Totals not selected \\
\hline $\begin{array}{l}6 \text { Ejaculatory function (MSHQ- } \\
\text { EjD; sexually active men only) }\end{array}$ & 1 & & $\begin{array}{l}\text { Mean Difference (IV, Random, } \\
95 \% \mathrm{Cl} \text { ) }\end{array}$ & Totals not selected \\
\hline 7 Minor adverse events & 1 & & Risk Ratio (M-H, Random, 95\% Cl) & Totals not selected \\
\hline
\end{tabular}




\begin{tabular}{lllll}
\hline Outcome or subgroup title & No. of studies & $\begin{array}{l}\text { No. of partici- } \\
\text { pants }\end{array}$ & Statistical method & Effect size \\
\hline 8 Acute urinary retention & 1 & Risk Ratio (M-H, Random, 95\% Cl) & Totals not selected \\
\hline $\begin{array}{l}\text { 9 Indwelling urinary catheter } \\
\text { (hours) }\end{array}$ & 1 & $\begin{array}{l}\text { Mean Difference (IV, Random, } \\
95 \% \mathrm{Cl})\end{array}$ & Totals not selected \\
\hline 10 Hospital stay (days) & 1 & $\begin{array}{l}\text { Mean Difference (IV, Random, } \\
95 \% \mathrm{Cl})\end{array}$ & Totals not selected \\
\hline
\end{tabular}

Analysis 1.1. Comparison 1 Aquablation versus TURP (up to 12 months), Outcome 1 Urologic symptom scores (IPSS).

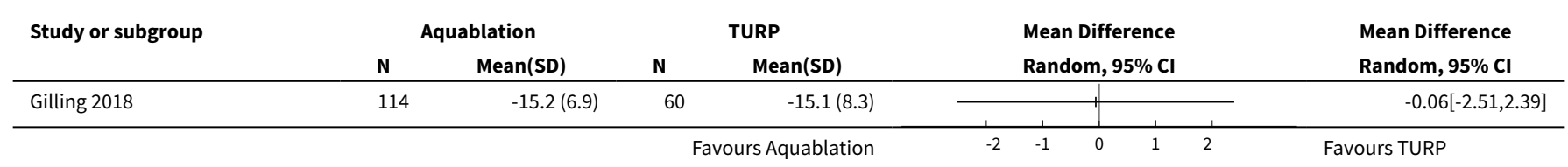

Analysis 1.2. Comparison 1 Aquablation versus TURP (up to 12 months), Outcome 2 Quality of life (IPSS-QoL).

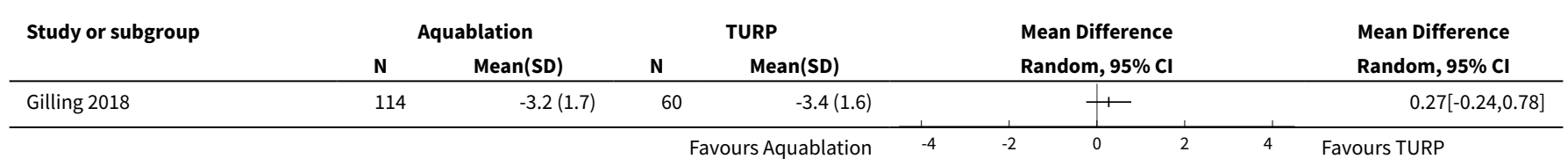

Analysis 1.3. Comparison 1 Aquablation versus TURP (up to 12 months), Outcome 3 Major adverse events.

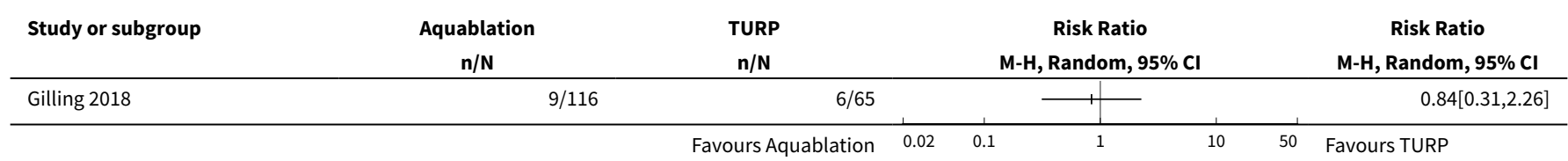

Analysis 1.4. Comparison 1 Aquablation versus TURP (up to 12 months), Outcome 4 Retreatment.

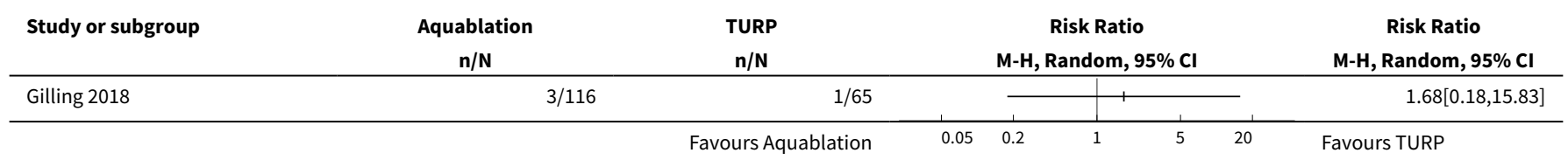


Analysis 1.5. Comparison 1 Aquablation versus TURP (up to 12

months), Outcome 5 Erectile function (IIEF; sexually active men only).

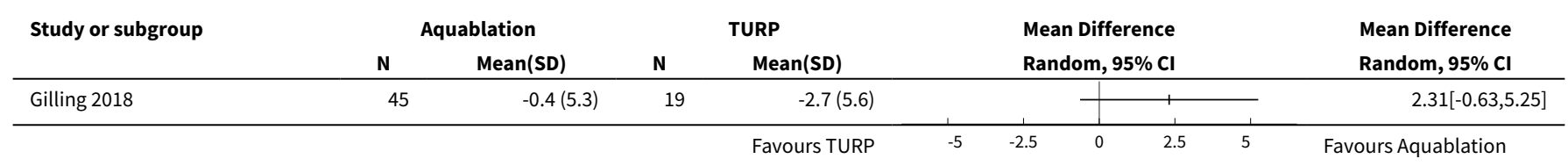

Analysis 1.6. Comparison 1 Aquablation versus TURP (up to 12 months), Outcome 6 Ejaculatory function (MSHQ-EjD; sexually active men only).

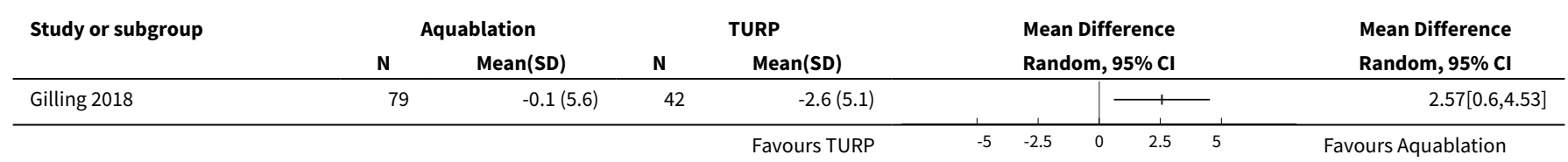

Analysis 1.7. Comparison 1 Aquablation versus TURP (up to 12 months), Outcome 7 Minor adverse events.

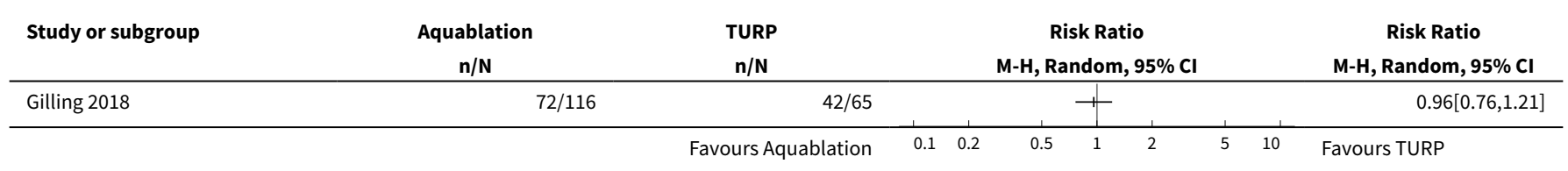

Analysis 1.8. Comparison 1 Aquablation versus TURP (up to 12 months), Outcome 8 Acute urinary retention.

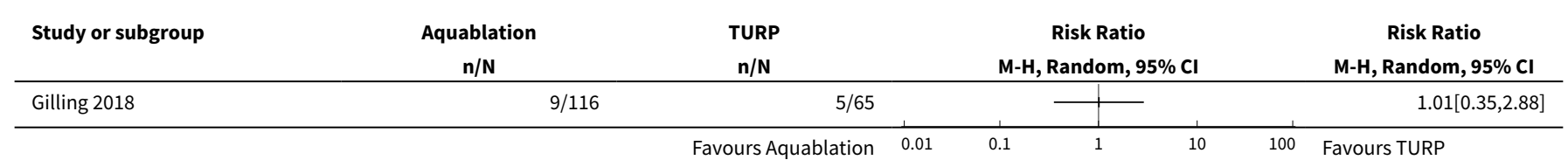

Analysis 1.9. Comparison 1 Aquablation versus TURP (up to 12 months), Outcome 9 Indwelling urinary catheter (hours).

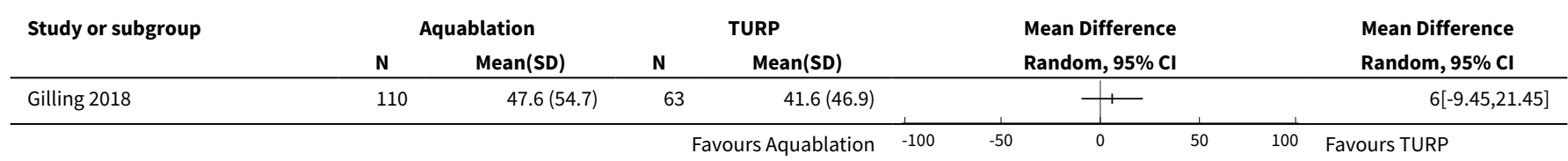


Analysis 1.10. Comparison 1 Aquablation versus TURP (up to 12 months), Outcome 10 Hospital stay (days).

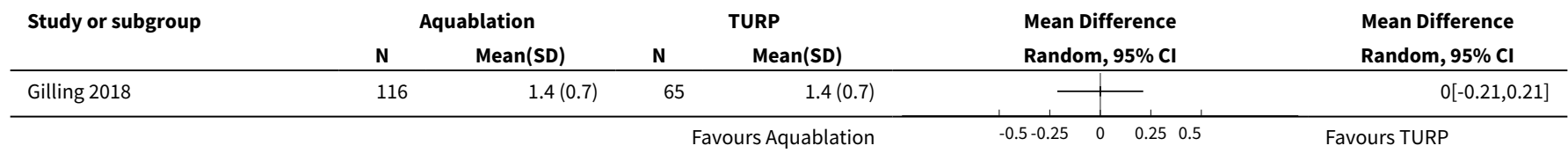

\section{Comparison 2. Aquablation versus TURP (up to 6 months)}

\begin{tabular}{|c|c|c|c|c|}
\hline Outcome or subgroup title & No. of studies & $\begin{array}{l}\text { No. of partici- } \\
\text { pants }\end{array}$ & Statistical method & Effect size \\
\hline $\begin{array}{l}1 \text { Urologic symptom scores } \\
\text { (IPSS) }\end{array}$ & 1 & & $\begin{array}{l}\text { Mean Difference (IV, Random, 95\% } \\
\mathrm{CI})\end{array}$ & Totals not selected \\
\hline 2 Quality of life (IPSS-QoL) & 1 & & $\begin{array}{l}\text { Mean Difference (IV, Random, 95\% } \\
\mathrm{CI})\end{array}$ & Totals not selected \\
\hline 3 Major adverse events & 1 & & Risk Ratio (M-H, Random, 95\% Cl) & Totals not selected \\
\hline 4 Retreatment & 1 & & Risk Ratio (M-H, Random, 95\% Cl) & Totals not selected \\
\hline 5 Erectile function (IIEF) & 1 & & $\begin{array}{l}\text { Mean Difference (IV, Random, 95\% } \\
\mathrm{Cl})\end{array}$ & Totals not selected \\
\hline $\begin{array}{l}6 \text { Ejaculatory function } \\
\text { (MSHQ-EjD) }\end{array}$ & 1 & & $\begin{array}{l}\text { Mean Difference (IV, Random, 95\% } \\
\mathrm{Cl})\end{array}$ & Totals not selected \\
\hline 7 Minor adverse events & 1 & & Risk Ratio (M-H, Random, 95\% Cl) & Totals not selected \\
\hline 8 Acute urinary retention & 1 & & Risk Ratio (M-H, Random, 95\% Cl) & Totals not selected \\
\hline $\begin{array}{l}9 \text { Indwelling urinary } \\
\text { catheter (hours) }\end{array}$ & 1 & & $\begin{array}{l}\text { Mean Difference (IV, Random, 95\% } \\
\mathrm{Cl} \text { ) }\end{array}$ & Totals not selected \\
\hline 10 Hospital stay (days) & 1 & & $\begin{array}{l}\text { Mean Difference (IV, Random, 95\% } \\
\mathrm{Cl} \text { ) }\end{array}$ & Totals not selected \\
\hline
\end{tabular}

Analysis 2.1. Comparison 2 Aquablation versus TURP (up to 6 months), Outcome 1 Urologic symptom scores (IPSS).

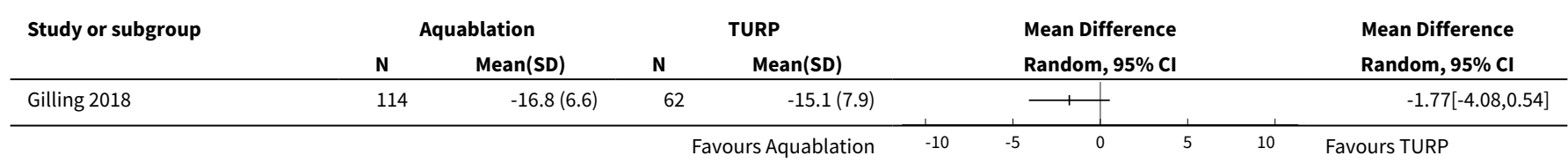


Analysis 2.2. Comparison 2 Aquablation versus TURP (up to 6 months), Outcome 2 Quality of life (IPSS-QoL).

\begin{tabular}{|c|c|c|c|c|c|c|}
\hline \multirow[t]{2}{*}{ Study or subgroup } & \multicolumn{2}{|c|}{ Aquablation } & \multicolumn{2}{|c|}{ TURP } & \multirow{2}{*}{$\begin{array}{l}\text { Mean Difference } \\
\text { Random, } 95 \% \mathrm{Cl}\end{array}$} & \multirow{2}{*}{$\begin{array}{l}\text { Mean Difference } \\
\text { Random, } 95 \% \mathrm{Cl}\end{array}$} \\
\hline & $\mathbf{N}$ & $\operatorname{Mean}(S D)$ & $\mathbf{N}$ & $\operatorname{Mean}(S D)$ & & \\
\hline Gilling 2018 & 114 & $-3.5(1.8)$ & 62 & $-3.2(1.7)$ & 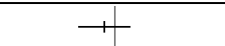 & $-0.21[-0.73,0.31]$ \\
\hline
\end{tabular}

Analysis 2.3. Comparison 2 Aquablation versus TURP (up to 6 months), Outcome 3 Major adverse events.

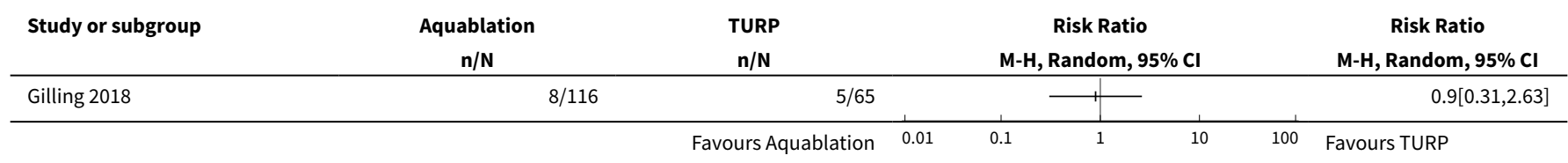

Analysis 2.4. Comparison 2 Aquablation versus TURP (up to 6 months), Outcome 4 Retreatment.

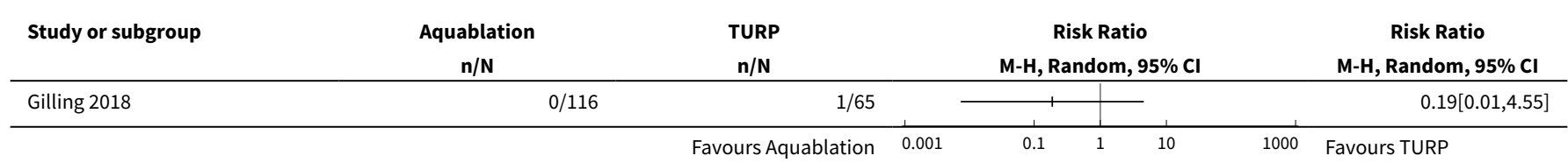

Analysis 2.5. Comparison 2 Aquablation versus TURP (up to 6 months), Outcome 5 Erectile function (IIEF).

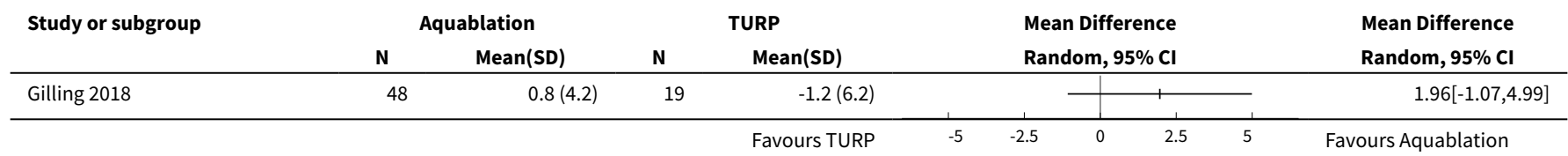

Analysis 2.6. Comparison 2 Aquablation versus TURP (up to 6 months), Outcome 6 Ejaculatory function (MSHQ-EjD).

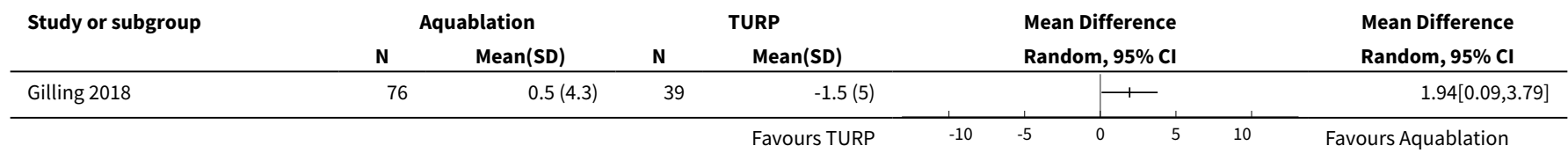

Analysis 2.7. Comparison 2 Aquablation versus TURP (up to 6 months), Outcome 7 Minor adverse events.

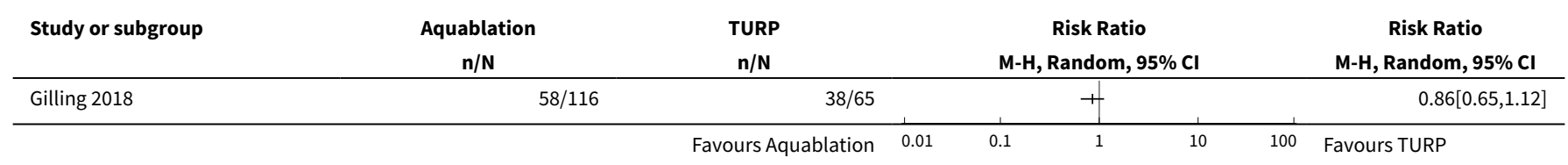


Analysis 2.8. Comparison 2 Aquablation versus TURP (up to 6 months), Outcome 8 Acute urinary retention.

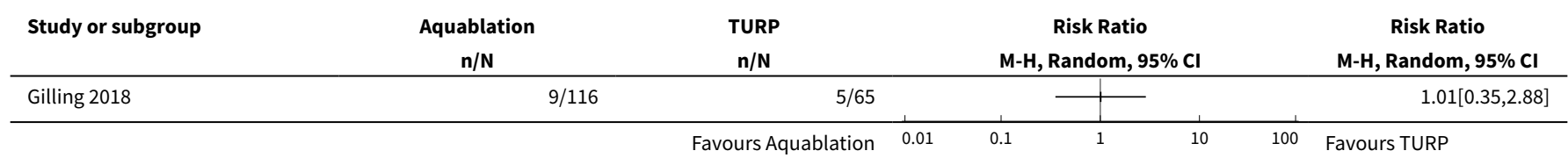

Analysis 2.9. Comparison 2 Aquablation versus TURP (up to 6 months), Outcome 9 Indwelling urinary catheter (hours).

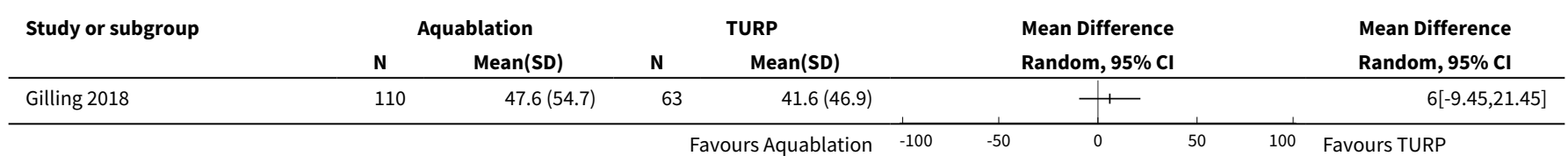

Analysis 2.10. Comparison 2 Aquablation versus TURP (up to 6 months), Outcome 10 Hospital stay (days).

\begin{tabular}{|c|c|c|c|c|c|c|}
\hline \multirow[t]{2}{*}{ Study or subgroup } & \multicolumn{2}{|c|}{ Aquablation } & \multicolumn{2}{|c|}{ TURP } & \multirow{2}{*}{$\begin{array}{l}\text { Mean Difference } \\
\text { Random, } 95 \% \mathrm{Cl}\end{array}$} & \multirow{2}{*}{$\begin{array}{l}\text { Mean Difference } \\
\text { Random, } 95 \% \mathrm{Cl}\end{array}$} \\
\hline & $\mathbf{N}$ & Mean(SD) & $\mathbf{N}$ & Mean(SD) & & \\
\hline Gilling 2018 & 116 & $1.4(0.7)$ & 65 & $1.4(0.7)$ & + & $0[-0.21,0.21]$ \\
\hline
\end{tabular}

Comparison 3. Aquablation versus TURP (subgroup analyses up to 6 months)

\begin{tabular}{|c|c|c|c|c|}
\hline Outcome or subgroup title & No. of studies & $\begin{array}{l}\text { No. of partici- } \\
\text { pants }\end{array}$ & Statistical method & Effect size \\
\hline $\begin{array}{l}1 \text { Urologic symptom scores (IPSS) } \\
\text { based on age }\end{array}$ & 1 & 176 & $\begin{array}{l}\text { Mean Difference (IV, Random, } \\
95 \% \mathrm{CI})\end{array}$ & $-1.67[-3.97,0.62]$ \\
\hline 1.1 Age less than 65 years old & 1 & 75 & $\begin{array}{l}\text { Mean Difference (IV, Random, } \\
95 \% \mathrm{CI} \text { ) }\end{array}$ & $-2.40[-6.34,1.54]$ \\
\hline $\begin{array}{l}1.2 \text { Age equal to or greater than } 65 \\
\text { years old }\end{array}$ & 1 & 101 & $\begin{array}{l}\text { Mean Difference (IV, Random, } \\
95 \% \mathrm{CI})\end{array}$ & $-1.30[-4.12,1.52]$ \\
\hline $\begin{array}{l}2 \text { Quality of life (IPSS-QoL) based } \\
\text { on age }\end{array}$ & 1 & 176 & $\begin{array}{l}\text { Mean Difference (IV, Random, } \\
95 \% \mathrm{CI})\end{array}$ & $-0.15[-0.83,0.54]$ \\
\hline 2.1 Age less than 65 years old & 1 & 75 & $\begin{array}{l}\text { Mean Difference (IV, Random, } \\
95 \% \mathrm{CI})\end{array}$ & $0.20[-0.52,0.92]$ \\
\hline $\begin{array}{l}2.2 \text { Age equal to or greater than } 65 \\
\text { years old }\end{array}$ & 1 & 101 & $\begin{array}{l}\text { Mean Difference (IV, Random, } \\
95 \% \mathrm{CI})\end{array}$ & $-0.5[-1.23,0.23]$ \\
\hline $\begin{array}{l}3 \text { Major adverse events based on } \\
\text { age }\end{array}$ & 1 & 181 & $\begin{array}{l}\text { Risk Ratio (M-H, Random, 95\% } \\
\text { Cl) }\end{array}$ & $0.96[0.03,26.71]$ \\
\hline
\end{tabular}




\begin{tabular}{|c|c|c|c|c|}
\hline Outcome or subgroup title & No. of studies & $\begin{array}{l}\text { No. of partici- } \\
\text { pants }\end{array}$ & Statistical method & Effect size \\
\hline 3.1 Age less than 65 years old & 1 & 77 & $\begin{array}{l}\text { Risk Ratio (M-H, Random, 95\% } \\
\text { Cl) }\end{array}$ & $6.04[0.35,105.26]$ \\
\hline $\begin{array}{l}3.2 \text { Age equal to or greater than } 65 \\
\text { years old }\end{array}$ & 1 & 104 & $\begin{array}{l}\text { Risk Ratio (M-H, Random, 95\% } \\
\mathrm{Cl} \text { ) }\end{array}$ & $0.23[0.05,1.13]$ \\
\hline $\begin{array}{l}4 \text { Urologic symptom scores (IPSS) } \\
\text { based on prostate volume }\end{array}$ & 1 & 176 & $\begin{array}{l}\text { Mean Difference (IV, Random, } \\
95 \% \mathrm{CI} \text { ) }\end{array}$ & $-1.54[-6.44,3.35]$ \\
\hline $\begin{array}{l}4.1 \text { prostate volume less than } 50 \\
\mathrm{~mL}\end{array}$ & 1 & 80 & $\begin{array}{l}\text { Mean Difference (IV, Random, } \\
95 \% \mathrm{CI} \text { ) }\end{array}$ & $0.90[-2.12,3.92]$ \\
\hline $\begin{array}{l}4.2 \text { prostate volume equal to or } \\
\text { greater than } 50 \mathrm{~mL}\end{array}$ & 1 & 96 & $\begin{array}{l}\text { Mean Difference (IV, Random, } \\
95 \% \mathrm{CI} \text { ) }\end{array}$ & $-4.10[-7.45,-0.75]$ \\
\hline $\begin{array}{l}5 \text { Quality of life (IPSS-QoL) based } \\
\text { on prostate volume }\end{array}$ & 1 & 176 & $\begin{array}{l}\text { Mean Difference (IV, Random, } \\
95 \% \mathrm{CI} \text { ) }\end{array}$ & $-0.19[-0.78,0.40]$ \\
\hline $\begin{array}{l}5.1 \text { prostate volume less than } 50 \\
\mathrm{~mL}\end{array}$ & 1 & 80 & $\begin{array}{l}\text { Mean Difference (IV, Random, } \\
95 \% \mathrm{CI} \text { ) }\end{array}$ & $0.10[-0.61,0.81]$ \\
\hline $\begin{array}{l}5.2 \text { prostate volume equal to or } \\
\text { greater than } 50 \mathrm{~mL}\end{array}$ & 1 & 96 & $\begin{array}{l}\text { Mean Difference (IV, Random, } \\
95 \% \mathrm{CI} \text { ) }\end{array}$ & $-0.5[-1.24,0.24]$ \\
\hline $\begin{array}{l}6 \text { Major adverse events based on } \\
\text { prostate volume }\end{array}$ & 1 & 181 & $\begin{array}{l}\text { Risk Ratio (M-H, Random, 95\% } \\
\text { Cl) }\end{array}$ & $0.81[0.15,4.28]$ \\
\hline $\begin{array}{l}6.1 \text { prostate volume less than } 50 \\
\mathrm{~mL}\end{array}$ & 1 & 82 & $\begin{array}{l}\text { Risk Ratio (M-H, Random, 95\% } \\
\mathrm{Cl} \text { ) }\end{array}$ & $2.31[0.27,19.71]$ \\
\hline $\begin{array}{l}6.2 \text { prostate volume equal to or } \\
\text { greater than } 50 \mathrm{~mL}\end{array}$ & 1 & 99 & $\begin{array}{l}\text { Risk Ratio (M-H, Random, 95\% } \\
\mathrm{Cl} \text { ) }\end{array}$ & $0.41[0.10,1.73]$ \\
\hline $\begin{array}{l}7 \text { Urologic symptom scores (IPSS) } \\
\text { based on severity of LUTS }\end{array}$ & 1 & 176 & $\begin{array}{l}\text { Mean Difference (IV, Random, } \\
95 \% \mathrm{CI} \text { ) }\end{array}$ & $-1.45[-3.69,0.80]$ \\
\hline 7.1 IPSS less than or equal to 19 & 1 & 59 & $\begin{array}{l}\text { Mean Difference (IV, Random, } \\
95 \% \mathrm{CI} \text { ) }\end{array}$ & $-2.70[-5.42,0.02]$ \\
\hline 7.2 IPSS greater than 19 & 1 & 117 & $\begin{array}{l}\text { Mean Difference (IV, Random, } \\
95 \% \mathrm{CI} \text { ) }\end{array}$ & $-0.40[-2.77,1.97]$ \\
\hline $\begin{array}{l}8 \text { Quality of life (IPSS-QoL) based } \\
\text { on severity of LUTS }\end{array}$ & 1 & 176 & $\begin{array}{l}\text { Mean Difference (IV, Random, } \\
95 \% \mathrm{CI} \text { ) }\end{array}$ & $-0.18[-0.70,0.34]$ \\
\hline 8.1 IPSS less than or equal to 19 & 1 & 59 & $\begin{array}{l}\text { Mean Difference (IV, Random, } \\
95 \% \mathrm{CI} \text { ) }\end{array}$ & $-0.30[-1.14,0.54]$ \\
\hline 8.2 IPSS greater than 19 & 1 & 117 & $\begin{array}{l}\text { Mean Difference (IV, Random, } \\
95 \% \mathrm{CI} \text { ) }\end{array}$ & $-0.10[-0.77,0.57]$ \\
\hline $\begin{array}{l}9 \text { Major adverse events based on } \\
\text { severity of LUTS }\end{array}$ & 1 & 181 & $\begin{array}{l}\text { Risk Ratio (M-H, Random, 95\% } \\
\mathrm{Cl} \text { ) }\end{array}$ & $0.78[0.26,2.39]$ \\
\hline
\end{tabular}




\begin{tabular}{lllll}
\hline Outcome or subgroup title & No. of studies & $\begin{array}{l}\text { No. of partici- } \\
\text { pants }\end{array}$ & Statistical method & Effect size \\
\hline 9.1 IPSS less than or equal to 19 & 1 & 59 & $\begin{array}{l}\text { Risk Ratio (M-H, Random, 95\% } \\
\text { Cl) }\end{array}$ & $0.64[0.10,4.22]$ \\
\hline 9.2 IPSS greater than 19 & 1 & 122 & $\begin{array}{l}\text { Risk Ratio (M-H, Random, 95\% } \\
\text { Cl) }\end{array}$ & $0.88[0.22,3.48]$ \\
\hline
\end{tabular}

Analysis 3.1. Comparison 3 Aquablation versus TURP (subgroup analyses up to 6 months), Outcome 1 Urologic symptom scores (IPSS) based on age.

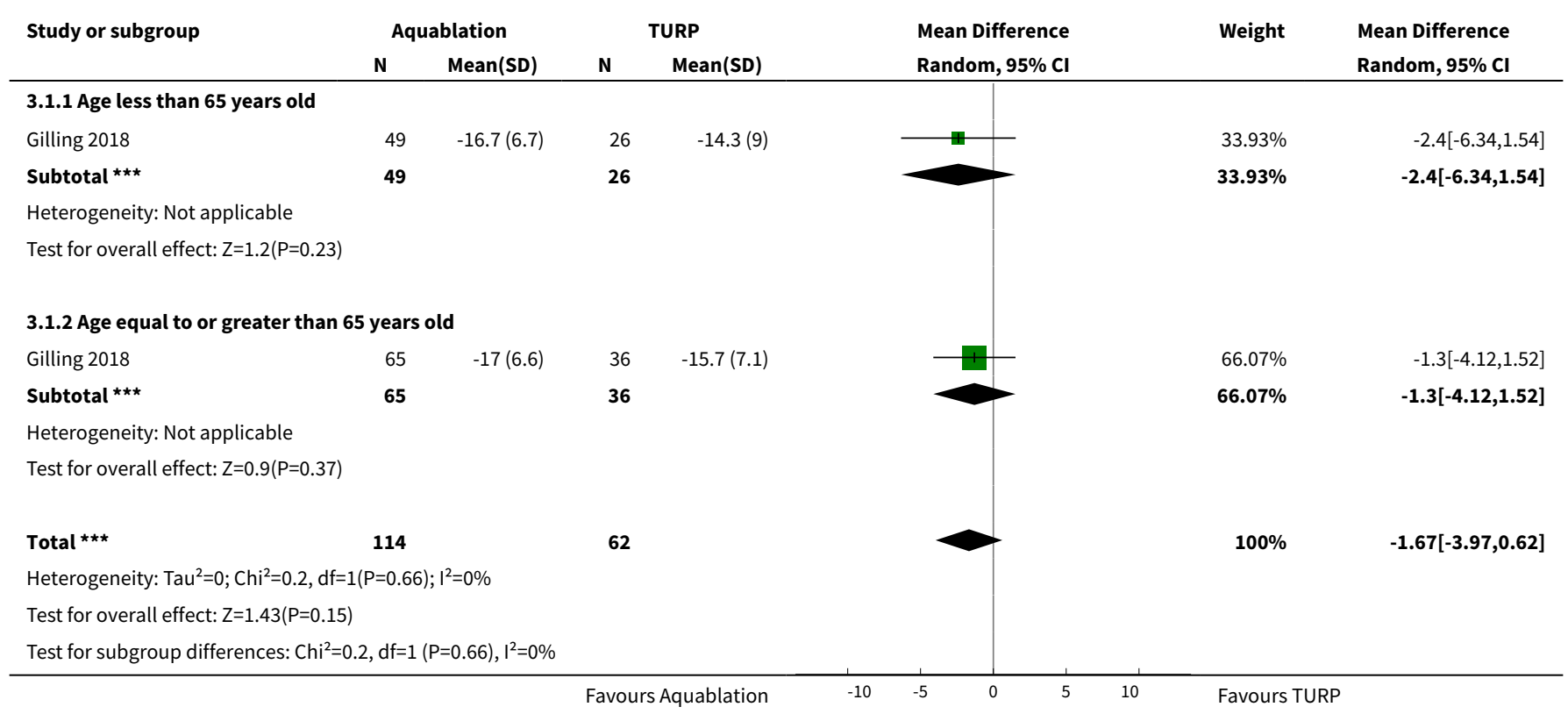

\section{Analysis 3.2. Comparison 3 Aquablation versus TURP (subgroup analyses up to 6 months), Outcome 2 Quality of life (IPSS-QoL) based on age.}

\begin{tabular}{|c|c|c|c|c|c|c|c|}
\hline \multirow[t]{2}{*}{ Study or subgroup } & \multicolumn{2}{|c|}{ Aquablation } & \multicolumn{2}{|c|}{ TURP } & \multirow{2}{*}{$\begin{array}{l}\text { Mean Difference } \\
\text { Random, } 95 \% \mathrm{Cl} \\
\end{array}$} & \multirow[t]{2}{*}{ Weight } & \multirow{2}{*}{$\begin{array}{l}\text { Mean Difference } \\
\text { Random, } 95 \% \mathrm{Cl}\end{array}$} \\
\hline & $\mathbf{N}$ & $\operatorname{Mean}(S D)$ & $\mathbf{N}$ & Mean(SD) & & & \\
\hline \multicolumn{8}{|c|}{ 3.2.1 Age less than 65 years old } \\
\hline Gilling 2018 & 49 & $-3.3(1.7)$ & 26 & $-3.5(1.4)$ & 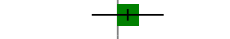 & $50.56 \%$ & $0.2[-0.52,0.92]$ \\
\hline 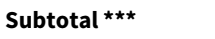 & 49 & & 26 & & & $50.56 \%$ & $0.2[-0.52,0.92]$ \\
\hline \multicolumn{8}{|c|}{ Heterogeneity: Not applicable } \\
\hline \multicolumn{8}{|c|}{ Test for overall effect: $Z=0.55(P=0.59)$} \\
\hline \multicolumn{8}{|c|}{ 3.2.2 Age equal to or greater than 65 years old } \\
\hline Gilling 2018 & 65 & $-3.6(1.8)$ & 36 & $-3.1(1.8)$ & $\longrightarrow$ & $49.44 \%$ & $-0.5[-1.23,0.23]$ \\
\hline 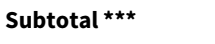 & 65 & & 36 & & & $49.44 \%$ & $-0.5[-1.23,0.23]$ \\
\hline \multicolumn{8}{|c|}{ Heterogeneity: Not applicable } \\
\hline \multicolumn{8}{|c|}{ Test for overall effect: $Z=1.34(P=0.18)$} \\
\hline
\end{tabular}




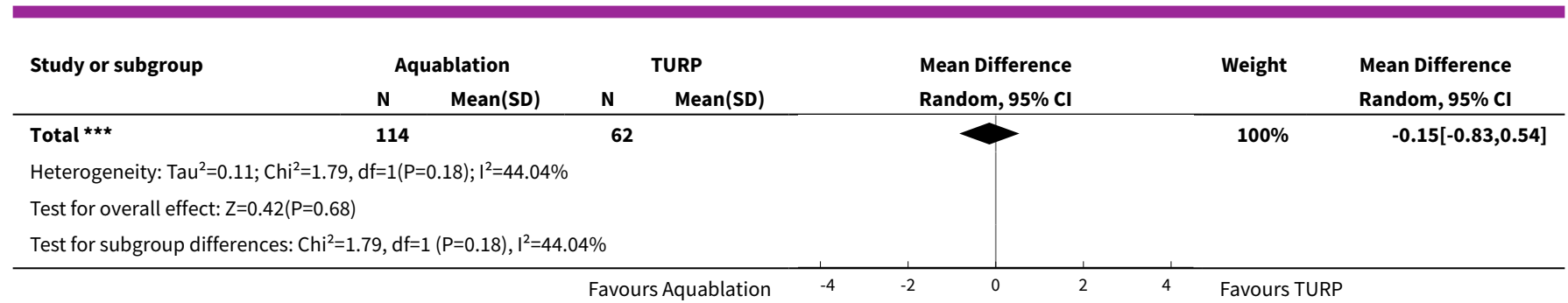

Analysis 3.3. Comparison 3 Aquablation versus TURP (subgroup analyses up to 6 months), Outcome 3 Major adverse events based on age.

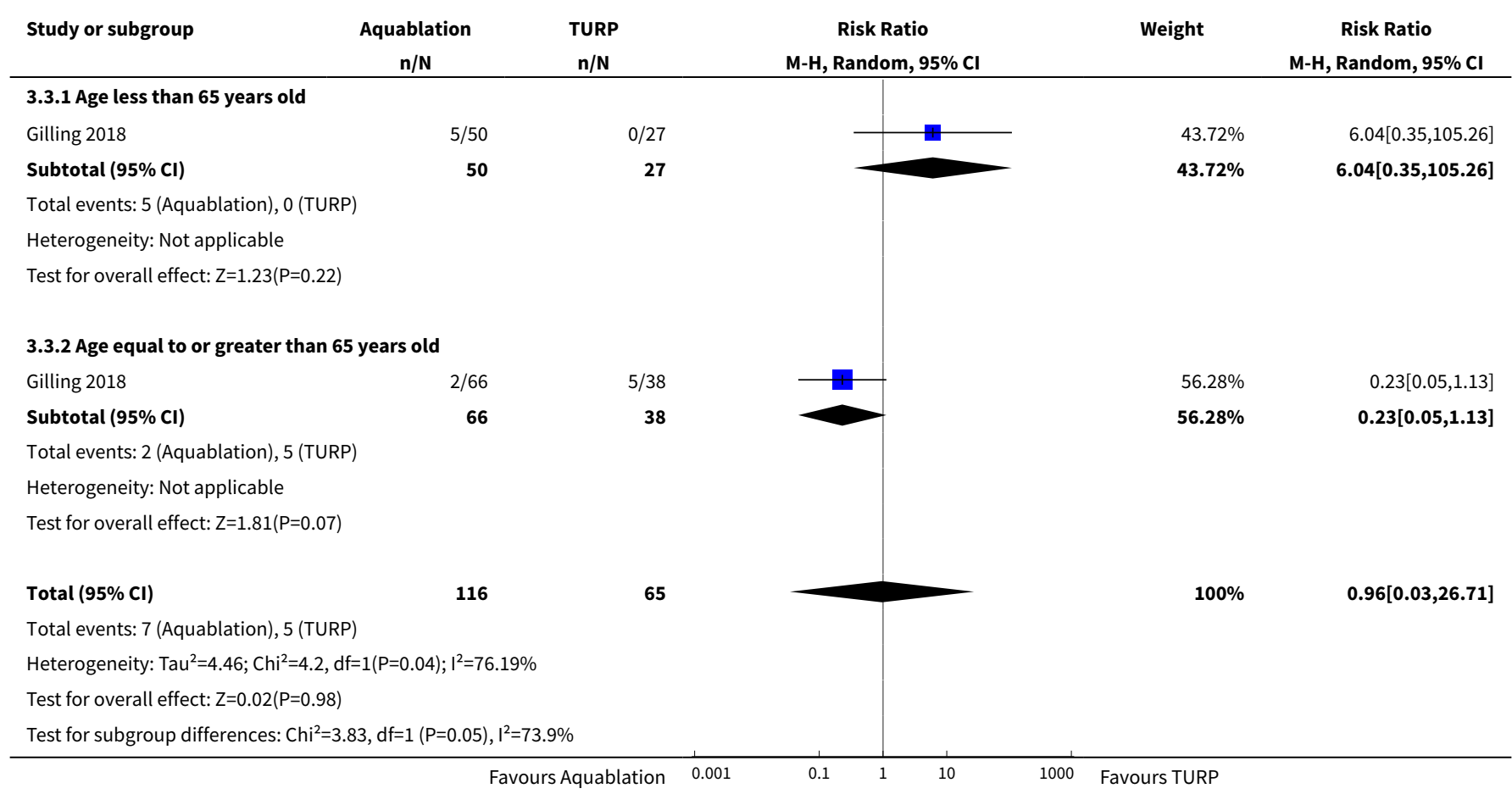

Analysis 3.4. Comparison 3 Aquablation versus TURP (subgroup analyses up to 6 months), Outcome 4 Urologic symptom scores (IPSS) based on prostate volume.

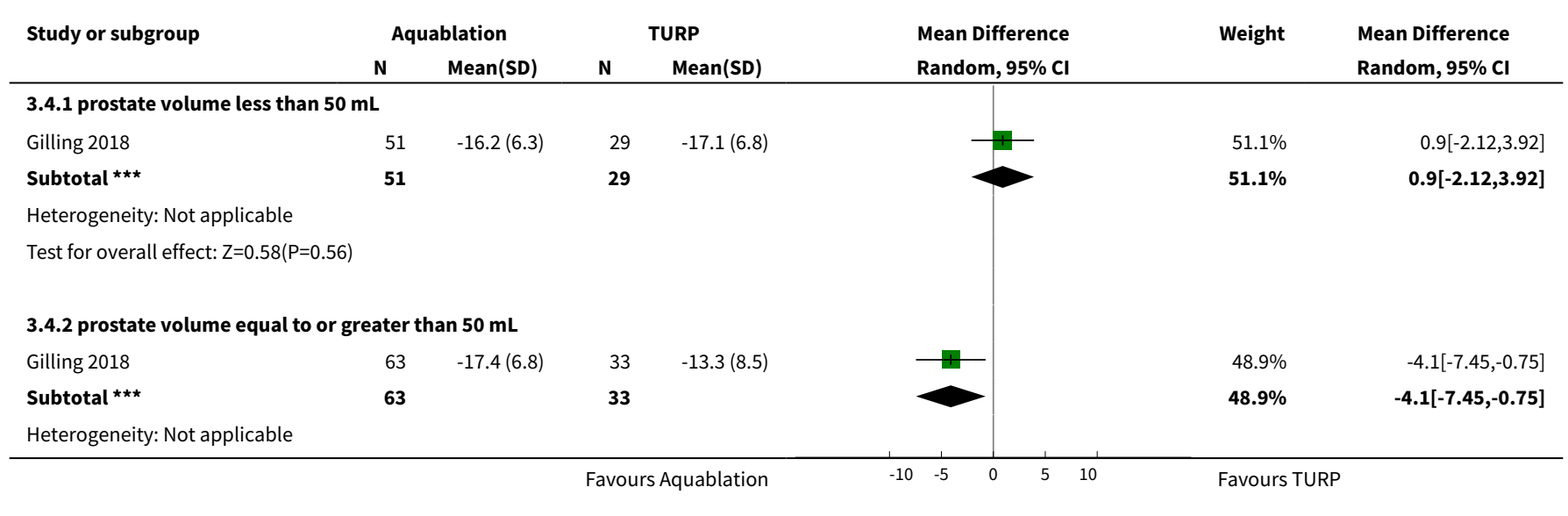




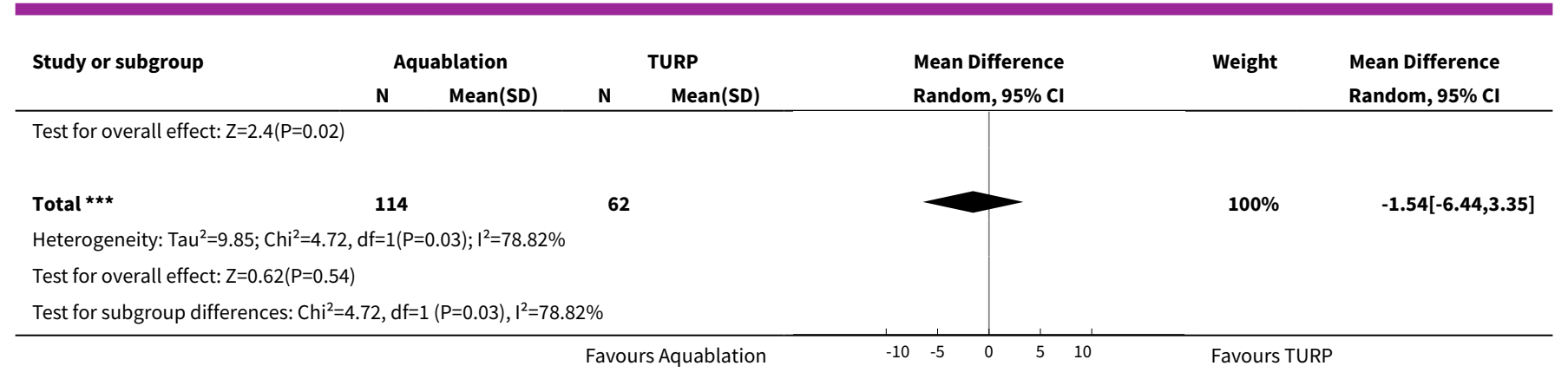

Analysis 3.5. Comparison 3 Aquablation versus TURP (subgroup analyses up to 6 months), Outcome 5 Quality of life (IPSS-QOL) based on prostate volume.

\begin{tabular}{|c|c|c|c|c|c|c|c|}
\hline \multirow[t]{2}{*}{ Study or subgroup } & \multicolumn{2}{|c|}{ Aquablation } & \multicolumn{2}{|c|}{ TURP } & \multirow{2}{*}{$\begin{array}{l}\text { Mean Difference } \\
\text { Random, } 95 \% \mathrm{Cl}\end{array}$} & \multirow[t]{2}{*}{ Weight } & \multirow{2}{*}{$\begin{array}{l}\text { Mean Difference } \\
\text { Random, } 95 \% \mathrm{Cl}\end{array}$} \\
\hline & $\mathbf{N}$ & Mean(SD) & $\mathbf{N}$ & Mean(SD) & & & \\
\hline \multicolumn{8}{|c|}{ 3.5.1 prostate volume less than $50 \mathrm{~mL}$} \\
\hline Gilling 2018 & 51 & $-3.2(1.8)$ & 29 & $-3.3(1.4)$ & & $51.8 \%$ & $0.1[-0.61,0.81]$ \\
\hline Subtotal $\star \star \star$ & 51 & & 29 & & & $51.8 \%$ & $0.1[-0.61,0.81]$ \\
\hline \multicolumn{8}{|c|}{ Heterogeneity: Not applicable } \\
\hline \multicolumn{8}{|c|}{ Test for overall effect: $Z=0.28(P=0.78)$} \\
\hline \multicolumn{8}{|c|}{ 3.5.2 prostate volume equal to or greater than $50 \mathrm{~mL}$} \\
\hline Gilling 2018 & 63 & $-3.7(1.7)$ & 33 & $-3.2(1.8)$ & 1 & $48.2 \%$ & $-0.5[-1.24,0.24]$ \\
\hline Subtotal $\star \star \star$ & 63 & & 33 & & & $48.2 \%$ & $-0.5[-1.24,0.24]$ \\
\hline \multicolumn{8}{|c|}{ Heterogeneity: Not applicable } \\
\hline \multicolumn{8}{|c|}{ Test for overall effect: $Z=1.32(P=0.19)$} \\
\hline \multicolumn{8}{|c|}{ Heterogeneity: $\mathrm{Tau}^{2}=0.04 ; \mathrm{Chi}^{2}=1.31, \mathrm{df}=1(\mathrm{P}=0.25) ; \mathrm{I}^{2}=23.56 \%$} \\
\hline \multicolumn{8}{|c|}{ Test for overall effect: $Z=0.63(P=0.53)$} \\
\hline \multicolumn{8}{|c|}{ Test for subgroup differences: $\mathrm{Chi}^{2}=1.31, \mathrm{df}=1(\mathrm{P}=0.25), \mathrm{I}^{2}=23.56 \%$} \\
\hline
\end{tabular}

Analysis 3.6. Comparison 3 Aquablation versus TURP (subgroup analyses up to 6 months), Outcome 6 Major adverse events based on prostate volume.

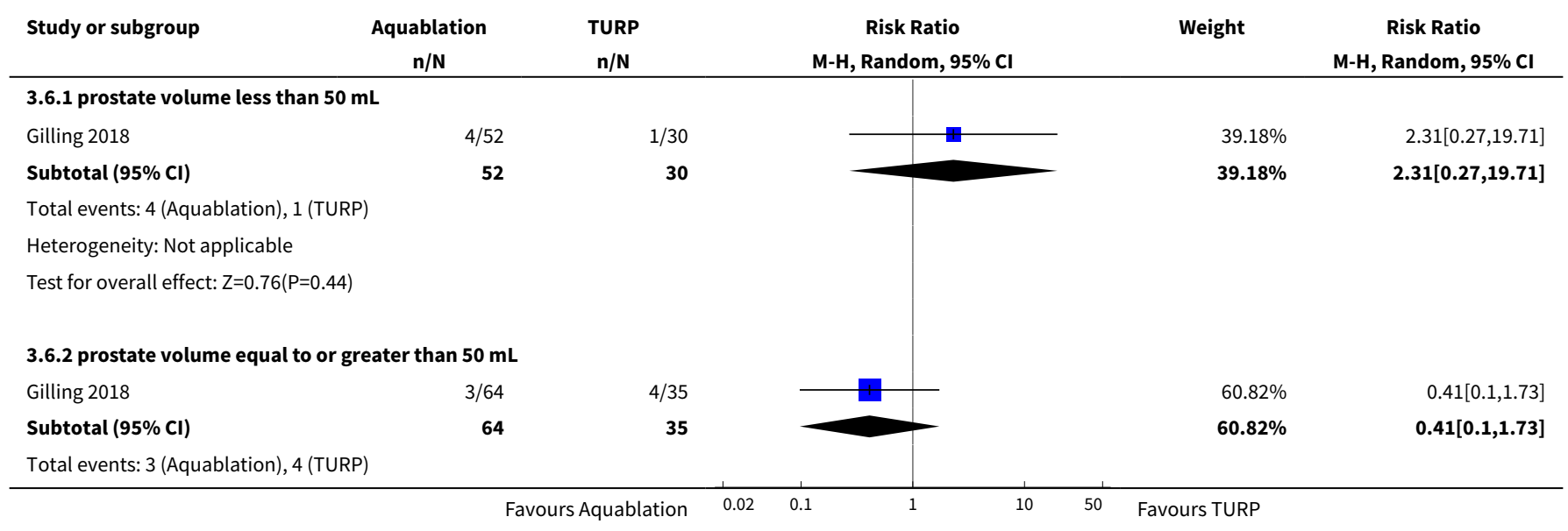




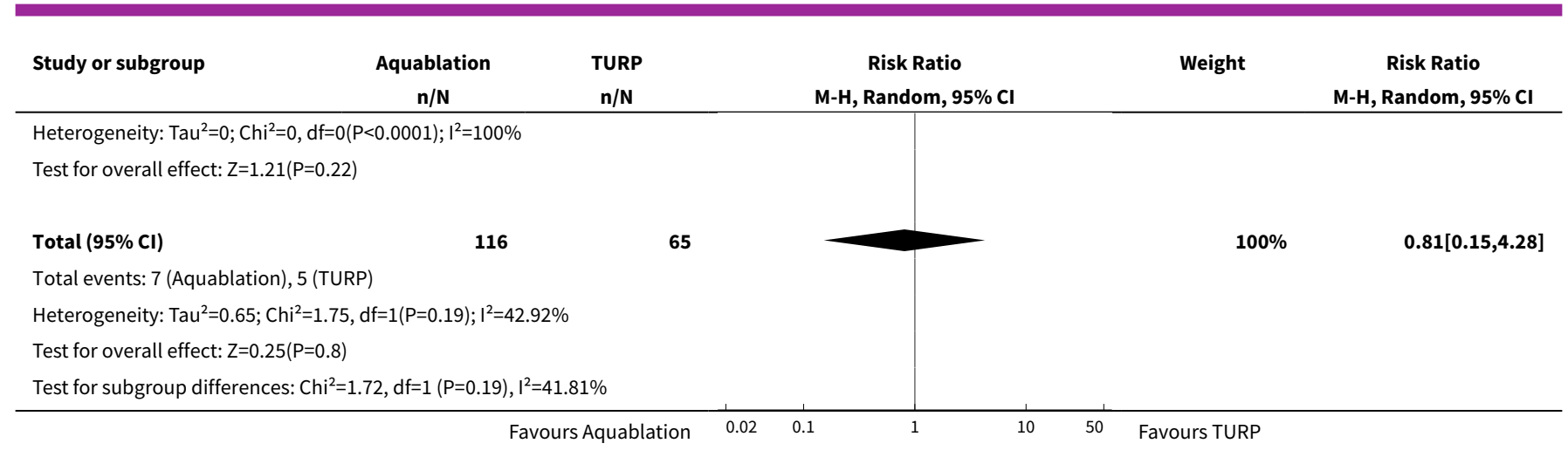

Analysis 3.7. Comparison 3 Aquablation versus TURP (subgroup analyses up to 6 months), Outcome 7 Urologic symptom scores (IPSS) based on severity of LUTS.

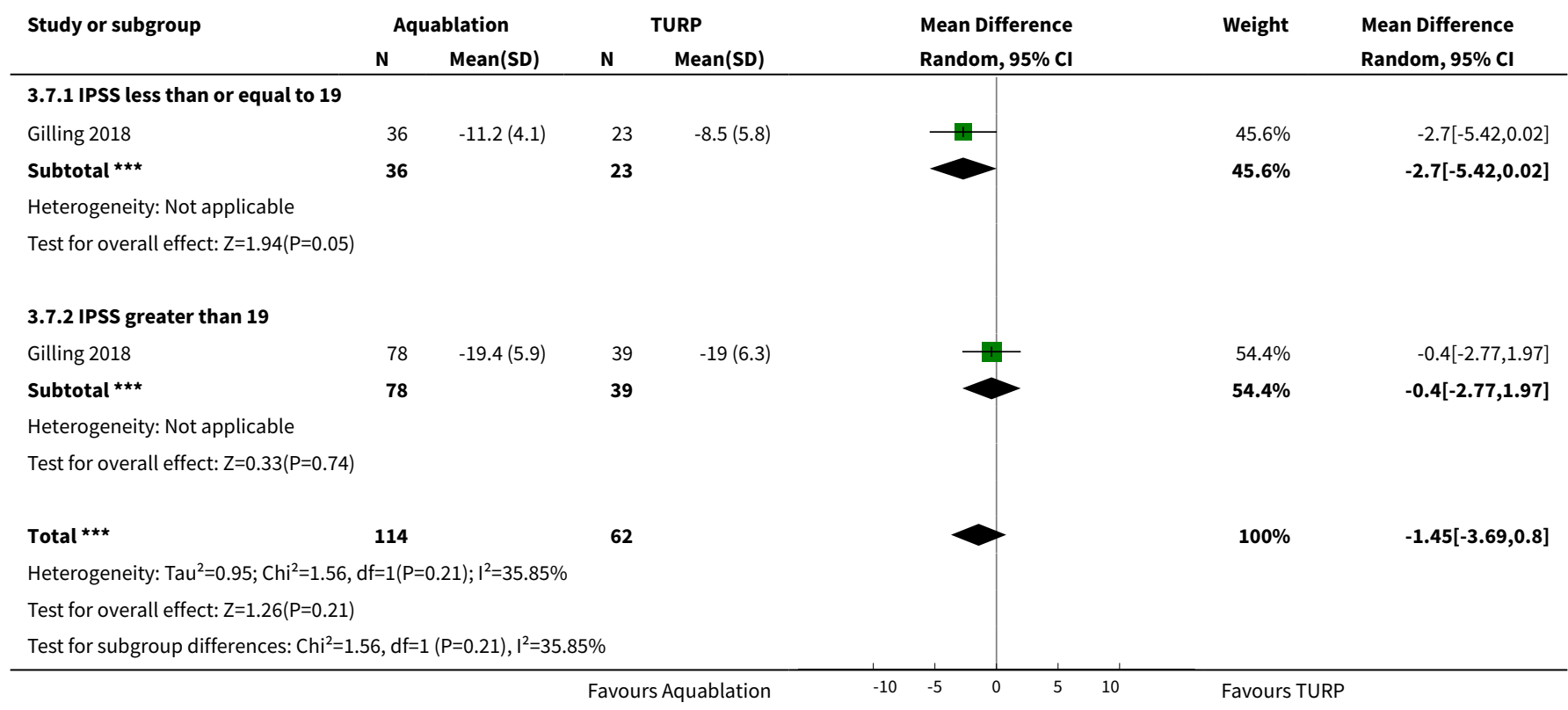

Analysis 3.8. Comparison 3 Aquablation versus TURP (subgroup analyses up to 6 months), Outcome 8 Quality of life (IPSS-QoL) based on severity of LUTS.

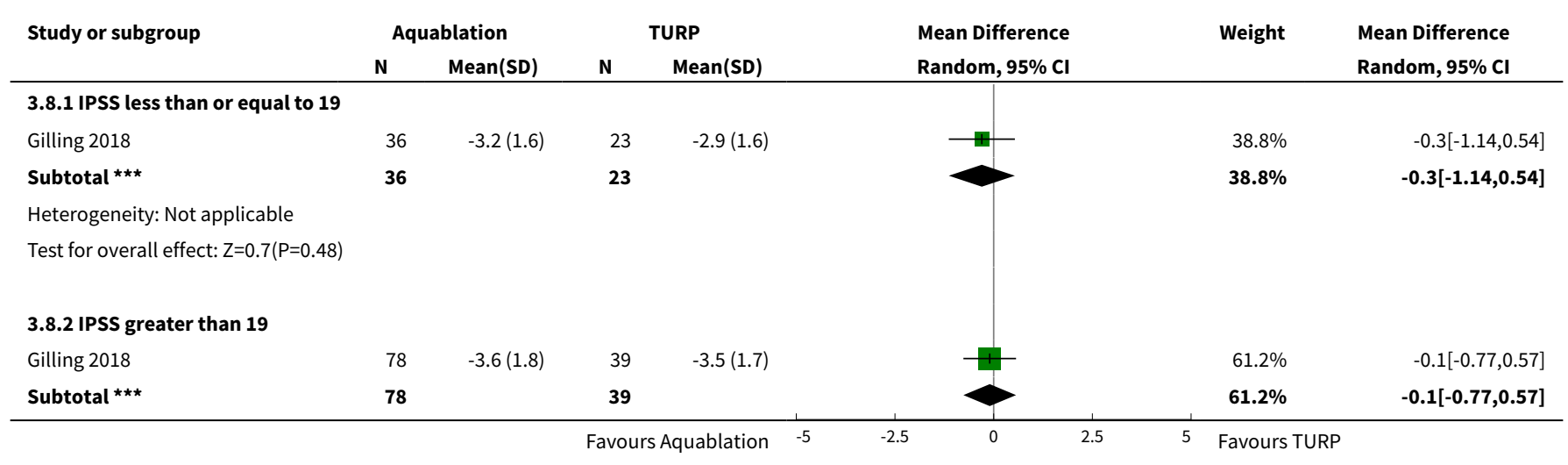




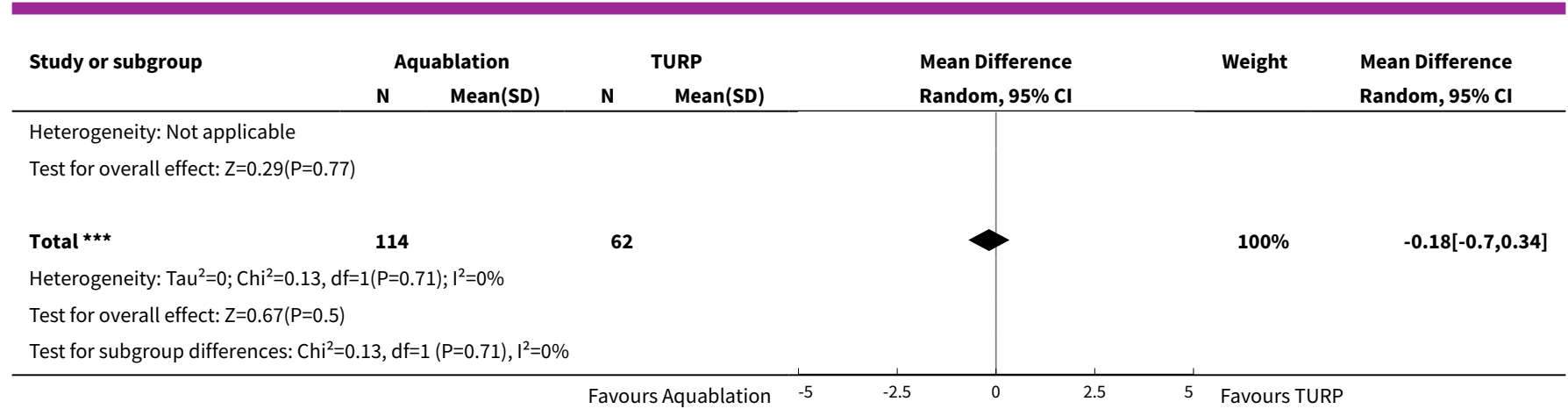

Analysis 3.9. Comparison 3 Aquablation versus TURP (subgroup analyses up to 6 months), Outcome 9 Major adverse events based on severity of LUTS.

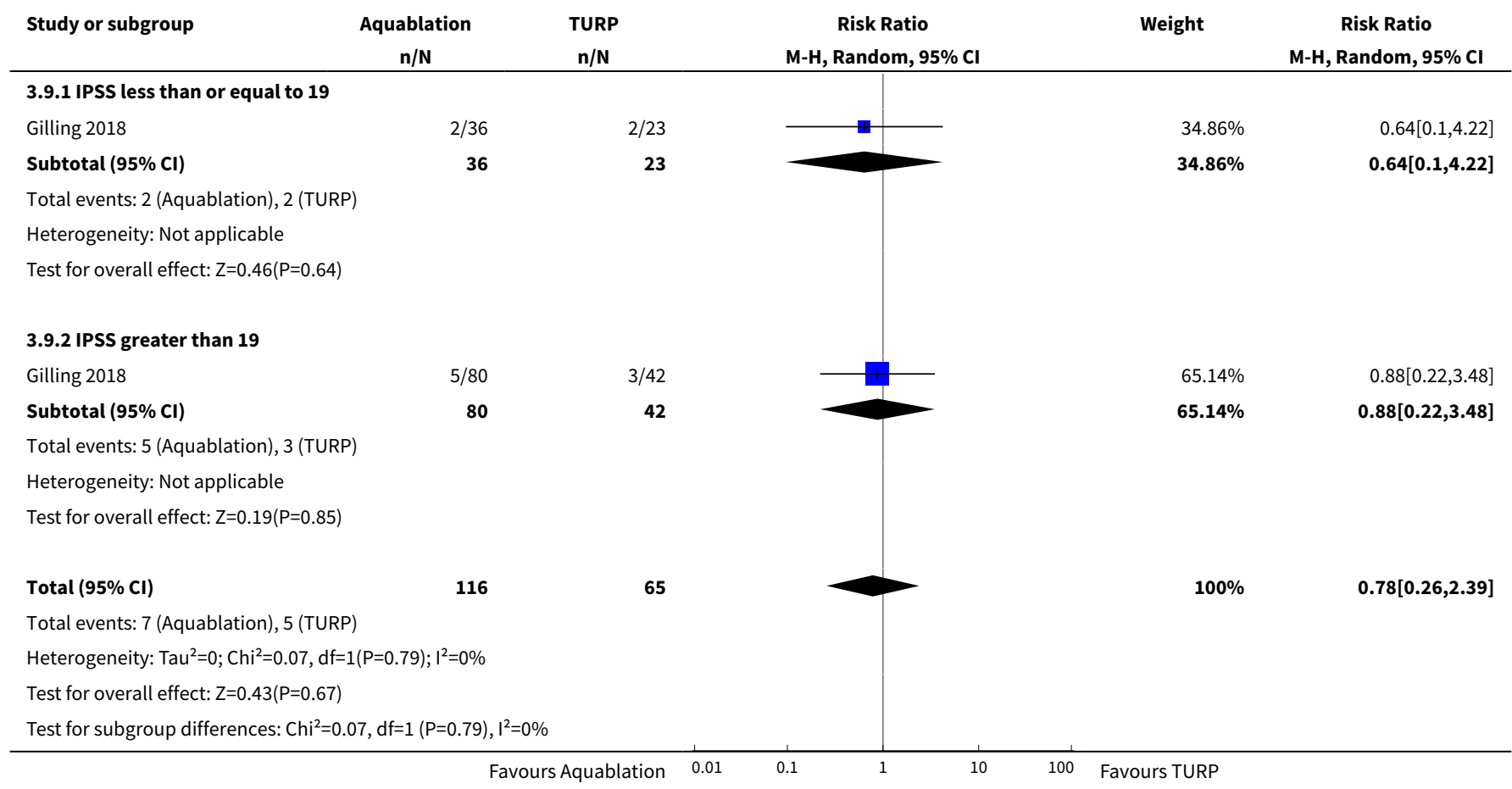




\begin{tabular}{|c|c|c|c|c|c|c|c|c|c|}
\hline \multirow{3}{*}{ 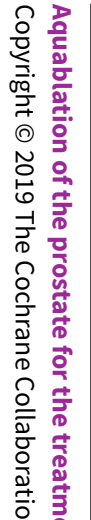 } & Study name & $\begin{array}{l}\text { Study peri- } \\
\text { od (year to } \\
\text { year) }\end{array}$ & Setting/Country & Description of participants & $\begin{array}{l}\text { Intervention(s) } \\
\text { and compara- } \\
\text { tor(s) }\end{array}$ & $\begin{array}{l}\text { Duration of } \\
\text { follow-up }\end{array}$ & Age & IPSS & $\begin{array}{l}\text { Prostate } \\
\text { volume }\end{array}$ \\
\hline & \multirow[t]{2}{*}{ Gilling 2018} & \multirow{2}{*}{$\begin{array}{l}\text { October } \\
\text { 2015-De- } \\
\text { cember } \\
2016\end{array}$} & \multirow{2}{*}{$\begin{array}{l}\text { Multicenter (17 } \\
\text { centres)/mul- } \\
\text { ticountry (Aus- } \\
\text { tralia, New } \\
\text { Zealand, UK, } \\
\text { USA) }\end{array}$} & \multirow{2}{*}{$\begin{array}{l}\text { LUTS due to BPH in men } 45-80 \\
\text { years of age with a prostate size } \\
\text { between } 30 \text { and } 80 \mathrm{~mL} \text { (measured } \\
\text { with transrectal ultrasound), IPSS } \geq \\
12, Q_{\max }<15 \mathrm{~mL} / \mathrm{s}\end{array}$} & Aquablation & \multirow[t]{2}{*}{12 months } & $66.0 \pm 7.3$ & $22.9 \pm 6.0$ & $54.1 \pm 16.2$ \\
\hline & & & & & $\begin{array}{l}\text { TURP (monopo- } \\
\text { lar } 36(55.4 \%) \text {, } \\
\text { bipolar } 29 \\
(44.6 \%))\end{array}$ & & $65.8 \pm 7.2$ & $22.2 \pm 6.1$ & $51.8 \pm 13.8$ \\
\hline
\end{tabular}

BPH: benign prostatic hyperplasia; IPSS: International Prostate Symptom Score; LUTS: low urinary tract symptoms; $\mathbf{Q}_{\text {max }}$ maximum flow rate; TURP: transurethral resection of prostate 
Table 2. Participants in included study

\begin{tabular}{lllllll}
\hline $\begin{array}{l}\text { Study } \\
\text { name }\end{array}$ & Intervention(s) and comparator(s) & $\begin{array}{l}\text { Screened/ } \\
\text { eligible (N) }\end{array}$ & $\begin{array}{l}\text { Ran- } \\
\text { domised } \\
(\mathbf{N})\end{array}$ & $\begin{array}{l}\text { Analysed } \\
\text { (N): effica- } \\
\text { cy } \boldsymbol{a}\end{array}$ & $\begin{array}{l}\text { Analysed } \\
(\mathbf{N}): \text { safe- } \\
\text { tyb }\end{array}$ & $\begin{array}{l}\text { Finishing study } \\
(\mathbf{N}(\%))\end{array}$ \\
\hline $\begin{array}{l}\text { Gilling } \\
2018\end{array}$ & Aquablation & $275 / 184$ & 117 & 114 & 116 & $115(98.2)$ \\
\cline { 2 - 6 } & $\begin{array}{l}\text { TURP monopolar (36 (55.4\%), bipolar } \\
\text { 29(44.6\%)) }\end{array}$ & 67 & 60 & 65 & $62(92.5)$ \\
\cline { 2 - 6 } & Total & $\mathbf{1 8 4}$ & $\mathbf{1 7 4}$ & $\mathbf{1 8 1}$ & $\mathbf{1 7 7}$ \\
\hline
\end{tabular}

TURP: transurethral resection of prostate

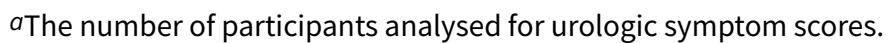

bThe number of participants with adverse events.

\section{APPENDICES}

\section{Appendix 1. Search strategy}

\section{MEDLINE (via Ovid)}

\begin{tabular}{|c|c|}
\hline 1 & exp Prostatic Hyperplasia/ \\
\hline 2 & (Prostat* adj3 hyperplasia*).tw. \\
\hline 3 & $\left(\right.$ Prostat $^{\star}$ adj3 hypertroph*).tw. \\
\hline 4 & $\left(\right.$ Prostat $^{*}$ adj3 adenoma*).tw. \\
\hline 5 & (BPH or $\mathrm{BPO}$ or $\mathrm{BPE}) . \mathrm{tw}$. \\
\hline 6 & $\left(\right.$ prostat $^{\star} \operatorname{adj}$ enlarg $\left.{ }^{\star}\right) . t w$. \\
\hline 7 & exp Prostatism/ \\
\hline 8 & Prostatism.tw. \\
\hline 9 & exp Urinary Bladder Neck Obstruction/ \\
\hline 10 & $\left(\right.$ Bladder $^{\star}$ adj3 obstruct $\left.{ }^{\star}\right) . t w$. \\
\hline 11 & BOO.tw. \\
\hline 12 & 1 or 2 or 3 or 4 or 5 or 6 or 7 or 8 or 9 or 10 or 11 \\
\hline 13 & (AQUABEAM or Aquablation or Waterjet).tw. \\
\hline 14 & 12 and 13 \\
\hline 15 & (animals not (humans and animals)).sh. \\
\hline
\end{tabular}

Aquablation of the prostate for the treatment of lower urinary tract symptoms in men with benign prostatic hyperplasia (Review) 


\section{Cochrane Library}

\begin{tabular}{|c|c|}
\hline 1 & MeSH descriptor: [Prostatic Hyperplasia] explode all trees \\
\hline 2 & (prostat* near/3 hyperplasia*):ti,ab,kw (Word variations have been searched) \\
\hline 3 & (prostat* near/3 hypertroph*):ti,ab,kw (Word variations have been searched) \\
\hline 4 & (prostat* ${ }^{\star}$ ear/3 adenoma*):ti,ab,kw (Word variations have been searched) \\
\hline 5 & (BPH or BPO or BPE):ti,ab,kw (Word variations have been searched) \\
\hline 6 & (prostat* near/3 enlarg*):ti,ab,kw (Word variations have been searched) \\
\hline 7 & MeSH descriptor: [Prostatism] explode all trees \\
\hline 8 & prostatism:ti,ab,kw (Word variations have been searched) \\
\hline 9 & MeSH descriptor: [Urinary Bladder Neck Obstruction] explode all trees \\
\hline 10 & ("bladder outlet obstruction" or BOO):ti,ab,kw (Word variations have been searched) \\
\hline 11 & $\# 1$ or $\# 2$ or $\# 3$ or $\# 4$ or \#5 or \#6 or \#7 or \#8 or \#9 or \#10 \\
\hline 12 & (AQUABEAM or Aquablation or Waterjet):ti,ab,kw (Word variations have been searched) \\
\hline 13 & \#11 and \#12 \\
\hline
\end{tabular}

\section{Embase}

\begin{tabular}{ll}
\hline 1 & 'prostate hypertrophy'/exp \\
\hline 2 & (Prostat* NEAR/3 hyperplasia*):ab,ti \\
\hline 3 & (Prostat* NEAR/3 hypertroph*):ab,ti \\
\hline 5 & (Prostat* NEAR/3 adenoma*):ab,ti \\
\hline 6 & 'bph':ab,ti OR 'bpo':ab,ti OR 'bpe':ab,ti \\
\hline 7 & (prostat* NEAR/3 enlarg*):ab,ti \\
\hline 8 & 'prostatism'/exp \\
\hline 9 & 'prostatism':ab,ti \\
\hline 10 & 'bladder obstruction'/exp \\
\hline 11 & (bladder* NEAR/3 obstruct*):ab,ti \\
\hline 12 & 'BOO':ab,ti \\
\hline \#1 OR \#2 OR \#3 OR \#4 OR \#5 OR \#6 OR \#7 OR \#8 OR \#9 OR \#10 OR \#11
\end{tabular}


(Continued)

\begin{tabular}{ll} 
& (AQUABEAM or Aquablation or Waterjet):ab,ti \\
\hline 14 & $\# 12$ AND \#13 \\
\hline 15 & ('animals'/exp) NOT ('humans'/exp and 'animals'/exp) \\
\hline 16 & $\# 14$ NOT \#15
\end{tabular}

\begin{tabular}{|c|c|}
\hline \multicolumn{2}{|c|}{ Scopus } \\
\hline 1 & 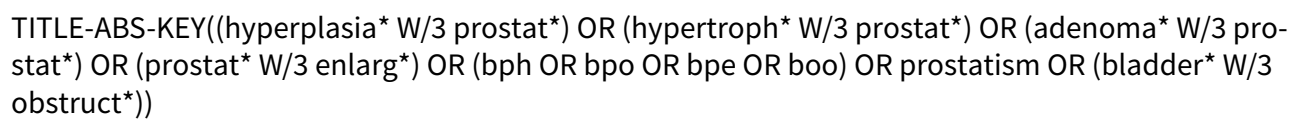 \\
\hline 2 & TITLE-ABS-KEY((AQUABEAM or Aquablation or Waterjet)) \\
\hline 3 & 1 AND 2 \\
\hline
\end{tabular}

\begin{tabular}{|c|c|}
\hline \multicolumn{2}{|c|}{ Web of Science } \\
\hline 1 & $\begin{array}{l}\text { TS }=\left(\left(\text { hyperplasia* NEAR/3 prostat }{ }^{\star}\right) \text { OR (hypertroph }{ }^{\star} \text { NEAR/3 prostat }{ }^{\star}\right) \text { OR (adenoma* NEAR/3 pro- } \\
\left.\text { stat }^{\star}\right) \text { OR (prostat* NEAR/3 enlarg*) OR (bph OR bpo OR bpe OR boo) OR prostatism OR (bladder } \\
\text { NEAR/3 obstruct*) }\end{array}$ \\
\hline 2 & $\mathrm{TS}=($ AQUABEAM or Aquablation or Waterjet) \\
\hline 3 & 1 AND 2 \\
\hline \multicolumn{2}{|c|}{ LILAC } \\
\hline 1 & $\begin{array}{l}\text { (mh:("Prostatic Hyperplasia" or Prostatism or "Urinary Bladder Neck Obstruction")) OR (tw:("Pro- } \\
\text { static Hyperplasia" or "Prostatic Adenoma" or "Prostatic Hypertrophy" or "Prostatic Enlargement" } \\
\text { or BPH or BPO or BPE or Prostatism or "Bladder Neck Obstruction" or "Bladder Outlet Obstruction" } \\
\text { or BOO)) }\end{array}$ \\
\hline 2 & (tw:(AQUABEAM or Aquablation or Waterjet)) \\
\hline 3 & 1 AND 2 \\
\hline
\end{tabular}

\section{ClinicalTrials.gov}

\begin{tabular}{ll}
\hline 1 & $\begin{array}{l}\text { ("Prostatic Hyperplasia" OR "Prostatic Hypertrophy" OR "Prostatic Adenoma" OR BPH OR BPO OR } \\
\text { BPE OR Prostatism OR "Bladder Neck Obstruction" OR "Bladder Outlet Obstruction" OR BOO) }\end{array}$ \\
\hline 2 & (AQUABEAM OR Aquablation OR Waterjet) \\
\hline 3 & 1 AND 2
\end{tabular}

\section{World Health Organization (WHO) International Clinical Trials Registry Platform search portal}

1

In the title = ("Prostatic Hyperplasia" OR "Prostatic Hypertrophy" OR "Prostatic Adenoma" OR BPH or BPO or BPE OR Prostatism OR "Bladder Neck Obstruction" or "Bladder Outlet Obstruction" or $\mathrm{BOO}$ ) AND In the intervention= (AQUABEAM or Aquablation or Waterjet)

\section{Grey Literature (Open Grey)}




\section{Appendix 2. Survey of study investigators providing information on included studies}

\begin{tabular}{llll}
\hline Study & $\begin{array}{l}\text { Date study author } \\
\text { contacted (first) }\end{array}$ & $\begin{array}{l}\text { Date study author } \\
\text { provided data (lat- } \\
\text { est) }\end{array}$ & $\begin{array}{l}\text { Data study author provided } \\
\text { (short summary) }\end{array}$ \\
\hline Gilling 2018 & 7 September 2018 & 20 December 2018 & $\begin{array}{l}\text { Whole dataset, subgroup analysis data, race information and } \\
\text { indwelling catheter time }\end{array}$ \\
& & $\begin{array}{l}\text { Medical device company (PROCEPT BioRobotics) provided rele- } \\
\text { vant information }\end{array}$ \\
\hline
\end{tabular}

\section{CONTRIBUTIONS OFAUTHORS}

Eu Chang Hwang (ECH): conception and study design, study selection, extracting data, assessing risk of bias, performing data analysis, interpretation of data, and drafting the review Jae Hung Jung (JHJ): study selection, extracting data, assessing risk of bias, and interpretation of data Michael Borofsky (MB): providing clinical advice and critical content Myung Ha Kim (MHK): creating search strategies and searching for studies Philipp Dahm (PD): conception and study design, providing clinical and methodological advice on the review, and final approval

\section{DECLARATIONS OF INTEREST}

$\mathrm{ECH}$ : none known $\mathrm{JHJ}$ : none known MB: Boston Scientific (consultant for endourology and stone management), Auris Health (consultant for robotic surgery and endourology). MHK: none known

PD: serves as Co-ordinating Editor of Cochrane Urology. However, he was not involved in the editorial processing or decision-making for this review. Other editors of Cochrane Urology managed the editorial process, including final sign-off for this review.

\section{SOURCES OF SUPPORT}

\section{Internal sources}

- Minneapolis Veterans Administration Medical Center, USA.

Salary support for Philipp Dahm

- Chonnam National University Medical School, Korea, South.

Salary support for Eu Chang Hwang

- Department of Urology, Yonsei University Wonju College of Medicine, Korea, South.

- Department of Urology, University of Minnesota, USA.

- Department of Urology, Chonnam National University Medical School, Korea, South.

\section{External sources}

- No sources of support supplied 


\section{DIFFERENCES BETWEEN PROTOCOLAND REVIEW}

This review is based on a published protocol (Hwang 2018).

- Types of outcome measures: given the small observed differences, we used hours instead of days to describe the duration of indwelling urinary catheter usage.

- We were unable to obtain study results to perform subgroup analysis based on the predefined threshold of $40 \mathrm{~mL}$ but instead used a threshold of $50 \mathrm{~mL}$

\section{NOTES}

We have based parts of the Methods section of this review on a standard template developed by the Cochrane Metabolic and Endocrine Disorders Group, which has been modified and adapted for use by Cochrane Urology.

\section{N DEX TERMS}

\section{Medical Subject Headings (MeSH)}

*Water; Ejaculation; Lower Urinary Tract Symptoms [etiology] [ ${ }^{*}$ surgery]; Organ Size; Penile Erection; Prostate [pathology] [ ${ }^{\star}$ surgery]; Prostatic Hyperplasia [complications] [*surgery]; Quality of Life; Retreatment [statistics \& numerical data]; Robotic Surgical Procedures [ ${ }^{*}$ methods]; Surgery, Computer-Assisted [methods]; Transurethral Resection of Prostate

\section{MeSH check words}

Aged; Aged, 80 and over; Humans; Male; Middle Aged 